\title{
Analysis of the Clean Air Act Amendments of 1990: A Forecast of the Electric Utility Industry Response to Title IV, Acid Deposition Control
}

by J.C. Molburg, J.A. Fox, G. Pandola, and C.M. Cilek

Policy and Economic Analysis Group,

Environmental Assessment and Information Sciences Division,

Argonne National Laboratory, 9700 South Cass Avenue, Argonne, Illinois 60439

Work sponsored by United States Department of Energy, Assistant Secretary for Domestic and International Energy Policy, 


\section{Contents}

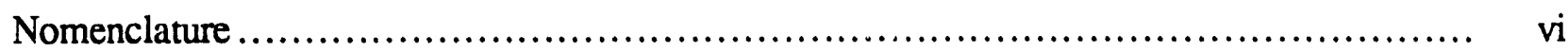

Abstract........................................................................ 1

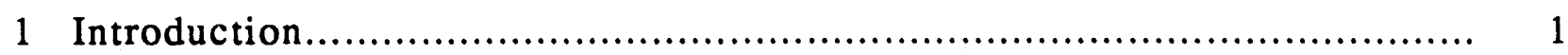

2 Title IV Requirements........................................................ 4

2.1 Regulatory Context........................................................... 4

2.2 Overview of Title IV .......................................................... 6

2.3 Summary of Title IV Provisions by Section....................................... 8

2.3.1 Section 401: Findings and Purposes...................................... 8

2.3.2 Section 402: Definitions ......................................... 8

2.3.3 Section 403: $\mathrm{SO}_{2}$ Allowance Program for Existing and New Units .. 8

2.3.4 Section 404: Phase I Sulfur Dioxide Requirements .................... 10

2.3.5 Section 405: Phase II Sulfur Dioxide Requirements ................. 12

2.3.6 Section 407: Nitrogen Oxides Emission Reduction Program ........... 15

2.3.7 Section 409: Repowered Sources................................... 16

2.3.8 Section 416: Contingency Guarantee; Auctions, Reserve .............. 16

3 Electric Utility Industry Background....................................... 17

3.1 Organization of the Industry .............................................. 17

3.2 Historical Emission Sources ............................................... 19

3.3 Compliance Options........................................................ 21

3.3.1 Retrofit Options......................................................... 22

3.3.2 Repowering Options ................................................... 22

3.3.3 Fuel Switching...................................................... 22

3.3.4 Dispatch Options ...................................................... 23

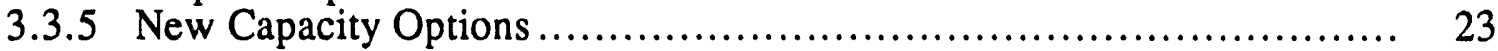

3.3.6 Emission Allowance Options........................................... 23

3.4 Rate Effects ............................................................... 24

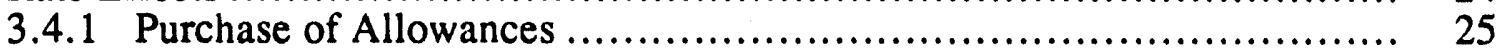

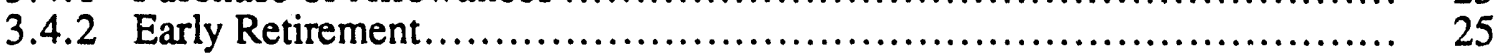

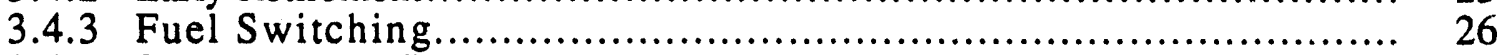

3.4.4 Scrubber Retrofit .................................................... 26

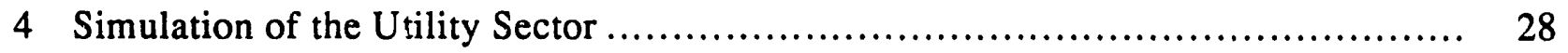

4.1 Methodology.............................................................. 28

4.2 Simulation Assumptions ......................................................... 30

4.2.1 Utility Sector Fuel Prices ............................................ 31

4.2.2 Future Electricity Demand and Capacity................................ 31

4.2.3 Fossil Fuel and Nuclear Technology Costs and Characteristics........... 34

4.2.4 Renewable Energy Technology Costs and Characteristics ................. 34

4.2.5 Extent to Which Retirement, Life Extension, and Repowering Occur... 34

4.2.6 Extent to Which Nonutility Generating Sources Are Used .............. 37

4.3 Representation of Title IV.................................................. 37

4.3.1 Emission Allowance Trading...................................... 38

4.3.2 Emission Allowance Banking and the Phase I Extension Program ...... $40^{\prime}$

4.3.3 Phase $\mathrm{I} \mathrm{SO}_{2}$ Emission Allowances for 1995 and $1996 \ldots \ldots \ldots \ldots \ldots \ldots . \ldots 3$ 


\section{Contents (Cont'd)}

4.3.4 Phase $\mathrm{I} \mathrm{SO}_{2}$ Emission Allowances for 1997, 1998, and 1999 ........ 44

4.3.5 Phase II SO 2 Emission Allowances........................................ 45

5 Simulation Results ............................................................. 46

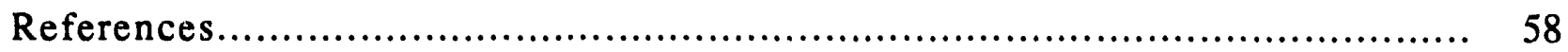

Appendix A: Affected Sources and Units in Phase I and Their Sulfur

Dioxide Allowances

Appendix B: Policy Alternatives for Controlling Emissions of Precursors of

Acid Precipitation.

\section{Tables}

2.1 Technology Standards Applicable to Major Sources of Pollutant Emissions........ 5

2.2 Phase II Sulfur Dioxide Emission Allowances Set by Section 405.............. 14

3.1 Distribution of Electric Utility Types...................................... 17

3.2 Relative Importance of Dominant Firms for Each Utility Type .................. 18

3.3 Electric Utility Fuel Use Distribution by Region ............................. 21

4.1 Noncoal Fossil Fuel Prices.................................................. 32

4.2 Bus Bar Electricity Demand and Demand Growth Rates....................... 33

4.3 Characteristics and Costs of New Electricity Generating Units..................... 35

4.4 Market Penetration Rates of New Electricity Generating Units.................. 36

4.5 Contribution of Renewable Energy Technologies ............................. 37

4.6 Retirement Ages of Existing Generating Units............................... 38

4.7 Life-Extension Costs for Generating Units More Than 45 Years Old............ 38

4.8 Contribution of Nonutility Generating Sources................................. 39

4.9 Distribution of Emission Reduction Obligations among the States as Identified in Various Studies.................................................... 41

4.10 Calculation of Net Sulfur Dioxide Emissions Allowed, 1990-2010 .............. 44 


\section{Figures}

2.1 Revised New Source Performance Standard for Sulfur Dioxide ................. 5

3.1 North American Electric Reliability Council Regions ......................... 20

3.2 Approximate Geographical Boundaries of Power Pools......................... 20

4.1 General Logic of an ARGUS Simulation ................................. 29

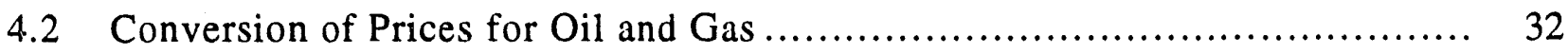

5.1 Effect of Phase I Extension and Banking on Sulfur Dioxide Emissions ......... 47

5.2 Growth in Total Utility Generating Capacity and Electricity Generation............ 47

5.3 Distribution of Generating Capacity by Fuel Type............................ 48

5.4 Distribution of Electricity Generation by Fuel Type ......................... 49

5.5 Distribution of Generating Capacity and Electricity Generation for Conventional and Advanced Coal-Fired Units................................. 50

5.6 Distribution of Generating Capacity by Fuel Type for Noncoal Resources........ 51

5.7 Distribution of Electricity Generation by Fuel Type for Noncoal Resources ...... 52

5.8 Distribution of Generating Capacity and Electricity Generation for Advanced Gas-Fired and Conventional Oil- and Gas-Fired Units ............... 53

5.9 Distribution of Generating Capacity among New, Planned, and Existing Units

5.10 Distribution of Electricity Generation among New, Planned, and Existing Units

5.11 Distribution of $\mathrm{SO}_{2}$ Emissions among New, Planned, and Existing Units

$5.12 \mathrm{SO}_{2}$ Emissions Trajectory and Growth of Scrubbed Capacity...................... 55

5.13 Projected Average Sulfur Content in Steam Coal ............................. 56

5.14 Additional Costs Incurred to Comply with Title IV Requirements .............. 56

5.15 Changes in Regional Coal Production due to Title IV Requirements............. 57

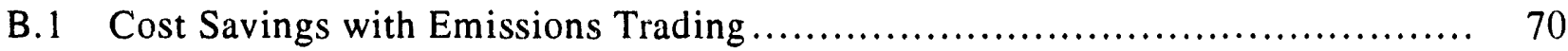




\section{Nomenclature}

$\begin{array}{ll}\text { AFBC } & \text { atmospheric fluidized-bed combustion } \\ \text { ARGUS } & \text { Argonne Utility Simulation model } \\ \text { BACT } & \text { best available control technology } \\ \text { BART } & \text { best available retrofit technology } \\ \text { BCM } & \text { Build Cost Module } \\ \text { CAAA90 } & \text { Clean Air Act Amendments of } 1990 \\ \text { CCT } & \text { clean coal technology } \\ \text { CSTM } & \text { Coal Supply and Transportation Module } \\ \text { ECAR } & \text { East Central Area Reliability Coordination Agreement } \\ \text { ECM } & \text { Emissions and Control Module } \\ \text { EIA } & \text { Energy Information Administration } \\ \text { EPA } & \text { U.S. Environmental Protection Agency } \\ \text { EPRI } & \text { Electric Power Research Institute } \\ \text { FBC } & \text { fluidized-bed combustion } \\ \text { FERC } & \text { Federal Energy Regulatory Commission } \\ \text { FGD } & \text { flue-gas desulfurization } \\ \text { GCC } & \text { gasification with combined cycle } \\ \text { ICARUS } & \text { Investigation of Costs and Reliability in Utility Systems module } \\ \text { IGCC } & \text { integrated gasification combined cycle } \\ \text { IOU } & \text { investor-owned utility } \\ \text { IPP } & \text { independent power producer } \\ \text { ISTIG } & \text { intercooled steam-injected gas turbine } \\ \text { LAER } & \text { lowest achievable emission rate } \\ \text { MCFC } & \text { molten carbonate fuel cell } \\ \text { NAAQS } & \text { National Ambient Air Quality Standards } \\ \text { NERC } & \text { North American Electric Reliability Council } \\ \text { NES } & \text { National Energy Strategy } \\ \text { NGCC } & \text { natural gas combined cycle } \\ \text { NSPS } & \text { New Source Performance Standards } \\ \text { NUFS } & \text { National Utility Financial Statement } \\ \text { NUG } & \text { nonutility generation } \\ \text { PC } & \text { pulverized coal } \\ \text { PFBC } & \text { pressurized fluidized-bed combustion } \\ \text { PSD } & \text { Prevention of Significant Deterioration } \\ \text { RACT } & \text { reasonably available control technology } \\ \text { RNSPS } & \text { Revised New Source Performance Standards } \\ \text { SIP } & \text { State Implementation Plan } \\ \text { STIG } & \text { steam-injected gas turbine } \\ \text { TAG } & \text { Technical Assessment Guide } \\ \text { VOC } & \text { volatile organic compounds } \\ & \end{array}$




\title{
Analysis of the Clean Air Act Amendments of 1990: A Forecast of the Electric Utility Industry Response to Title IV, Acid Deposition Control
}

\author{
by \\ J.C. Molburg, J.A. Fox, G. Pandola, and C.M. Cilek
}

\begin{abstract}
The Clean Air Act Amendments of 1990 incorporate, for the first time, provisions aimed specifically at the control of acid rain. These provisions restrict emissions of sulfur dioxide $\left(\mathrm{SO}_{2}\right)$ and oxides of nitrogen $\left(\mathrm{NO}_{\mathrm{x}}\right)$ from electric power generating stations. The restrictions on $\mathrm{SO}_{2}$ take the form of an overall cap on the aggregate emissions from major generating plants, allowing substantial flexibility in the industry's response to those restrictions. This report discusses one response scenario through the year 2030 that was examined through a simulation of the utility industry based on assumptions consistent with characterizations used in the National Energy Strategy reference case. It also makes projections of emissions that would result from the use of existing and new capacity and of the associated additional costs of meeting demand subject to the emission limitations imposed by the Clean Air Act. Fuel-use effects, including coal-market shifts, consistent with the response scenario are also described. These results, while dependent on specific assumptions for this scenario, provide insight into the general character of the likely utility industry response to Title IV.
\end{abstract}

\section{Introduction}

Acid rain - or, in more general terms, acidic deposition - has been implicated in damage to aquatic ecosystems, forests, structural materials, visibility, and health. Acidic deposition includes the dry deposition of gaseous sulfur dioxide $\left(\mathrm{SO}_{2}\right)$ and nitrogen oxides $\left(\mathrm{NO}_{\mathrm{x}}\right)$, the deposition of these species through precipitation following adsorption by cloud moisture, and the dry and wet deposition of sulfate and nitrate particulates. These particulates are formed in atmospheric reactions of $\mathrm{SO}_{2}$ and $\mathrm{NO}_{x}$ involving volatile organic compounds (VOC). The amount of acidic deposition is thought to be essentially linearly related to emissions of $\mathrm{SO}_{2}$ and $\mathrm{NO}_{\mathrm{x}}$, although the complex reactions between various atmospheric species and the influence of meteorology suggest that this linearity is only valid on large geographic and temporal scales. This nearly linear relationship between emissions and deposition suggests that a sensible policy option for controlling acidic deposition is to control emissions of $\mathrm{SO}_{2}$ and $\mathrm{NO}_{\mathrm{x}}$. This is the approach that is taken in the Clean Air Act Amendments of 1990 (CAAA90) and that is the subject of this analysis. Previous Clean Air Act Amendments also sought to control emissions of $\mathrm{SO}_{2}$ and $\mathrm{NO}_{\mathrm{x}}$, although the reason behind the controls was concern over the direct health effects of these species rather than their contribution to acid rain. 
Roughly $94 \%$ of $\mathrm{SO}_{2}$ emissions and $88 \%$ of $\mathrm{NO}_{\mathrm{x}}$ emissions in North America can be attributed to anthropogenic sources. Of these anthropogenic emissions, $70 \%$ of the $\mathrm{SO}_{2}$ and $34 \%$ of the $\mathrm{NO}_{\mathrm{x}}$ are attributable to fossil-fuel-fired electric power plants (Kohout et al. 1990). As a percentage of total emissions, $61 \%$ of the $\mathrm{SO}_{2}$ and $25 \%$ of the $\mathrm{NO}_{\mathrm{x}}$ are from fossil-fuel-fired electric power plants. In recognition of that contribution, Title IV, the acid rain provisions of the CAAA90, imposes new constraints almost exclusively on electric utility sources. Previous emission limits on electric utility boilers had taken the form of performance standards (e.g., a reduction in the number of pounds of pollutant permitted per million Btu of heat input or a percent reduction from uncontrolled emission levels). However, growth in electricity generation, which necessarily accompanies a growth in demand for energy, results in increasing emissions under this type of standard. The CAAA90 address this difficulty by setting an absolute "cap" (or limit) on utility $\mathrm{SO}_{2}$ emissions; it allocates emission allowances only up to the level of the cap. Owners of new capacity must purchase or otherwise obtain allowances sufficient to cover that capacity's anticipated emissions from this limited pool of available allowances. The CAAA90 include other innovative provisions, such as those that deal with the trading and banking of allowances, which are intended to minimize the cost of the prescribed emission reductions.

The stated purpose of Title IV is to ameliorate acidic deposition effects through a reduction in annual average emissions of $\mathrm{SO}_{2}$ and $\mathrm{NO}_{\mathrm{x}}$ in the continental United States. The goal for $\mathrm{SO}_{2}$ is to reduce emissions each year by 10 million tons below the estimated total anthropogenic $\mathrm{SO}_{2}$ emissions for 1980. The goal for $\mathrm{NO}_{\mathrm{x}}$ is to reduce emissions each year by 2 million tons below $1980 \mathrm{NO}_{\mathrm{x}}$ emissions from these same anthropogenic sources. However, because there have been "historical" (i.e., not related to CAAA90) reductions in industrial and utility $\mathrm{SO}_{2}$ emissions since 1980, it will not be necessary for utilities to achieve a full 10 -million-ton reduction from present levels to meet Title IV requirements. In fact, a reduction of less than $50 \%$ of current utility emissions, to a cap of about 8.9 million tons, will achieve the reduction goal. This cap, in conjunction with a cap on industrial $\mathrm{SO}_{2}$ emissions of 5.6 million tons, will ensure that future annual $\mathrm{SO}_{2}$ emissions remain 10 million tons below the 1980 level. $\mathrm{NO}_{\mathrm{x}}$ emissions are not limited by a cap.

The utility sector can respond to these new Title IV constraints by applying retrofit controls on existing units, using "low-emitting" new capacity (i.e., units designed to emit fewer pollutants), repowering existing units, and/or trading emission allowances. Each response will impose its own set of costs and result in other region-specific effects. The utility sector's response will depend on:

- The current makeup of the industry in terms of existing technologies and service demands;

- The availability and cost of new technologies, especially electricity generating technologies with low emission rates;

- The availability and cost of fuels with inherently low emission rates;

- Growth in energy demand; 
- Interest rates, tax policies, and other financial considerations; and

- State and local regulations.

The present study projects the utility sector's response through the year 2030, a prediction that was made on the basis of known conditions and assumptions about the above factors. The assumptions are consistent with those used for the analysis conducted for the National Energy Strategy (NES), including those related to the growth in demand for energy and the specified market penetration of new electricity-generating technologies. The projection forecasts the amounts of pollutant emissions that will result from the use of existing and new capacity and predicts the associated costs of meeting the demand for energy, subject to the emission limitations imposed by the Clean Air Act, including the 1990 amendments. Predictions of fuel-use effects, including coal market shifts, that are consistent with that projection are also presented. The study results rely primarily on a simulation of the electric utility sector by the Argonne Utility Simulation (ARGUS) computer model, but they also reflect an analysis of historical data and the application of dialectical methods to some specific provisions of the amendments that are too detailed for the simulation approach.

Sections 2 and 3 provide information on the Clean Air Act and its amendments, the utility sector, and technical compliance options. Although this background material is available in many other sources, it is included here to provide a context for understanding the analysis. The specific analysis that leads to the projection is discussed in Section 4 . The projection results are presented in detail in Section 5. Appendix A lists the power plants, generating units, and $\mathrm{SO}_{2}$ emission allowances that will be allocated to meet the Phase I requirements of CAAA90. Appendix B on incentive regulation provides a policy context for interpreting the CAAA90 acid rain provisions. 


\section{Title IV Requirements}

\subsection{Regulatory Context}

Previous amendments to the 1963 Clean Air Act sought to control emissions of $\mathrm{SO}_{2}$ and $\mathrm{NO}_{\mathrm{x}}$ as a strategy for achieving primary and secondary National Ambient Air Quality Standards (NAAQS) and for protecting areas already in attainment of these standards. The NAAQS set concentration limits. The primary NAAQS are intended to protect public health. The secondary NAAQS are intended to protect public welfare, including "soils, water, crops, vegetation, manmade materials, animals, wildlife, weather, visibility, climate, damage to and deterioration of property, and hazards tc transportation, as well as effects on economic values and on personal comfort and well being" (Moore et al. 1989). Under the provisions of Section 108 of the 1963 Clean Air Act, the U.S. Environmental Protection Agency (EPA) was required to issue "criteria" documents identifying the effects of specific air pollutants that "may reasonably be anticipated to endanger public health or welfare." Before the 1990 amendments, $\mathrm{SO}_{2}$ and $\mathrm{NO}_{\mathrm{x}}$ were regulated, but as two of these "criteria" pollutants and not as precursors to acid rain.

In areas that are already in attainment of the NAAQS, air quality is protected by restrictions on the permitted increase in concentrations of criteria pollutants. These Prevention of Significant Deterioration (PSD) provisions recognize three categories of attainment areas. In Class 1 areas, which include national parks and other important recreational or historic areas, degradation in air quality is severely restricted. In Class 2 areas, which currently include all other areas, a moderate amount of degradation is permitted, although pollutant concentrations are not permitted to reach the level of the NAAQS. Only in Class 3 areas is the air quality permitted to degrade to the level of the NAAQS. However, no areas are currently designated as Class 3.

The NAAQS and PSD air quality requirements are to be achieved, in part, through limitations on emissions from stationary sources. These technology-based or performance standards take several forms, and the requirements applicable to a specific plant depend on the date of initial operation, the extent of likely emissions, and the air quality of the region in which the plant is located. Emissions from plants constructed after the 1972 Amendments are subject to New Source Performance Standards (NSPS). For $\mathrm{SO}_{2}$ emissions, that standard is 1.2 pounds per million Btu (1.2 lb/106 Btu). $\mathrm{SO}_{2}$ emissions from new plants built after the 1977 Amendments are subject to Revised New Source Performance Standards (RNSPS), which are stricter for most coals, as shown in Figure 2.1. They require a percent reduction below the emission rate that would result without the use of controls. In effect, the RNSPS constitute a mandatory scrubbing requirement. Actually, the NSPS and RNSPS set only minimal requirements for pollutant emissions limits for new plants. Stricter limits now generally apply, especially in "attainment" regions (regions that meet NAAQS requirements), where plants are subject to PSD increments. In nonattainment areas, plants are not only subject to performance standards but must also obtain offsets to ensure a net reduction in regional emissions. Existing sources are restricted only if they are located in a nonattainment area. Table 2.1 provides a summary of current technology standards. 


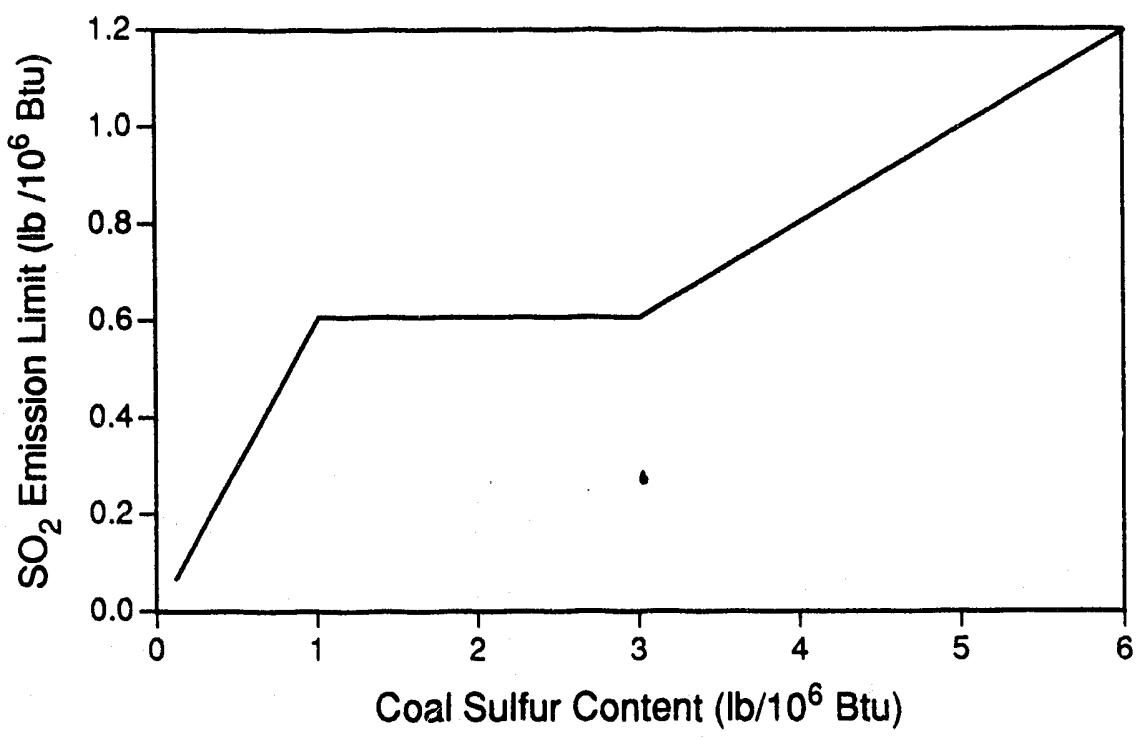

FIGURE 2.1 Revised New Source Performance Standard for Sulfur Dioxide

TABLE 2.1 Technology Standards Applicable to Major Sources of Pollutant Emissions

\begin{tabular}{llll}
\hline & \multicolumn{2}{c}{ Standards To Be Met by Sources Located in Various Areas } \\
\cline { 2 - 4 } $\begin{array}{c}\text { Type of } \\
\text { Source }\end{array}$ & All Areas & Attainment Areas & Nonattainment Areas \\
\hline New & $\begin{array}{l}\text { Revised New Source } \\
\text { Performance Standards } \\
\text { (RNSPS) }\end{array}$ & $\begin{array}{l}\text { Best Available Control } \\
\text { Technology (BACT) }\end{array}$ & $\begin{array}{l}\text { Lowest Achievable } \\
\text { Emission Rate (LAER) }\end{array}$ \\
Existing & $\begin{array}{l}\text { Best Available Retrofit } \\
\text { Technology (BART) }\end{array}$ & $\begin{array}{l}\text { Reasonably Available } \\
\text { Control Technology } \\
\text { (RACT) }\end{array}$ \\
\hline
\end{tabular}

Local responsibility for attainment of the NA.AQS is addressed in the State Implementation Plans (SIPs). In general, SIPs clarify the technology standards listed in Table 2.1 and provide for construction and operating permitting procedures to ensure compliance. General technology standards are interpreted as plant-specific performance standards in the SIPs. These performance standards are referred to as SIP limits. Some plants that existed before the 1972 Amendments have SIP limits that far exceed the NSPS or RNSPS requirements. Implementation of the CAAA90 requirements will, on average, reduce $\mathrm{SO}_{2}$ emissions at these plants to levels close to those required by 1972 NSPS, $1.2 \mathrm{lb} / 10^{6} \mathrm{Btu}$. 
Although they eliminate the percent reduction requirement, Title IV provisions allow most of the $\mathrm{SO}_{2}$ and $\mathrm{NO}_{\mathrm{x}}$ requirements of previous amendments to remain intact, and other provisions of CAAA90 will force a reduction in emission rates to well below current SIP limits for some existing sources. The most significant departures of Title IV from prior law are as follows:

- The intent to control acidic deposition in addition to achieving NAAQS compliance,

- The specific inclusion of an emissions trading approach intended to reduce the direct costs of emission control, and

- The imposition of an absolute emissions cap.

It is coincidental that two of the six criteria pollutants are implicated in acidic deposition. The regulation of $\mathrm{SO}_{2}$ and $\mathrm{NO}_{\mathrm{x}}$ emissions was originally justified on other grounds. The CAAA90 are the first federal law intended specifically to reduce acidic deposition. The use of emissions trading became a feature of prior regulations when areas that failed to meet deadlines for NAAQS attainment were prohibited from issuing permits for new emission sources. This situation put urban economic growth at risk and led to an EPA ruling that new sources would be permitted in nonattainment areas if they could arrange to offset their new emissions by obtaining reductions at other existing sources (Raufer and Feldman 1987). Trading in this context was not implemented to reduce the direct costs of emission control, and the resulting application of trading has been very limited. Control by emission rate standards alone offers no insurance against the amount of emissions increasing as demand for energy grows. The absolute cap on $\mathrm{SO}_{2}$ emissions set in CAAA90 is intended to preserve the near-term gains that will be achieved by reducing average emission rates.

Because the CAAA90 do not repeal most of the provisions of the earlier amendments applicable to the electric utility sector, a knowledge of these earlier requirements is essential background for the present study. Compliance options that utilities might use to satisfy CAAA90 requirements must also conform to these earlier requirements. In fact, Section 413 of CAAA90 explicitly states that compliance with Title IV does not exempt a plant owner or operator from compliance with other requirements of the 1963 Clean Air st and its previous amendments. For instance, a plant subject to an $\mathrm{SO}_{2}$ emission limit of $1.2 \mathrm{lb} / 10^{6}$ Btu cannor exceed that limit, even if the plant operator holds enough emission allowances from Title IV to cover the total emissions.

\subsection{Overview of Title IV}

The primary objective of Title IV, as described in Section 401, is to mitigate the effects of acidic deposition through a reduction in emissions of $\mathrm{SO}_{2}$ and $\mathrm{NO}_{\mathrm{x}}$, which are the most significant precursors of acidic species in the atmosphere. Specific total reduction goals of 10 million tons of $\mathrm{SO}_{2}$ and 2 million tons of $\mathrm{NO}_{\mathrm{x}}$ below 1980 emission levels are to be achieved primarily through constraints on emissions from fossil-fuel-fired electric power plants. Secondary objectives are to encourage energy conservation, renewable energy resources, clean fossil fuel technologies, and pollution prevention. The most outstanding feature of the legislation is the use of an emissions 
market, which gives individual utilities the flexibility to choose a compliance strategy that meets their overall goals in an economically efficient manner.

The $\mathrm{SO}_{2}$ emission reduction goal is to be achieved in two phases by the allocation of a limited number of emission allowances. An allowance is an authorization to enit one ton of $\mathrm{SO}_{2}$ in a specified calendar year or in a subsequent year. In addition to adhering to the NSPS or SIP performance requirements, a source must "hold" allowances equal to its total annual $\mathrm{SO}_{2}$ emissions.

In the first phase, which will take effect or January 1,1995 , only the units that are listed in Title IV, Section 404, Table A, of CAAA90 will be allocated allowances and will have to hold allowances (see Appendix A). Table A includes all electricity-generating units in the continental United States with a capacity of $100 \mathrm{MW}$ or more and a $1985 \mathrm{SO}_{2}$ emission rate exceeding $2.5 \mathrm{lb} / 10^{6} \mathrm{Btu}$. These "affected" units will be allocated sufficient allowances to emit at a rate of about $2.5 \mathrm{lb} / 10^{6} \mathrm{Btu}$. The precise number of allowances to be allocated to each unit (which are listed in Table A) is calculated as the product of $2.5 \mathrm{lb} / 10^{6} \mathrm{Btu}$ and the average annual heat input for each unit in the years 1985, 1986, and 1987. Outage periods exceeding four months during these years are not included in the average. The average heat input thus determined is called the baseline. Units without an operating history in these years will have their baselines set by the Administrator (EPA). The allowances to be allocated under this scheme will clearly not permit an average emission rate at an affected unit to exceed $2.5 \mathrm{lb} / 10^{6} \mathrm{Btu}$ unless the average capacity factor for that unit is below the factor for 1985 through 1987. If capacity utilization exceeds the baseline average, the average emission rate will have to be decreased or supplemental allowances will have to be obtained.

In Phase II, which will take effect on January 1, 2000, allowances will be allocated to virtually all categories of fossil-fuel-fired plants. In most cases, the allowance allocation will amount to a grandfathering of emissions from existing units, i.e., existing units will be granted sufficient allowances to permit emissions at their historical rates. (The precise allocations are summarized in the following section.) However, for units with capacities of more than $75 \mathrm{MW}$ and a $1985 \mathrm{SO}_{2}$ emission rate exceeding $1.2 \mathrm{lb} / 10^{6} \mathrm{Btu}$, the allocation will not permit an average emission rate exceeding $1.2 \mathrm{lb} / 10^{6} \mathrm{Btu}$. Most of the Phase II emission reductions will be achieved by this group of plants. As in Phase I, the allocations will be calculated as the product of an emission rate and the baseline fuel consumption.

For $\mathrm{NO}_{\mathrm{x}}$ emissions, neither a cap nor an allowance system is imposed. Instead, a performance requirement similar to the NSPS established in previous amendments is to be set by the EPA. That performance requirement is to be set on the basis of the capability of "low-NO burners (i.e., burners designed to emit less $\mathrm{NO}_{\mathrm{x}}$ ) or other technologies of comparable cost. The law is carefully written to avoid the implication that $\mathrm{NO}_{\mathrm{x}}$ scrubbing will be required. Other provisions of the amendments may affect utility $\mathrm{NO}_{\mathrm{x}}$ emissions. In Title IV, the possibility of interpollutant trading $\left(\mathrm{SO}_{2}\right.$ for $\mathrm{NO}_{\mathrm{x}}$ ) is left open, pending a study on the environmental and economic consequences of such trading. According to the provisions of Title I of CAAA90, additional $\mathrm{NO}_{\mathrm{x}}$ controls may be required for sources that are also major sources of VOC. This requirement could affect utilities in ozone nonattainment areas. 


\subsection{Summary of Title IV Provisions by Section}

\subsubsection{Section 401: Findings and Purposes}

The need for Title IV is rationalized in Subsection (a), "Findings," which states that acidic deposition's threat to "ecosystems, materials, visibility, and public health" is of national and international significance. The findings recognize the dominant role of fossil-fuel combustion in contributing to the acid rain precursors $\mathrm{SO}_{2}$ and $\mathrm{NO}_{\mathrm{x}}$ and the increasing availability of costeffective controls to reduce these emissions. They conclude that the need to reduce these emissions from steam-electric generators is urgent. Specifically, an emissions limitation program is prescribed to achieve reductions of 10 million tons for $\mathrm{SO}_{2}$ and 2 million tons for $\mathrm{NO}_{\mathrm{x}}$ below 1980 emission levels. These reductions are intended to achieve the main purpose of the title, the reduction of adverse impacts from acidic deposition. Other purposes of Title IV include the encouragement of energy conservation, renewable and clean energy conversion technologies, and pollution prevention.

\subsubsection{Section 402: Definitions}

Although most of the definitions presented in this section are consistent with conventional usage, two new terms, "allowance" and "baseline," are introduced. These terms are central to the emissions limitation program that is intended to achieve the purposes of Title IV. An allowance is an authorization to emit one ton of $\mathrm{SO}_{2}$ during a specified calendar year. A baseline is the average annual energy input to a fossil-fuel-fired generating unit in the years 1985 through 1987. Special pattistions are made for plants that had extended outages during this period or that were not on linv The baseline multiplied by a permitted emission rate (e.g., $1.2 \mathrm{lb} / 10^{6} \mathrm{Btu}$ ) yields an annual emission amount, which is then used to allocate allowances as described in subsequent sections.

\subsubsection{Section 403: $\mathrm{SO}_{2}$ Allowance Program for Existing and New Units}

Sections 404, 405, 406, 409, and 410 specify emissions limitations for fossil-fuel-fired utility units, which, when taken together, will achieve the $\mathrm{SO}_{2}$ emission reduction objectives of Title IV. These limitations require that annual tonnage emissions of $\mathrm{SO}_{2}$ by any unit not exceed the number of allowances held for that unit by its owner or operator. Section 403 authorizes the allocation of sufficient allowances to permit operation at the applicable emission limit, as defined in the sections listed above. A total allocation of 8.9 million tons is authorized for the year 2000 and subsequent years. If the total allocation based on the provisions of these later sections exceeds 8.9 million tons, each unit's allocation is to be reduced in proportion to its share of the total to achieve a total of 8.9 million tons. The 8.9 -million-ton total is exclusive of certain bonus provisions, which apply only until 2010, and exclusive of a 50,000-ton special allocation to midwestern states, which applies as long as the CAAA90 are in force.

Allowances will be allocated annually at no cost and without regard for the operating status of a unit; in other words, even if a unit retires at any time after the enactment of the amendments, it 
will still be allocated allowances. The emission limitations established in the latter sections of Title IV are to be related to a particular unit's historical emissions in two ways. First, the historical level of fuel use will determine the baseline, and emissions will be linearly related to fuel use by the emission factor. Second, the allowed annual average emission rate will reflect the historical rate. In brief, Section 403 authorizes the allocation of emissions essentially by grandfathering, i.e., owners will be allocated allowances unequally, according to a scheme that recognizes their historical emission patterns. Of course, the full amount of historical emissions will not be permitted, because some net reduction is to be achieved. This approach to the allocation of emissions is discussed further in the background section on incentive regulation provided in Appendix B.

The allocation of allowances up to a specified cap is one of two key features of the $\mathrm{SO}_{2}$ reduction program. The second is the authorization of allowance transfers, which is outlined in Subsection 403 (b). Allowance transfers, a form of emissions trading, are essentially unrestricted, since they are permitted among units under both common and separate ownership and without regard for location or timing, except that no allowance may be used before the calendar year for which it is allocated. However, allowances may be used in years following the year for which they are allocated, thus permitting emissions "banking" and the trading of banked emissions.

Both the U.S. Senate and House versions of the bills on which the final amendments are based included restrictions on trading. Primarily, trading was to be permitted only within two multistate geographic regions, basically eastern and western states. This provision was intended to protect regional interests, although its value in that regard is uncertain and its enforcement would greatly complicate the allowance system. New units, however, were to be permitted to obtain allowances from any source, despite the geographical limitations on trading. Once obtained, these allowances could then be further traded - in effect, negating the geographical constraint. So a geographical constraint is not included in CAAA90 as passed.

Subsection 403 (c) mandates an evaluation of interpollutant trading between $\mathrm{SO}_{2}$ and $\mathrm{NO}_{\mathrm{x}}$ by January 1,1994 . Both the House and Senate bills permitted interpollutant trading at a rate of 1.0 ton of $\mathrm{SO}_{2}$ for 1.5 tons of $\mathrm{NO}_{\mathrm{x}}$. The evaluation requirement has replaced those provisions and may put interpollutant trading on a firmer scientific and economic foundation.

EPA is to establish an allowance tracking system to ensure that allowances are used in accordance with the CAAA90. However, this system is not to interfere with the transfer of allowances. In addition, the tracking system is not to be concerned with temporary increases in emissions, such as those that might occur as a result of plant operating problems. Compliance with the emission limitations of this section is strictly an annual obligation. In other words, the total emissions in a calendar year must not exceed the total allowances held.

Except for new units that will begin commercial operation before 1996, new units will not be allocated allowances. Their owners or operators will have to obtain all necessary allowances from those allocated to existing units. A new unit is defined as one that will begin commercial operation after the date of enactment of these amendments. This prohibition on the allocation of allowances to new units is essential to ensure compliance with the emissions cap. 
Subsection 403 (f) further clarifies the nature of allowances by stating that they do not constitute property rights. They are strictly a "limited authorization to emit sulfur dioxide." This provision is intended to avoid litigation under the "takings" clause of the Constitution, which protects private property. The allowances are intended as an instrument to effect emissions reduction, and subsequent regulations governing emissions may further restrict emissions. The relevance of this provision to the current study is that it may serve to constrain the allowance trading market, since the value of allowances could be affected by such subsequent regulations.

\subsubsection{Section 404: Phase I Sulfur Dioxide Requirements}

First-phase emission limitations will take effect on January 1, 1995. These limitations will apply to a specific group of 110 large, high-emitting plants that are listed in Table A of Section 404 of Title IV (see Appendix A). No Phase I limitations will be established for any units not on this list. To be consistent with the scheme of these amendments, the emission limitations are expressed as tons of $\mathrm{SO}_{2}$ that may be emitted in one calendar year. The emission limitation is calculated as each unit's baseline (heat input) multiplied by $2.5 \mathrm{lb} / 10^{6} \mathrm{Btu}$, converted to tons. These limitations will apply until the onset of Phase II on January 1, 2000. Also to be consistent with the general scheme of these amendments, all units in this list will be granted sufficient allowances to permit emissions up to the specified emission limit. All the units in Table A exceed $100 \mathrm{MW}$ in capacity and have historical $\mathrm{SO}_{2}$ emission rates in excess of $2.5 \mathrm{lb} / 10^{6} \mathrm{Btu}$. As discussed in the utility background section, these plants are responsible for a substantial portion of total $\mathrm{SO}_{2}$ emissions.

A listed unit may exceed its Table A emission limit if its owner/operator holds sufficient allowances to cover the total emissions. In other words, the owner/operator will have to obtain additional allowances from other units to cover the listed unit's exceedance. In Phase I, all these other units will, of necessity, also be listed in Table A, since they are the only units allocated allowances in Phase I. A unit may also exceed the Table A emission limit if the owner/operator reassigns some or all of the emission reduction requirement implicit in that limitation to another unit under control of the same owner/operator. This is really a special case of emissions trading or allowance transfer, which permits units not included in Table A to be used to meet the Phase I emission reduction goal embodied in Table A.

A unit may also exceed the emission limitation specified in Table $A$ if it is an eligible "Phase I extension unit" (one of a limited number of units that will be permitted to postpone their compliance with the Table A emission limitation for up to two years if they apply an emission reduction system with $90 \%$ removal efficiency by January 1,1997 ). This provision serves as an incentive to use scrubbers and permits some additional planning and construction time for units that will be able to meet the Phase I and II emission limits by scrubbing. As a scrubber incentive, the Phase I extension provision also provides some protection to the high-sulfur-coal industry. It is also an incentive for early reduction of emissions, since $90 \%$ removal applied to virtually any coal will result in emissions below the $2.5 \mathrm{lb} / 10^{6} \mathrm{Btu}$ rate that was used to set the Table A emission limits. In most cases, the resulting emissions will be below the Phase II nominal requirements for these plants $\left(1.2 \mathrm{lb} / 10^{6} \mathrm{Btu}\right)$. In fact, the provision provides an additional incentive that grants these Phase I extension units an additional allowance for every ton of $\mathrm{SO}_{2}$ removed beyond that 
which would be removed at the $1.2 \mathrm{lb} / 10^{6} \mathrm{Btu}$ rate. This provision has been referred to as the two-for-one provision, because it gives the plant operator two usable allowances for one unit of excess emission reduction.

In the Administration's original proposal, the emission reduction program lacked the Phase I extension provisions. However, the CAAA90 as passed achieve the same overall reductions as the original proposal, since it imposes the emission limitations one year earlier. The additional allowances allocated under the Phase I extension provisions are taken from a reserve created by the reductions achieved in that first year, 1995. However, that reserve is limited to 3.5 million tons, which must be allocated over two years (1995 and 1996) to the Phase I extension units. According to an analysis by ICF Resources, Inc. (1990), the additional reduction achieved by the one-year-earlier implementation is between 3.1 and 4.1 million tons. A simple analysis made by using the ARGUS computer model and by applying an across-the-board limitation of $2.5 \mathrm{lb} / 10^{6} \mathrm{Btu}$ on all plants with higher emission rates estimated the reduction to be about 4.5 million tons below a status-quo case (which applies no reduction requirements beyond those of the prior Clean Air Act Amendments). This amount is something of an overestimate, since it imposes the 2.5-lb limit on smaller plants, which are not included in Table A. In any case, approximately one-half of the Phase I reduction requirement may be deferred by election of the extension option. It is not known how many units will elect to employ scrubbers in Phase I. However, in recognizing tougher Phase II reductions and an increasing demand for low-sulfur coal, the scrubber strategy, with its capability to "free up" allowances for banking or trading, has substantial appeal. It is possible, then, that the number of units electing the extension option will be limited by the availability of reserve allowances, which is limited to 3.5 million tons. In that case, allowances will be allocated on a first-come, first-served basis.

Subsection 404 (e) defines an additional early reduction incentive. For Phase I affected units (listed in Table A), allowances will be granted for emission reductions achieved after enactment (1990) but before Phase I. The total number of allowances granted must be less than an amount that would allow the unit to exceed its 1985 emission rate. For Phase II affected units, the prior years are 1995 through 1999, and the total allowances cannot let the unit exceed $2.5 \mathrm{lb} / 10^{6} \mathrm{Btu}$ multiplied by the prior year's fuel use or let it exceed the emission rate permitted under its implementation plan multiplied by the prior year's fuel use. Two additional restrictions constrain eligibility for these early reduction credits. First, the unit must be part of a utility system for which the fraction of total system generation by coal was reduced $20 \%$ or more between 1980 and 1985, inclusive. Second, the weighted average capacity factor of all coal-fired units on the system must have been below 50\% during the years for which the baseline fuel use is calculated (1985-1987). This provision provides some compensation to systems that would otherwise have a low allowance allocation because of reduced coal usage in the baseline years. It is "tonnage neutral" over time, since the allowances that are granted are offset by early reductions. Because of constrained applicability, this early reduction incentive is not represented in this analysis.

Phase I also includes an incentive for the application of conservation and renewable energy. For each ton of $\mathrm{SO}_{2}$ avoided by the application of conservation or renewable energy, one additional allowance is conditionally granted to the implementing utility. To qualify, the utility must be paying for the conservation measure or for the power from the renewable energy resource. The utility must also have adopted a least-cost energy plan to meet future demand at the lowest 
system cost, and the subject conservation and renewable energy supply programs must be consistent with that plan. In addition, the Secretary of Energy must certify that the utility's income is not reduced by the application of the conservation and renewable energy technology. The incentive allowances will be granted for emissions avoided between January 1, 1992, and the date on which any unit in the affected utility system becomes an affected unit under Title IV.

The estimation of avoided emissions is made on the basis of the energy saved by the conservation measure or the energy generated by the renewable resource. In both the conservation and renewable energy cases, the avoided emissions are taken to be $0.004 \mathrm{lb} / \mathrm{kWh}$. It is interesting to consider the magnitude of this incentive. If an allowance is worth $\$ 800$ (per ton of emissions), $0.004 \mathrm{lb}$ is worth $1.6 \mathrm{mils}$. Thus, the incentive is about $1.6 \mathrm{mils} / \mathrm{kWh}$. This amount is unlikely to provide significant incentive in cases where conservation and renewable energy are not already competitive. The aliowances for this incentive program are to be taken from a reserve of 300,000 allowances, which will be established by setting aside 30,000 allowances in each of the first 10 years of Phase II. These are taken on a pro rata basis from all units allocated allowances under Phase II.

An additional total allocation of 200,000 annual allowances is to be distributed to the Table A units in Illinois, Indiana, and Ohio in proportion to the emission limitations listed on Table A. This provision is an acknowledgment of uncertainty in the estimate of reductions already achizved. These reductions plus those required by the new amendments will result in achievement of the 10-million-ton reduction goal.

\subsubsection{Section 405: Phase II Sulfur Dioxide Requirements}

Second-phase emission limitations will take effect on January 1, 2000. As was the case for Phase I, this date is one year earlier than the starting date in the Administration's original proposal. The reductions that will be achieved as a result of this early start, up to 5.3 million tons, will again be placed into a reserve. In Phase II, however, the reserve will not be used as a scrubber incentive. Instead it will provide a benefit to historically low-emitting plants, which are at something of a disadvantage in the distribution of basic allowances because more allowances are allocated to historically higher-emitting plants. The mechanism for the distribution of these reserve allowances will be a bonus program. The bonus program will allocate up to 530,000 allowances per year in each of the first 10 years of Phase II. No bonus allowances will be distributed thereafter. The basic allowances will be allocated in proportion to baseline fuel use, just as they will be in Phase I. However, the Phase II formula is $1.2 \mathrm{lb} / 10^{6} \mathrm{Btu}$ multiplied by the baseline energy use. Also, while the Phase I formula of $2.5 \mathrm{lb} / 10^{6} \mathrm{Btu}$ multiplied by the baseline will apply uniformly to all affected units (which are listed in Table A), Phase II allocations will include many exceptions to the basic allocation formula. Like the bonus allowances, these exceptions will compensate low-emitting units for the favorable allocation received by high emitters. This compensation is particularly important in cases where the low-emitting units are in high-growth areas, such as Florida, where the cap on allowances might otherwise constrain economic growth.

It is at the onset of Phase II that the goal of a 10-million-ton reduction below 1980 emission levels is to be achieved. This goal was deemed to require an emission limit in the utility sector of 
8.9 million tons or less. A cap at this level is probably a conservative measure because of the reductions that will be achieved in the nonutility sectors and because of the common utility practice of overcompliance (i.e., average emissions are below SIP limits at most utilities as a hedge against operational upsets). In recognition of this conservative emissions cap, additional Phase I allowances will be allocated, as noted above, totaling 200,000 annually. In Phase II, the additional allocation, which will also go to midwestern states, will be 50,000 annually. This additional allocation will not be derived from the bonus reserve and will continue even after the bonuses cease in 2010 . Thus, the effective cap will be 8.95 million tons.

Subsections 405 (b) through 405 (h) set emission limitations on various classes of units. Sufficient allowances will be allocated to these units, as authorized in Section 403, to permit operation at these limits. Units are classified according to the type of fuel used, unit size, size of the operating utility, historical (1985) emission rate, and on-line date. These classifications and the emission limitations that apply to each are summarized in Table 2.2. There are two groups of "large, dirty" units. Both are coal fired and have capacities of more than $75 \mathrm{MW}$. One group has historical emissions exceeding $2.5 \mathrm{lb} / 10^{6} \mathrm{Btu}$. Most of these units are affected by Phase I also, although the size cutoff for Phase $\mathrm{I}$ is $100 \mathrm{MW}$. The second group has a historical emission rate of between 1.2 and $2.5 \mathrm{lb} / 10^{6} \mathrm{Btu}$. Note that it is the actual 1985 emission rate, not the applicable performance standard, that is used. Both of these groups will be subject to the same emission limitation and hence receive the same number of permanent or basic allowances (i.e., $1.2 \mathrm{lb} / 10^{6} \mathrm{Btu}$ multiplied by baseline fuel use). However, the second group will be favored with a bonus during each of the first 10 years of Phase II. This bonus will compensate the operators of these plants, where low usage will have resulted in low baseline energy use (and consequently a low allowance allocation). For units with a capacity factor below $60 \%$, the bonus will make up one half of the difference between the allowances that would have been granted had the unit operated at a $60 \%$ capacity factor and the allowances that are in fact granted on the basis of actual operating experience. Most large, high-emitting units are operated at high capacity factors because of their low operating costs. Thus, few bonus allowances will be allocated as a result of this provision. However, for those units that operated at a low capacity factor in the baseline years, the bonuses will be important. Estimates of the permanent and bonus allowances allocated to each category are discussed in Section 5.

Two groups of "small, dirty" plants are also identified. In this case, the two groups are not differentiated on the basis of historical emissions but on the size of the operating utility. If the total capacity of the operating utility is less than $250 \mathrm{MW}$, the basic allowance is calculated as the baseline multiplied by the lesser of the 1985 actual or 1985 allowable emissions. When compared with the allowance calculated by multiplying the baseline times $1.2 \mathrm{lb} / 10^{6} \mathrm{Btu}$, this allowance represents favorable treatment, since the actual emissions for all "dirty" plants exceed $1.2 \mathrm{lb} / 10^{6} \mathrm{Btu}$. The small utility group will receive further favorable treatment in the form of a bonus, which is calculated as it was for the large, dirty group, compensating for low historical usage. This example represents only one of a number of Phase II provisions that ancnymously benefit a small number of special-interest units. In some instances, such exceptions are applicable to only a single plant. 


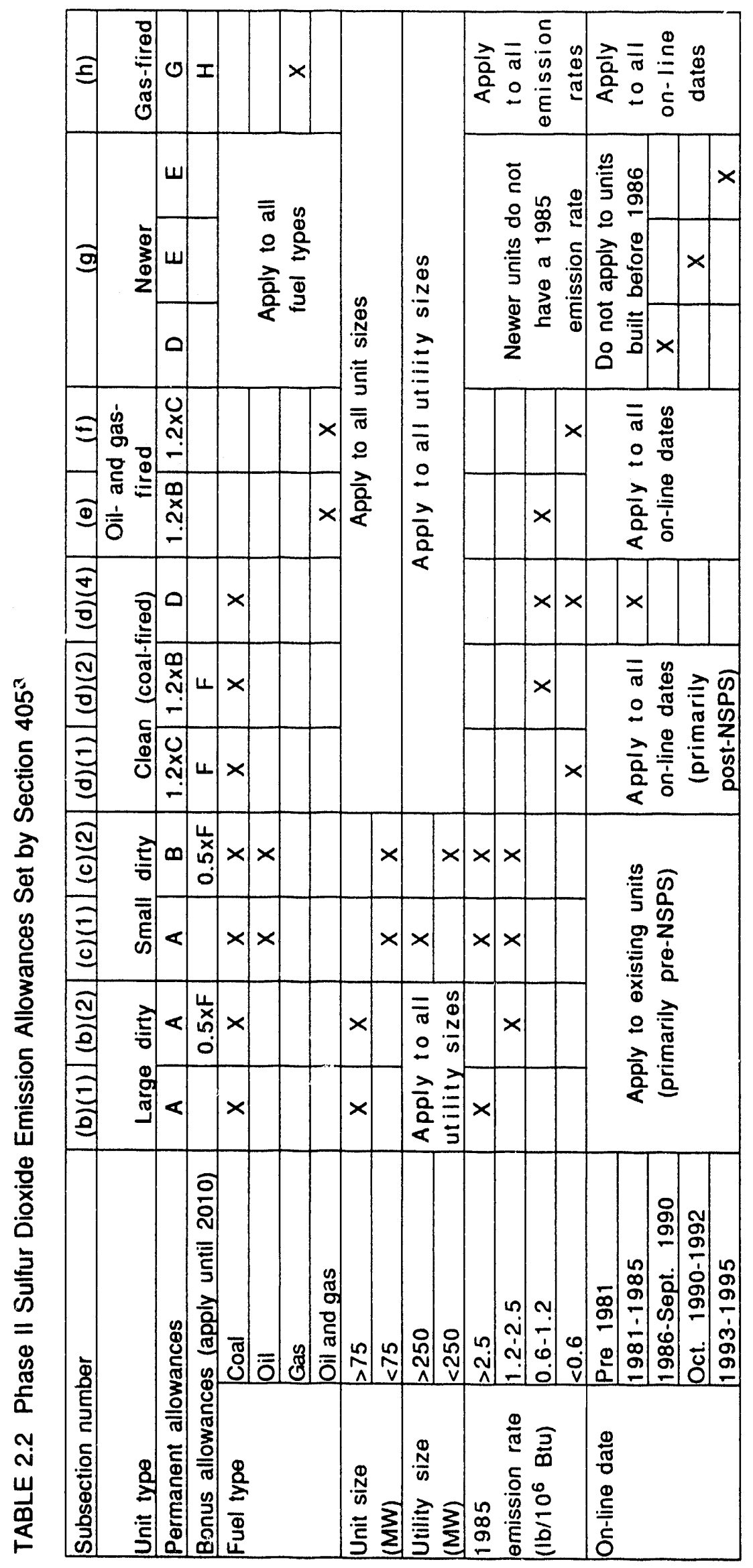

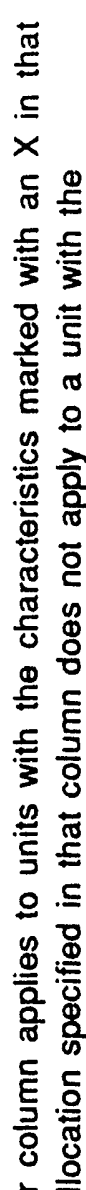

๖ำ

$\stackrel{8}{\circ}$

疍

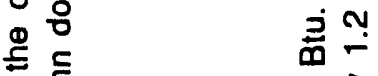

동 \&े

으

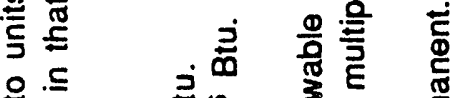

\&

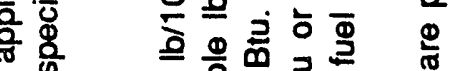

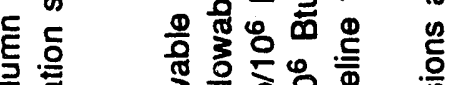

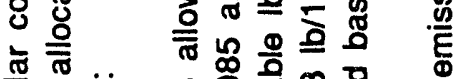

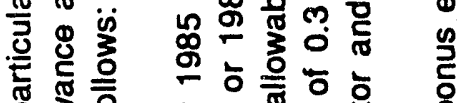

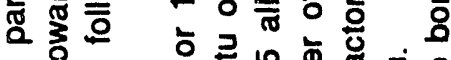

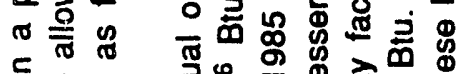

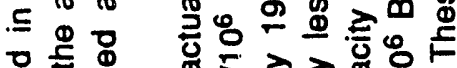

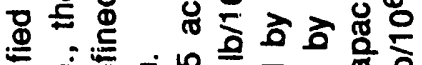

产 $\stackrel{0}{=}$

용 $\Phi$

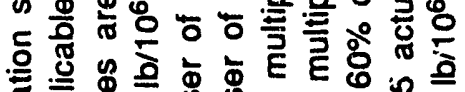

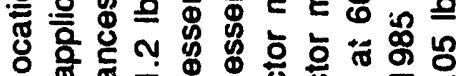

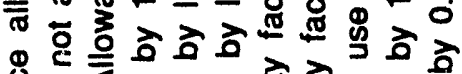
进

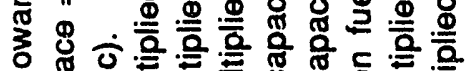

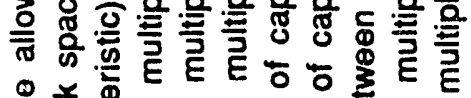

总要

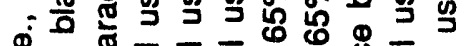

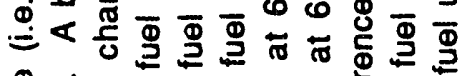

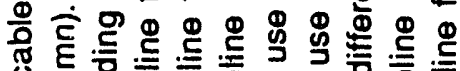

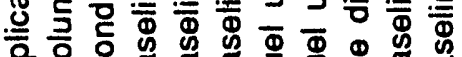

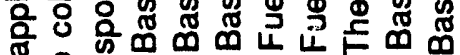

" ह : $\times$ 舟 8000 U 
Clean, coal-fired units are separated into two main groups according to whether or not their 1985 emissions were less than $0.6 \mathrm{lb} / 10^{6} \mathrm{Btu}$. Units emitting more than $0.6 \mathrm{lb} / 10^{6} \mathrm{Btu}$ will be permitted to emit at essentially their historical rate: baseline multiplied by the lesser of the 1985 actual or allowable emission rate. Units in the cleaner group will be permitted to emit as though their historical rate were $0.6 \mathrm{lb} / 10^{6} \mathrm{Btu}$. All of these clean, coal-fired units will be allocated bonus allowances that will fully correct their baseline fuel use to the equivalent of a $60 \%$ capacity factor. The bulk of bonus allowances will be allocated to these units. The bonus can be viewed as compensating such units for the low baseline fuel use that would have resulted from their relatively high operating cost. This low baseline then results in a low allocation of basic allowances. There is actually a third group of clean, coal-fired units, although it is a subset of the other groups. Clean, coal-fired units with on-line dates of 1981 through 1985 are allocated allowances at a fuel use corresponding to a $65 \%$ capacity factor and an emission rate equal to their 1985 allowable rate. This provision may have been intended to compensate these units for their low historical usage in the baseline years because of high operating costs and start-up complications.

Oil-fired units are relatively clean, although the use of high-sulfur residual oil could result in uncontrolled emissions exceeding $1.2 \mathrm{lb} / 10^{6} \mathrm{Btu}$. All of these units, however, have historical emission rates below $1.2 \mathrm{lb} / 10^{6} \mathrm{Btu}$. They are separated into two groups according to whether their emissions are below $0.6 \mathrm{lb} / 10^{6} \mathrm{Btu}$. The emission limitations and basic allowance allocations for these groups are calculated in the same manner as for the corresponding clean coal groups. No bonus allowances will be allocated to this group.

Newer fossil-fuel-fired units (i.e., those without a 1985 operating history) are placed in three groups according to their age. Those built between 1986 and passage of the amendments will receive allowances at their RNSPS or other allowable rate multiplied by an energy use corresponding to a $65 \%$ capacity factor. Units built after enactment but before Phase I will receive allowances corresponding to fuel use at a $65 \%$ capacity factor, but at the lower rate of $0.3 \mathrm{lb} / 10^{6} \mathrm{Btu}$. Units completed after January 1, 1993, must have begun being built before December 31, 1990, in order to be eligible for these allowances.

Finally, gas-fired units will receive a small allocation of allowances to permit them to operate on oil during periods of gas supply interruption. This allocation will include basic allowances equivalent to the baseline energy use multiplied by the 1985 actual emissions plus a permanent bonus at the rate of $0.05 \mathrm{lb} / 10^{6} \mathrm{Btu}$.

\subsubsection{Section 407: Nitrogen Oxides Emission Reduction Program}

The $\mathrm{NO}_{\mathrm{x}}$ emission reduction goal is 2 million tons below the 1980 emission level. This goal is to be achieved by the application of low- $\mathrm{NO}_{\mathrm{x}}$ combustion controls. No tradable allowances are to be allocated, and no emissions cap will be imposed. Instead, EPA is to set performance standards that will reflect the capabilities of low- $\mathrm{NO}_{\mathrm{x}}$ burners when they are applied to specific boiler types. For tangentially fired boilers, the limit is $0.45 \mathrm{lb} / 10^{6} \mathrm{Btu}$. For dry-bottom, wallfired boilers, the limit is $0.50 \mathrm{lb} / 10^{6} \mathrm{Btu}$. If these rates cannot be achieved by burner modifications, higher limits may be set. For other technologies, EPA is to set performance standards that can be met through retrofit of the best available control technology (BACT) at costs 
comparable to those imposed by the application of low- $\mathrm{NO}_{\mathbf{x}}$ burners to tangentially fired or drybottom, wall-fired units.

If an owner can demonstrate that a unit cannot meet the performance requirements using low- $\mathrm{NO}_{\mathbf{x}}$ burner technology, an alternative limitation may be granted to permit emission at the achievable rate.

Although trading is not specifically authorized, an owner or operator of several affected units may apply for authorization to comply with the $\mathrm{NO}_{\mathrm{x}}$ emission limitation on an average basis over those units. This, essentially, allows trading among units with a common owner or operator.

\subsubsection{Section 409: Repowered Sources}

Units that are to be repowered with a clean coal technology (CCT) will be eligible for a four-year extension of the Phase II compliance date. During the extension period, these units will be granted allowances equal to their baseline multiplied by their SIP limit or 1995 actual rate. On the basis of the assumption that repowering candidates are primarily older, high-emitting units, the 1995 rate is likely to be the rate underlying the Phase II allowance allocations, $2.5 \mathrm{lb} / 10^{6} \mathrm{Btu}$. This rate will provide the repowering candidate with somewhat more than twice the basic Phase II allowances to which it would otherwise be entitled. These allowances, however, will not be transferable. Without this provision, a utility would have to make a firm commitment to a CCT by about 1995. Current and planned demonstrations may not yet have provided utilities with full confidence in these technologies by that date. Therefore, this provision, which does not require a utility commitment until the end of 1997, may result in increased application of CCTs. However, this provision does not offer a direct incentive in the form of extra marketable allowances, such as those made available by the Phase I extension program. No attempt has been made to incorporate these extension provisions into the utility analysis provided here, although repowering with CCTs is among the technology options available for generation expansion.

\subsubsection{Section 416: Contingency Guarantee; Auctions, Reserve}

Section 416 provides that a contingency reserve be established to make allowances available to independent power producers (IPPs) if such allowances are unavailable from utilities. The cost is to be $\$ 1500$ for each allowance. Section 416 also requires that an auction reserve be established to make allowances available to the highest bidder in both Phase I allowances and Phase II. The reserves for these provisions will be established from a $2.8 \%$ pro rata reduction of all Phase I allowances and on basic Phase II allowances. Proceeds from the direct sales and from the auctions will be returned to the utilities from which the allowances were tapped. Both of these provisions are intended to encourage a competitive market for allowances, and both provisions will expire if they are not used. The relevance of Section 416 to this analysis is that these provisions will encourage emissions trading. 


\section{Electric Utility Industry Background}

\subsection{Organization of the Industry}

As shown in Table 3.1, there are more than 3,200 electric utilities in the United States. They are classified according to type of ownership as being private, public/state, rural electric cooperatives, or federal. On the basis of electricity sales, the industry is dominated by private utilities, which provide more than three-quarters of the electricity sold to final consumers. Table 3.2 shows how many utilities within each ownership type account for most of the total sales within that type. The largest two-thirds of private utilities account for nearly all of the private utility sales. Thus, although the industry is characterized by a large number of utilities with different forms of ownership, a substantial portion of the industry is controlled by a relatively small number of privately owned utilities. Privately owned utilities are often referred to as investor-owned utilities (IOUs).

The electric utility industry is generally believed to be a natural monopoly. A natural monopoly is characterized by large economies of scale relative to market demand such that only one firm can efficiently serve a particular market area (since economies of scale mean that the average cost of electricity declines as the scale of the firm increases). The existence of these scale economies, which occur in the generation, transmission, and distribution of electricity, were important in the development of the concentrated market structure that characterizes the industry today. It has been suggested that some utilities have exhausted these economies of scale, especially in the generating stage, and may be operating inefficiently large generating units. The recent growth of the nonutility generation (NUG) market lends some support to that argument, although other factors are involved in this growth as well. More than $50 \%$ of new capacity additions in 1990 were nonutility plants. Fully one half of the new capacity to be installed in the current decade might be nonutility (Smith 1991). Although 50\% of this new capacity for both

TABLE 3.1 Distribution of Electric Utility Types

\begin{tabular}{|c|c|c|c|c|c|c|}
\hline \multirow[b]{2}{*}{$\begin{array}{l}\text { Ownership } \\
\text { Category }\end{array}$} & \multirow[b]{2}{*}{ No. } & \multicolumn{5}{|c|}{ Share (\% of total US. utilities) } \\
\hline & & No. & $\begin{array}{l}\text { Revenue } \\
\text { from Final } \\
\text { Sales }\end{array}$ & $\begin{array}{l}\text { No. of Sales } \\
\text { to Final } \\
\text { Customers }\end{array}$ & $\begin{array}{l}\text { Revenue } \\
\text { from Sales } \\
\text { for Resale }\end{array}$ & $\begin{array}{l}\text { No. of Sales } \\
\text { for Resale }\end{array}$ \\
\hline Private (IOU) & 276 & 9 & 79 & 77 & 40 & 38 \\
\hline Public/state & 1,196 & 62 & 13 & 15 & 18 & 19 \\
\hline Cooperative & 961 & 30 & 7 & 7 & 25 & 22 \\
\hline Federal & 8 & 0 & 1 & 2 & 17 & 20 \\
\hline Total & $\overline{3,241}$ & $\overline{100}$ & $\overline{100}$ & $\overline{100}$ & $\overline{100}$ & $\overline{100}$ \\
\hline
\end{tabular}

Source: EIA 1987. 
TABLE 3.2 Relative Importance of Dominant Firms for Each Utility Type

Share (\% of total utilities within dominant category)

\begin{tabular}{|c|c|c|c|c|c|c|}
\hline $\begin{array}{l}\text { Ownership } \\
\text { Category }\end{array}$ & $\begin{array}{l}\text { No. of } \\
\text { Utilities in } \\
\text { Dominant } \\
\text { Portion of } \\
\text { Category }\end{array}$ & $\begin{array}{l}\text { No. of } \\
\text { Utilities in } \\
\text { Dominant } \\
\text { Portion of } \\
\text { Category }\end{array}$ & $\begin{array}{l}\text { Revenue } \\
\text { from Final } \\
\text { Sales }\end{array}$ & $\begin{array}{l}\text { No. of Sales } \\
\text { to Final } \\
\text { Customers }\end{array}$ & $\begin{array}{l}\text { Revenue } \\
\text { from Sales } \\
\text { for Resale }\end{array}$ & $\begin{array}{l}\text { No. of Sales } \\
\text { for Resale }\end{array}$ \\
\hline Private (IOU) & 181 & 66 & 99 & 99 & 98 & 96 \\
\hline Public/state & 479 & 24 & 82 & 85 & 99 & 99 \\
\hline Cooperative & 905 & 94 & 95 & 94 & 95 & 95 \\
\hline Federal & 6 & 75 & 100 & 100 & 100 & 100 \\
\hline
\end{tabular}

Source: EIA 1987.

utility and nonutility generators is expected to be gas rather than coal fired, the nonutiiity generators are expected to substitute a substantial amount of waste and other biomass for coal as well. This situation would result in lower $\mathrm{SO}_{2}$ emissions than would occur if capacity expansion were to be dominated by traditional electric utilities, which would be more inclined to install large, coal-fired units. To be on the conservative side, the present analysis assumes a less aggressive NUG expansion rate, having NUG account for $30 \%$ of new capacity during the 1990 s and only about $10 \%$ of new capacity from 2000 through 2030 .

Because most of the electric utilities are privately owned and the industry is believed to be a natural monopoly, in most cases IOUs operate as franchised monopolies serving retail customers in legally defined service territories. The provisions of these franchises vary from state to state. Usually one utility is granted a monopoly franchise, but a few companies have overlapping franchises and may thus compete for customers. Because of this monopoly status, $10 \mathrm{~W}$ s are subject to economic regulation at the municipal, state, and federal level. The franchising authority is usually at the municipal or state level. All states with IOUs now have state regulatory commissions that determine their retail rates and other conditions of service. Interstate electric service is regulated by the Federal Energy Regulatory Commission (FERC). Although ratemaking procedures vary somewhat among commissions, the underlying method is fair rate of return regulation (described later in this section) The utility sector's response to CAAA90 will depend upon intervention by these and other regulatory agencies. A commission may intervene, for example, to prevent the sale of allowances, to encourage scrubbing, or to encourage demand-side emission control measures.

Regardless of the type of ownership, there is a substantial amount of interconnection and coordination among utilities. For example, utilities sell wholesale power to one another for resale or to distribution companies, which lack sufficient self-generating capacity to meet demand. Joint ownership of generating facilities is common. Much of this utility coordination is done through 
power pools, which can be thought of geographically as subregions of the North American Electric Reliability Council (NERC) regions.

NERC is the principal organization for coordinating, promoting, and communicating about the reliability of North America's electric utilities. It is a nonprofit corporation whose owners are nine Regional Reliability Councils and one affiliate. The members of the Regional Councils are individual electric utilities (type of ownership does not matter). These utilities account for virtually all of the electricity supplied in the United States, Canada, and the northern portion of Baja, California. Figure 3.1 is a map of the NERC regions.

Most interutility coordination is done at the power pool level. In the short run, utilities jointly dispatch generating units within the power pool to minimize the cost of meeting electricity demand. In the long run, utilities frequently coordinate capacity expansion plans within a power pool to minimize capacity costs. Figure 3.2 is a map of the power pools in the contiguous United States. The ARGUS model uses power pools as the fundamental unit for both dispatching and capacity expansion. Overall capacity in each pool is assumed to be adequate to meet demand in that pool. Power pools provide a natural opportunity for emissions trading, since cost savings would benefit all members. Least emissions dispatch (in which power generation is allocated preferentially to those units having the lowest emission rates) within a power pool may also have cost advantages in special circumstances. The present study does not address least emissions dispatch.

\subsection{Historical Emission Sources}

Although precipitation is naturally acidic, man-made emissions of $\mathrm{SO}_{2}, \mathrm{NO}_{\mathrm{x}}$, and other precursors are thought to increase the acidity of precipitation in eastern North America. Electric utilities are responsible for approximately $65 \%$ of anthropogenic $\mathrm{SO}_{2}$ emissions and approximately $29 \%$ of all anthropogenic $\mathrm{NO}_{\mathrm{x}}$ emissions in the United States. Coal plants account for the majority of these emissions, since they are responsible for more than $90 \%$ of utility $\mathrm{SO}_{2}$ emissions and more than $80 \%$ of utility $\mathrm{NO}_{\mathrm{x}}$ emissions. There are two reasons why coal plants are responsible for the majority of utility acidic precipitation precursors. First, coal contains a larger percentage of sulfur and nitrogen per energy unit than do other utility fuels. Second, although several different generating technologies and fuels are being used to generate electricity, more than $55 \%$ of all electricity generated is produced by coal (see Table 3.3).

Virtually all of this coal is burned in conventional steam-electric generating plants. Steamelectric plants also account for all nuclear generation and more than $70 \%$ of gas-fired and oil-fired generation. Thus, steam-electric plants account for more than $85 \%$ of U.S. electricity generation. A relatively small portion of these steam-electric plants is responsible for the majority of $\mathrm{SO}_{2}$ emissions. Although there are more than 800 fossil-fuel-fired steam-electric plants in the United States, 121 coal-fired plants are responsible for more than $75 \%$ of utility $\mathrm{SO}_{2}$ emissions. Most of these plants are owned by IOUs, and most are affected by Phase I of Title IV. 


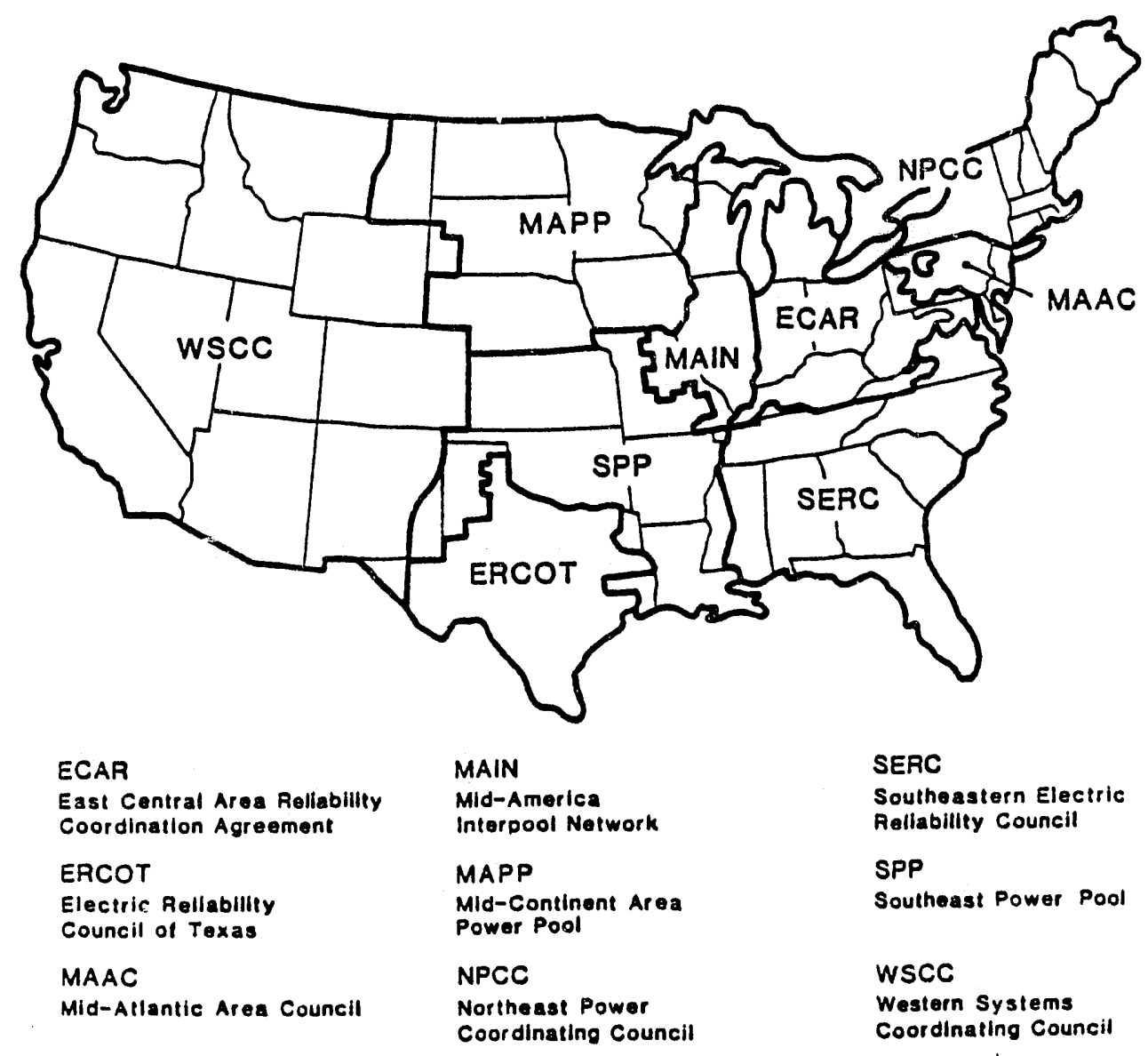

FIGURE 3.1 North American Electric Reliability Council Regions

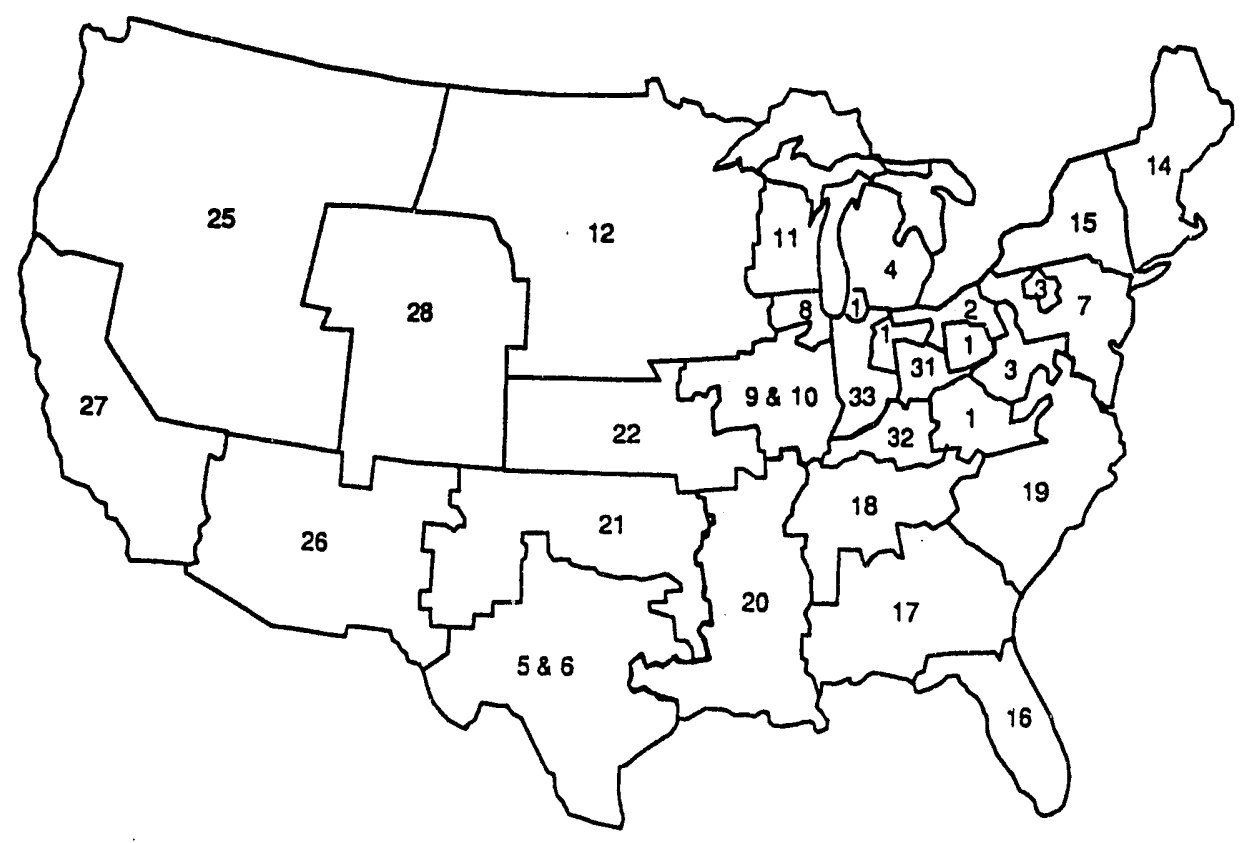

FIGURE 3.2 Approximate Geographical Boundaries of Power Pools 
TABLE 3.3 Electric Utility Fuel Use Distribution by Region

\begin{tabular}{|c|c|c|c|c|c|c|}
\hline \multirow[b]{2}{*}{ Region (States) } & \multicolumn{6}{|c|}{ Share of Generation, by Fuel or Energy Source (\% of total) } \\
\hline & Coal & Oil & Gas & Nuclear & Hydro & Other \\
\hline $\begin{array}{l}\text { New England (Maine, N.H., Vt., } \\
\text { Mass., R.I., Conn.) }\end{array}$ & 17.7 & 38.0 & 5.3 & 34.0 & 4.4 & 0.5 \\
\hline $\begin{array}{l}\text { Middle Atlantic (N.Y., N.J., } \\
\text { Penn.) }\end{array}$ & 42.7 & 16.8 & 6.8 & 26.1 & 7.6 & 0.0 \\
\hline $\begin{array}{l}\text { East North Central (Ohio, Ind., } \\
\text { III., Mich., Wis.) }\end{array}$ & 73.7 & 0.6 & 0.3 & 24.8 & 0.6 & 0.1 \\
\hline $\begin{array}{l}\text { West North Central (Minn., } \\
\text { lowa, Mo., N.D., S.D., Neb., } \\
\text { Kans.) }\end{array}$ & 75.0 & 0.4 & 1.1 & 18.8 & 4.7 & 0.1 \\
\hline $\begin{array}{l}\text { South Atlantic (Del., Md., D.C., } \\
\text { Va., W. Va., N.C., S.C., Ga., Fla.) }\end{array}$ & 61.3 & 7.5 & 3.8 & 24.5 & 2.9 & $<0.1$ \\
\hline $\begin{array}{l}\text { East South Central (Ky., Tenn., } \\
\text { Ala., Miss.). }\end{array}$ & 71.4 & 0.5 & 1.6 & 14.4 & 12.1 & 0.0 \\
\hline $\begin{array}{l}\text { West South Central (Ark., La., } \\
\text { Okla., Texas) }\end{array}$ & 49.4 & 0.7 & 39.2 & 8.6 & 1.9 & 0.1 \\
\hline $\begin{array}{l}\text { Mountain (Mont., Idaho, Wyo., } \\
\text { Colo., N.M., Ariz., Utah, Nev.) }\end{array}$ & 78.3 & 0.3 & 4.4 & 3.6 & 13.3 & 0.1 \\
\hline Pacific (Wash., Ore., Calif.) & 3.4 & 3.6 & 20.4 & 16.6 & 52.4 & 3.6 \\
\hline Alaska and Hawaii & 2.4 & 67.1 & 23.0 & 0.0 & 7.3 & 0.2 \\
\hline Total United States & 55.8 & 5.7 & 9.5 & 19.0 & 9.5 & 0.4 \\
\hline
\end{tabular}

Source: Energy Information Administration's Monthly Power Plant Report (ElA-759).

\subsection{Compliance Options}

The impact of Title IV on electricity supply will be determined by the specific compliance options chosen by affected utilities. Compliance with $\mathrm{SO}_{2}$ emission requirements means basically one thing: not exceeding each unit's available allowances. For $\mathrm{NO}_{\mathrm{x}}$, the requirements are not yet clear, except in the aggregate. The impacts are basically determined at the individual unit level, where technologies, fuel choices, and trading decisions are implemented. According to an Electric Power Research Institute study (EPRI 1990), $151 \mathrm{GW}$ of generating capacity will face new $\mathrm{SO}_{2}$ emission constraints in the form of a total tonnage cap; $60 \mathrm{GW}$ equipped with flue-gas 
desulfurization (FGD) technology will have to at least maintain its level of performance with respect to $\mathrm{SO}_{2}$ emissions, although improvements will probably be needed; $73 \mathrm{GW}$ currently committed to low-sulfur coals will face increased prices; and $12 \mathrm{GW}$ of new capacity already being implemented will not be permitted on line without offsets. The aggregate response of these individual unit decisions will determine market prices for fuels and technologies, limits to regional growth, interrelated environmental impacts, the economic health of the industry, the reliability of electricity supply, and the cost effectiveness of the acid rain protection afforded by the CAAA90.

\subsubsection{Retrofit Options}

The term retrofit generally applies to the addition of emission controls to existing units. An FGD unit can be added to remove $\mathrm{SO}_{2}$ from combustion gases. Literally hundreds of FGD processes have been proposed. Many of these fall into one of two categories - wet or dry process. In both processes, $\mathrm{SO}_{2}$ reacts with a reagent to form a sulfur compound that can be removed by further chemical treatment, precipitation, or filtration. Usually a calcium-based reagent (lime or limestone) is used, and nearly insoluble calcium sulfate is formed. In the dry processes, a minimal amount of water is used so that it will evaporate, leaving dry calcium and sulfur compounds, which can be rernoved by particulate collection devices. In the wet processes, a slurry of reagent and sulfur compounds is removed and must be dewatered before final disposal. Many other FGD options have been proposed, and some have been demonstrated; however, the cost and performance assumptions used in this analysis reflect the characteristics of these common wet and dry systems.

\subsubsection{Repowering Options}

Existing plants can also be brought into compliance if conventional furnaces are replaced with one of several new technologies that have a lower emission rate. Two options are generally discussed, fluidized-bed combustion (FBC) and gasification with combined cycle (GCC). In an FBC furnace, turbulent air flow is used to suspend solid reagents that consume $\mathrm{SO}_{2}$ as it is produced. The resulting wastes are collected by the solicis collection systems. The GCC system converts coal to gas, which is burned in a combustion turbine. Waste heat from the gasification process and the gas turbine is used to raise steam for the plant's original steam turbines. Repowering with GCC results in increased plant capacity because of the addition of the gas turbine capacity. The gasification technology is a very-low-emitting technology, since sulfur compounds are readily removed from the gas produced before combustion occurs.

\subsubsection{Fuel Switching}

Presumably, the easiest means of reducing emissions from a high-emitting unit is to switch to a lower-sulfur coal. Altiough this is a viable option for many units, it is not necessarily the option of choice for many others. The obvious issue of availability is one concern. In the northern and central Midwest, native coals have a high sulfur content. Low-sulfur coal is a premium fuel in these regions because of the transportation costs incurred in moving it. Boiler design is another 
impediment to coal switching. Slight variations in coal composition can result in dramatic differences in the tendency of furnace passages to retain ash as slag or other deposits. In addition, electrostatic precipitator performance is very sensitive to sulfur content. A precipitator designed for high-sulfur coal may not perform well with low-sulfur coal, forcing derating of the units it serves. Some utilities are dealing with these problems by boiler or precipitator modifications; others are blending coals to minimize the adverse operational impacts of fuel switching.

\subsubsection{Dispatch Options}

Economic dispatch, which minimizes total operating costs, is nearly universally used to establish the loading order of generating units (e.g., the selection of units to meet load requirements). Practical considerations, such as "must-run" units and spinning reserve requirements, force deviations from pure economic dispatch. Another alternative for setting the loading order is emissions dispatch, which seeks to minimize emissions. Emissions dispatch results in higher operating costs than economic dispatch.

\subsubsection{New Capacity Options}

The selection of low-emitting new technologies for capacity expansion will result in a declining average emission rate. The nuclear option and several low-emitting fossil fuel options are nearing large-scale commercialization. FBC, which was mentioned as a retrofit option, can capture about $90 \%$ of the $\mathrm{SO}_{2}$ formed during combustion. Sulfur removal systems for an integrated GCC plant (an IGCC plant) are capable of removing at least $95 \%$ of the sulfur before the product gas is combusted. The IGCC plant is similar to the GCC repowering option, except that a new plant can be uptimized for higher efficiency. Other near-term fossil fuel options are natural gas based. Natural gas combined cycle (NGCC) using new gas turbine technology offers few emissions and very high efficiency.

Other current options for new capacity include the use of renewable energy (combustion of wood or other biomass sources; energy generated by solar, wind, tidal, hydro, or geothermal), cogeneration, IPPs, and bidding. In bidding, a utility selects capacity bids offered by outside firms. In addition, demand-side measures, such as conservation, can reduce the need for new capacity.

\subsubsection{Emission Allowance Options}

The proposed amendments offer additional compliance options based on the allowance system. If the marginal cost of $\mathrm{SO}_{2}$ removal exceeds the cost at which an allowance can be purchased, a utility will favor purchasing additional allowances to achieve compliance. Conversely, a utility will reduce its costs if it can sell allowances for more than the cost at which it can achieve extra emission reductions. Other options made available by the proposals include allowance banking, bonus allowances for early emission reductions and the application of selected technologies, and interpollutant trading. 


\subsection{Rate Effects}

Although the CAAA90 mandate both $\mathrm{NO}_{\mathrm{x}}$ and $\mathrm{SO}_{2}$ emission reductions, the greatest portion of the cost for compliance will result from the $\mathrm{SO}_{2}$ requirements. The majority of utility $\mathrm{SO}_{2}$ emissions come from coal-fired steam-electric plants. The effect of an acid rain policy on electric rates can be examined by reviewing some of the options that a utility could implement to meet CAAA90's $\mathrm{SO}_{2}$ control standard for a coal plant that emits more $\mathrm{SO}_{2}$ emissions than the amount permitted by its CAAA90 allowances and by studying the effects of these options on the utility's rates and profits. To simplify this example, an assumption is made that the year is 2000 and that $\mathrm{SO}_{2}$ allowances equivalent to $1.2 \mathrm{lb} \mathrm{SO}_{2} / 10^{6} \mathrm{Btu}$ multiplied by the plant's baseline fuel use are available to the utility. Thus, the effect of bonus allowances or previously banked allowances is ignored.

The utility could apply one of three basic methods of compliance. First, it could buy enough additional allowances and not reduce emissions. Second, it could reduce emissions by retiring the plant and replacing its capacity with "cleaner" capacity or purchased power. Third, the utility could use a control method to reduce the plant's emissions. It could reduce emissions to an amount equal to its initial CAAA90 allowances, or it could overcontrol or undercontrol. Overcontrol means that utility would reduce the amount of the plant's controlled emissions to an amount even smaller than permitted by its initial allowances. Thus, the utility could sell or bank the unused allowances. Undercontrol means that the utility would reduce its controlled emissions, but to an amount greater than permitted by its initial allowances. The utility would thus have to purchase additional allowances. If the allowance market were efficient and the utility wanted to minimize the cost of meeting the CAAA90 standard, it could buy or sell allowances until the price of an allowance was equal to the marginal cost of reducing $\mathrm{SO}_{2}$ emissions by one ton. However, other utility objectives and the ratemaking procedure could conflict with the utility's incentive to minimize cost. For example, the utility's desire to support the local coal industry, the existence of rate practices that are favorable or unfavorable to capital investment, or the utility's need to comply with regulated or legislated restrictions on the use of allowances or on the choice of compliance options could cause conflicts.

All privately owned U.S. utilities are regulated by state commissions that determine rate schedules and total revenues. The allowed revenues or revenue requirements (RR) are determined using the concept of fair-rate-of-return regulation, which means that they are calculated as follows:

$$
R R=(s \times R B)+D E P+F U E L+P P+A M O T
$$

where:

$$
\begin{aligned}
\text { S } & =\text { allowed rate of return, } \\
\mathrm{RB} & =\text { utility's rate base, } \\
\mathrm{DEP} & =\text { utility's current-year depreciation, } \\
\text { FUEL } & =\text { utility's annual fuel cost, }
\end{aligned}
$$


$\mathrm{PP}=$ cost of purchased power, and

AMOT $=$ sum of the utility's annual operation, maintenance, tax, and other noncapital expenses.

The payment to the utility's capital stock is $s \times R B$. The allowed rate of return (s) is based on the utility's average cost of debt and equity financing. The rate base (RB) is calculated as the value of the utility's capital stock minus accumulated depreciation. For ratemaking purposes, depreciation is calculated by using the straight-line method. PP is negative if the utility is selling more electricity to other utilities than it is purchasing from them. Note that under rate-of-return regulation, the utility's allowed profits are determined by its rate base. Other expenses are generally collected dollar for dollar from the ratepayers. Regulatory commissions can disallow expenditures found to be imprudent.

The effects of four general methods of meeting the CAAA90 standards on this revenue requirements function are described below. The four methods are: (1) purchasing allowances without adding emission controls, (2) retiring the plant early, (3) switching fuels, and (4) installing a scrubber.

\subsubsection{Purchase of Allowances}

If a plant's emissions could not be reduced, the utility might purchase sufficient additional allowances to cover its emissions. The payments for these allowances would increase AMOT by an amount equal to these payments and - if found prudent by the regulatory commission would increase revenue requirements by the amount of these payments. This strategy would be likely to be employed by a utility with high control costs or an older plant that is near retirement.

\subsubsection{Early Retirement}

If the utility were to prematurely retire a plant, the utility's RB would be reduced by the plant's remaining undepreciated value. DEP would decline by the value of the plant's annual depreciation expense. For an older plant, this value would probably be small, because construction costs per kilowatt have increased dramatically during the past 20 years. In addition, base-load plants are usually straight-line depreciated for 35 years for ratemaking purposes. Thus, a 30 -year-old plant would have approximately $14 \%$ of its original cost in the rate base. If the utility were to purchase power to offset the retired plant's generation, PP would increase by the value of the purchased power. FUEL would decrease by the value of the retired plant's fuel use. AMOT would decrease because maintenance expenses at the plant (adjusted for any retirement costs) would have been eliminated and because the utility would be able to sell its unused allowances. This strategy could result in lower revenue requirements and customer rates if three conditions were to be met. First, the retired plant would have to have been costly to operate (because of its high fuel and maintenance costs) and clean. Second, purchasing power would have to be relatively inexpensive. Third, the market price of allowances would have to be high. Note that approximately one-third of the highest emitting plants are more than 30 years old. 
The utility could also construct a new plant rather than purchasing power. In this case, the utility's RB would increase by the value of the new plant minus the remaining value of the old plant. For reasons mentioned above, the RB would be likely to increase substantially in this case. FUEL expenses would also be likely to increase, even if the new plant were more thermodynamically efficient than the retired plant, because the new plant would be dispatched more intensively. PP would be likely to decline because the utility would become a smaller net purchaser of electricity. AMOT would decline if the new plant were to have lower maintenance costs than the old plant. The effect on allowance purchases or sales would depend on the emissions of the new plant relative to the emission allowances given to the old plant. The net effect of all of these changes would probably be an increase in revenue requirements and consumer rates, primarily because of the large increase in the utility's rate base. The utility's allowed profits would increase because of the increase in the rate base. The effect on actual profits would be less certain. For example, if the price elasticity of demand for electricity were high, the utility's actual revenues might decline as its rates increased.

\subsubsection{Fuel Switching}

If the utility were to control the plant's emissions by switching fuels (e.g., to a low-sulfur coal), RB would probably increase slightly because of the capital expenditures needed to handle the new fuel. This method would also mean a small increase in DEP. FUEL would be likely to increase significantly because the cost of low-sulfur fuels is higher. To some extent, this effect might be reduced by a lower generation rate, since the higher cost of the fuel would mean that the plant is dispatched less often. This reduced generation rate would increase PP. Also, use of lowsulfur fuel could result in plant derating and a corresponding increase in the need to purchase power. The effect on AMOT would greatly depend on the plant's emissions as a result of using the new fuel. If emissions were to be less than the amount permitted by allowances, the excess allowances could be sold, reducing AMOT. If emissions were to exceed the amount permitted by the plant's allowances, additional allowances would have to be purchased, increasing AMOT. The effect of fuel switching on maintenance expenses would also be uncertain. This strategy would probably be chosen by utilities with access to relatively cheap, low-sulfur coal. Most of the increase in revenue requirements and rates under this strategy would be a result of higher fuel expenditures. Because the effects on the rate base would be small, the increase in allowed profits would be small.

\subsubsection{Scrubber Retroflt}

If the utility were to control the plant's emissions by installing a scrubber, RB would increase because of the capital expenditures for the scrubber. This method would also result in an increase in DEP. FUEL would probably increase slightly because of the energy requirements of the scrubber. The reduced generation rate due to the scrubber would modestly increase PP. The effect on AMOT would partly depend on the plant's emissions as a result of using the new controls. If emissions were to be less than the amount permitted by allowances, the excess allowances could be sold, reducing AMOT. If emissions were to exceed the amount permitted by the plant's allowances, additional allowances would have to be purchased, increasing AMOT. The 
scrubber would also increase maintenance and other annual expenses because of the costs incurred for purchasing scrubber chemicals and the increased costs for solids disposal. This strategy would probably be chosen by utilities that do not have access to relatively cheap, low-sulfur coal. This compliance method could also be imposed on a utility to protect the high-sulfur-coal mining industry. Most of the increase in revenue requirements and rates under this strategy would result from the somewhat larger rate base and the annual cost of operating the scrubber. The effects on the rate base would increase the utility's allowed profits somewhat. 


\section{Simulation of the Utility Sector*}

\subsection{Methodology}

The provisions of Title IV are represented as input to ARGUS. The ARGUS model is a deterministic simulation model; it relies on engineering and accounting relationships between parameters that are assigned specific values. A stochastic simulation model, on the other hand, characterizes key parameters and results with a probability distribution. This distinction indicates that uncertainty must be dealt with outside the ARGUS model, through the use of alternative scenarios or other sensitivity evaluations. The present analysis relies on many assumptions about current and future values for important parameters such as fuel costs, discount rates, power plant efficiency, energy demand, and emission rates. These assumptions generally reflect characterizations that were used in the National Energy Strategy (NES) reference scenario (EIA 1990d), although many additional assumptions are inherent in the ARGUS model structure.

The ARGUS model integrates a simulation of electric power production, including fuel purchasing and dispatching decisions, with a capacity expansion planning model, which provides forecasting capability. Its module ICARUS (Investigation of Costs and Reliability in Utility Systems) evaluates system reliability and dispatch priority, matching available generation to demand. ICARUS also estimates unit generating costs and capacity factors. Available and future capacity is characterized in ARGUS's Build Cost Module (BCM), which estimates generating unit costs and performance for alternative coals and technologies and evaluates the need for capacity expansion. The Emissions and Control Module (ECM) estimates the emissions and emission control costs associated with use of pollution control equipment on dispatched units. Finally, the Coal Supply and Transportation Module (CSTM) estimates the effects of a utility's purchasing decisions on the coal market, thereby providing costs for the BCM's evaluation of generation options.

The simulation process, which is summarized in Figure 4.1 , begins with a summary of existing utility generating units, called a unit inventory. The unit inventory includes data on the power plant and unit name, capacity, heat rate (efficiency), types of pollution control equipment, and other key factors. The unit inventory is modified by the BCM as units are modified or added in response to demand and changes in environmental regulations. ARGUS selects new units from a slate of technologies that are characterized as part of the specifications for a particular simulation. (The characteristics of new units are summarized in Section 4.2.) As an alternative to letting ARGUS select new capacity, the user can specify the market penetration of new technologies as a percent of new capacity that comes on line during specified periods. This approach has been taken in this analysis, since the NES reference scenario includes the fraction of capacity of each generation type as projected by the FOSSIL 2 model. ${ }^{\dagger}$ In addition to conventional and advanced

\footnotetext{
"Portions of this section of the text were contributed by the authors to EIA (1990c).

${ }^{\dagger}$ Although cost projections for advanced technologies are very uncertain, the BCM capacity decision does not recognize that uncertainty. BCM makes a "knife-edge" decision on the basis of slight cost differentials. When a fixed share is assigned for new capacity, the judgment inherent in this process becomes explicit rather than being "buried" in cost assumptions. Consistency with the NES assumptions is desirable for comparison with other studies.
} 


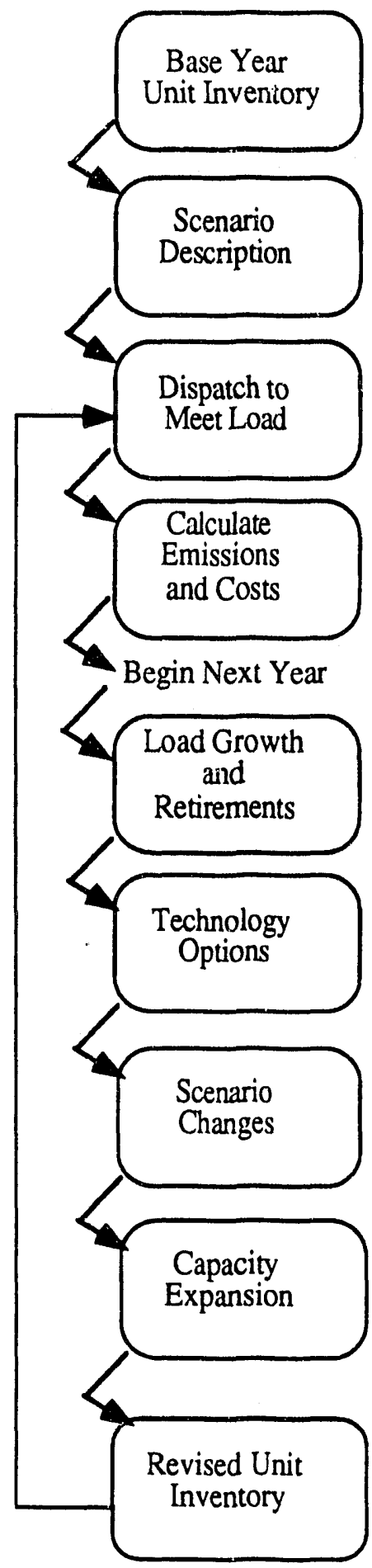

ARGUS begins with a base-year inventory of generating units. The database includes location, operating characteristics, fuel, pollution controls, emission regulations, and costs. It is updated annually with the clurrent database including 1987 data.

Special conditions can be applied, including fuel costs, special emission constraints, and emission taxes. In addition, this scenario characterizes initial demand.

The dispatch module determines a least-cost mix of units with which to meet demand. It allocates both base and peak loads. The dispatch module is also used for capacity expansion planning.

Unit characteristics, including efficiencies and emission factors, can now be used to calculate emission rates. Costs reflect capital, operating, and fuel costs.

ARGUS is annually recursive.

A new demand is established based on exogenously defined load growth. This demand, combined with plant retirements, provides a starting point for capacity expansion decisions.

The slate of technologies available for capacity expansion can be varied to reflect the development of new technology. Constraints on the use of life extension and repowering can also be set here.

Changes in fuel costs, emission constraints, taxes, etc., will not only affect the next year's dispatching but also the capacity expansion decisions made now for future years.

Information from the above three frames is now combined with an optimal capacity expansion calculation.

The capacity expansion, retirements, and plant modifications result in a new unit inventory, which can be dispatched to meet the new year's load.

FIGURE 4.1 General Logic of an ARGUS Simulation 
coal plant options, options for new capacity also include nuclear, renewable, and repowered fossil fuel options. The market penetration of these options is a user-specified parameter for all ARGUS model analyses.

Electricity demand is met at the power pool level by economic dispatch of the available capacity within that pool. ARGUS uses an equivalent load duration curve approach and assigns units to base, intermediate, or peaking duty. In some cases, unit capacity is split between base and intermediate duty to match spinning reserves and other operational considerations. This "blocking," as it is called, has also been used by ARGUS to match historical capacity factors for some units. The loading order is a strong function of fuel prices at particular units. Fuel prices depend, in turn, on demand for a particular fuel. ARGUS incorporates an iterative approach to ensure that assumed fuel prices are not significantly changed by dispatch decisions. In this way, it establishes an equilibrium between the coal supply system and demand by the utilities. CSTM incorporates detailed data on coal characteristics and prices for 32 supply regions. For each supply region, up to six sulfur categories and five heating value categories may be available. Each coal type can be specified as being available from deep or surface mines. These coal options are made available through an elaborate network of transport modes, representing existing linkages between the 32 supply regions and 48 demand regions - basically, one per state and four for export. A few states are combined.

With the capacity in place and coal selection and dispatching accomplished, the ECM calculates corresponding emissions, energy use by emission control systems, and costs of emission control. This is essentially a mass and energy balance task, which traces a potential pollutant from the fuel through combustion and control processes. Emission control parameters are set to meet NSPS or other applicable emission standards at the unit level. The ECM is also used with the BCM to establish the cost of pollution control alternatives. In a "bubble policy" (method of regulating emissions from a group of sources, in which limits apply to the combination of all sources rather than individual sources) or emissions trading situation, the marginal cost of control is determined for each control option. The control options are then implemented in a leastcost order until emission reduction goals are achieved.

Although ARGUS includes the engineering economics needed to estimate annualized capital and operating costs, a separate model, the National Utility Financial Statement (NUFS), has been employed to calculate rate effects on the basis of the revenue requirements approach (ICF

Resources, Inc., 1988). NUFS is not a part of the ARGUS model set; rather, it uses ARGUS results as input.

\subsection{Simulation Assumptions}

The ARGUS model has been used to project the behavior of the electric utility industry in terms of capacity expansion and unit-level operations under a set of energy and economic 
assumptions that are consistent with analyses performed for the NES. Values for the following parameters are included in the assumptions:

1. Utility sector fuel prices;

2. Future electricity demand and capacity;

3. Fossil fuel and nuclear technology costs and characteristics;

4. Renewable energy technology costs and characteristics;

5. Extent to which retirement, life-extension, and repowering options are employed; and

6. Extent to which nonutility generating sources are employed.

\subsubsection{Utllity Sector Fuel Prices}

Coal prices are calculated within ARGUS by CSTM. Demand curves in CSTM result in higher coal prices with increasing demand. This methodology would result in an increasing price premium on low-sulfur coal if coal switching were a preferred compliance strategy. Transportation bottlenecks are represented by higher shipping costs along heavily used transportation routes.

Oil and gas prices are based on national-level price projections from the FOSSIL 2 analysis of the NES reference case. FOSSIL 2 uses wellhead gas prices that reflect an equilibrium of supply and demand. For oil, FOSSIL2 adjusts base-case world oil price estimates to reflect demand. Thus, in a given period, FOSSIL 2 reflects the effect of the previous period's demand on oil and gas prices. The national-level prices thus determined by FOSSIL2 are the basis of the oil and gas prices applied by ARGUS. First, the national-level prices are disaggregated into federal region prices in proportion to historical regional price differentials as reported by DOE (EIA 1990a). In this way, ARGUS can use current price projections from FOSSIL2 while retaining the price diversity found in the DOE data. The regional-level price projections are further disaggregated into power pool price projections by mapping the 26 ARGUS power pools into the 10 federal regions. Finally, these power pool price projections are converted into a base-year price and a series of escalation rates over the study period. ARGUS was designed to use price data in this format. Since the study period goes beyond the period for which regional price data from DOE are available, regional escalation rates are assumed to converge to the national average late in the study period. Figure 4.2 summarizes this data conversion process, and Table 4.1 lists the baseline national price assumptions from FOSSIL2.

\subsubsection{Future Electricity Demand and Capacity}

National-level electricity demand growth rates are also based on the FOSSIL2 analysis of the NES reference case. This demand is disaggregated into projections of regional annual net 


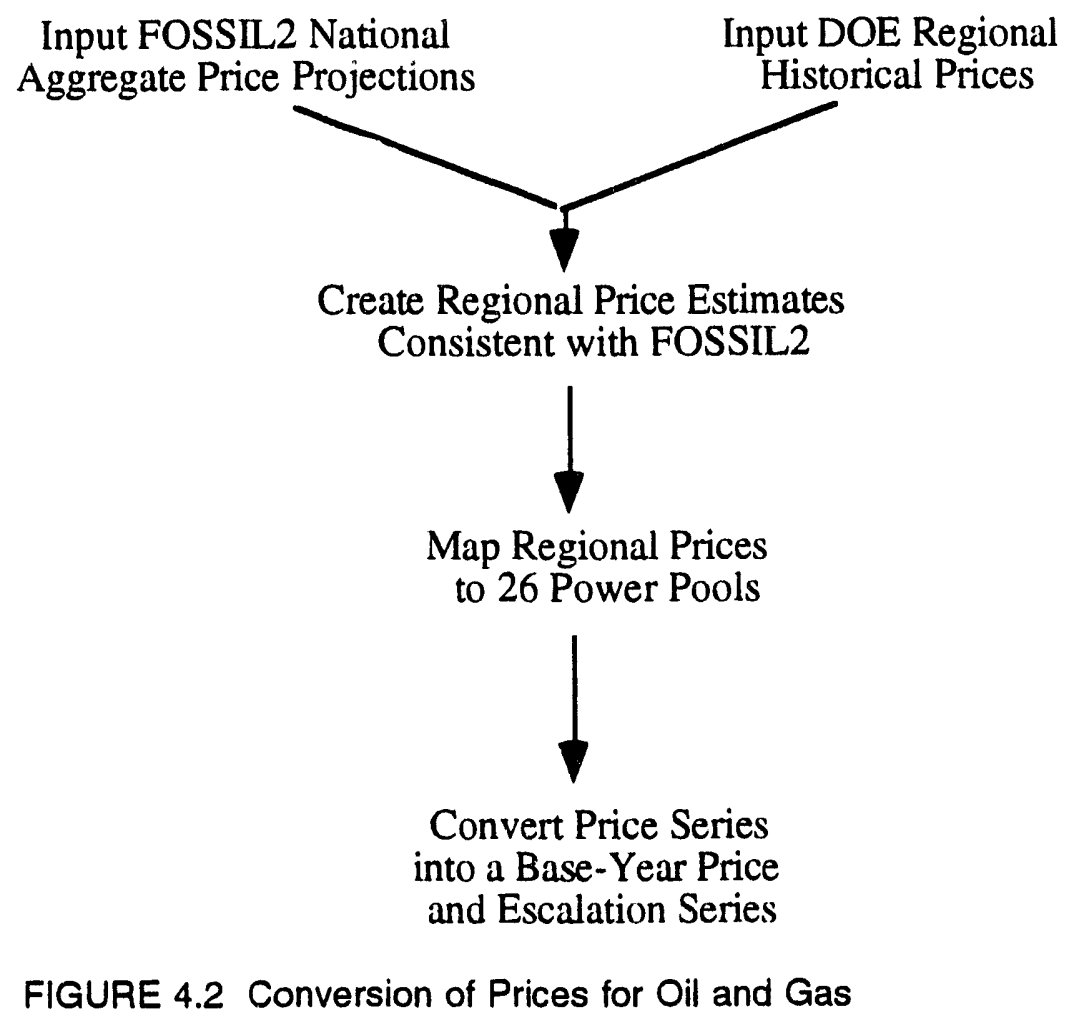

energy loads on the basis of the NERC forecast of electricity demand from 1989 through 1998. For the current analysis, NERC forecasts of load growth for 21 regions were scaled to match NES nationallevel forecasts. Since regional forecasts become increasingly uncertain with time, projections beyond the end of the NERC projection period (1998) were further adjusted such that regional growth rate differences gradually decline with time. It is assumed that regional growth rates will converge to the national average by 2015 . Projections of regional loads are provided in Table 4.2. Loads for ECAR (East Central Area Reliability Coordination Agreement, see Figure 3.1) are subdivided into loads for seven power pools $(1,2,3,4,31,32$, and 33). Maps showing the location of NERC regions and power pools were provided in Section 3 of this report, in Figures 3.1 and 3.2 , respectively.
TABLE 4.1 Noncoal Fossil Fuel Prices

\begin{tabular}{ccc}
\hline & \multicolumn{2}{c}{ Price $\left(1989 \$ / 10^{6} \mathrm{Btu}\right)$} \\
\cline { 2 - 3 } Year & Liquid Fuels & Natural Gas \\
& & \\
\hline & & \\
1990 & 2.96 & 2.52 \\
1995 & 3.58 & 3.11 \\
2000 & 4.92 & 4.46 \\
& & \\
2005 & 5.88 & 5.16 \\
2010 & 6.60 & 6.02 \\
2015 & 7.14 & 7.15 \\
& & \\
2020 & 7.56 & 7.47 \\
2025 & 7.96 & 8.00 \\
2030 & 8.23 & 8.51 \\
& & \\
\hline
\end{tabular}


TABLE 4.2 Bus Bar Electricity Demand and Demand Growth Rates

\begin{tabular}{|c|c|c|c|c|c|c|c|}
\hline \multirow[b]{2}{*}{$\begin{array}{l}\text { Power } \\
\text { Poola }\end{array}$} & \multirow{2}{*}{$\begin{array}{l}1990 \text { Peak } \\
\text { Demand } \\
\text { (MW) }\end{array}$} & \multicolumn{6}{|c|}{$\begin{array}{c}\text { Average Growth Rate in Peak and Energy Demand, } \\
\text { by Time Period }(\%)\end{array}$} \\
\hline & & $\begin{array}{l}1990 \\
1995\end{array}$ & $\begin{array}{l}1996- \\
2000\end{array}$ & $\begin{array}{l}2001 \\
2005\end{array}$ & $\begin{array}{l}2006- \\
2010\end{array}$ & $\begin{array}{c}2011 \text {. } \\
2020\end{array}$ & $\begin{array}{l}2021 \\
2030\end{array}$ \\
\hline 1 & 19,126 & 2.19 & 1.76 & 1.65 & 1.93 & 1.84 & 1.44 \\
\hline 2 & 12,364 & 1.49 & 2.50 & 1.84 & 2.02 & 1.84 & 1.44 \\
\hline 3 & 6,125 & 1.82 & 2.00 & 1.73 & 1.97 & 1.84 & 1.44 \\
\hline 4 & 15,348 & 1.69 & 2.55 & 1.84 & 2.02 & 1.84 & 1.44 \\
\hline 5 & 41,169 & 2.81 & 3.81 & 2.39 & 2.31 & 1.84 & 1.44 \\
\hline 7 & 41,565 & 2.29 & 2.06 & 1.91 & 2.06 & 1.84 & 1.44 \\
\hline 8 & 16,150 & 1.83 & 2.86 & 2.07 & 2.14 & 1.84 & 1.44 \\
\hline 9 & 13,717 & 1.82 & 2.57 & 1.89 & 2.05 & 1.84 & 1.44 \\
\hline 11 & 8,237 & 1.80 & 1.95 & 1.76 & 1.98 & 1.84 & 1.44 \\
\hline 12 & 23,519 & 2.04 & 2.90 & 2.08 & 2.15 & 1.84 & 1.44 \\
\hline 14 & 20,000 & 2.83 & 2.84 & 2.14 & 2.18 & 1.84 & 1.44 \\
\hline 15 & 26,070 & 2.45 & 2.31 & 1.95 & 2.08 & 1.84 & 1.44 \\
\hline 16 & 28,975 & 4.20 & 3.90 & 2.74 & 2.48 & 1.84 & 1.44 \\
\hline 17 & 28,712 & 3.38 & 3.68 & 2.48 & 2.35 & 1.84 & 1.44 \\
\hline 18 & 21,362 & 2.91 & 3.34 & 2.28 & 2.25 & 1.84 & 1.44 \\
\hline 19 & 39,105 & 3.31 & 3.27 & 2.37 & 2.29 & 1.84 & 1.44 \\
\hline 20 & 20,802 & 1.93 & 2.54 & 1.85 & 2.03 & 1.84 & 1.44 \\
\hline 21 & 16,136 & 2.61 & 3.46 & 2.33 & 2.27 & 1.84 & 1.44 \\
\hline 22 & 12,073 & 3.13 & 3.44 & 2.41 & 2.32 & 1.84 & 1.44 \\
\hline 25 & 35,017 & 1.73 & 1.80 & 1.58 & 1.89 & 1.84 & 1.44 \\
\hline 26 & 11,764 & 4.05 & 4.05 & 2.76 & 2.50 & 1.84 & 1.44 \\
\hline 27 & 44,238 & 2.41 & 2.89 & 1.93 & 2.07 & 1.84 & 1.44 \\
\hline 28 & 6,266 & 3.13 & 3.24 & 2.32 & 2.27 & 1.84 & 1.44 \\
\hline 31 & 6,190 & 1.10 & 2.07 & 1.67 & 1.94 & 1.84 & 1.44 \\
\hline 32 & 6,945 & 1.99 & 2.22 & 1.83 & 2.02 & 1.84 & 1.44 \\
\hline 33 & 10,814 & 2.68 & 2.68 & 2.16 & 2.18 & 1.84 & 1.44 \\
\hline \multicolumn{8}{|c|}{$\cdots \cdots \cdots$} \\
\hline Model & & \multicolumn{6}{|c|}{ National Total Energy Demand, by Time Period (GWh/yr) } \\
\hline FOSSIL2 & & 3,298 & 3,801 & 4,218 & 4,696 & 5,637 & 6,503 \\
\hline ARGUS & & 3,199 & 3,744 & 4,180 & 4,673 & 5,655 & 6,560 \\
\hline
\end{tabular}

asee Figure 3.2 for power pool locations. 
The loads presented in Table 4.2 include transmission losses and represent the electrical energy generated by the utilities' own generating sources plus the electrical energy purchased from other utility and nonutility generators, minus electrical energy sales to other utilities. Loads do not include electrical requirements for energy storage. Electricity demand load shapes were obtained from ECAR regional reports. Load shapes are assumed to remain constant with time. Peak loads grow at the same rate as overall energy demand.

\subsubsection{Fossil Fuel and Nuclear Technology Costs and Characteristics}

Operating characteristics and costs for greenfield units were supplied by DOE (Dye 1991). However, data for certain operating characteristics such as net dependable capacity, forced outage rates, and maintenance requirements were not provided by DOE; values for these parameters reflect data from the EPRI Technical Assessment Guide (TAG) and other industry sources (EPRI 1986; 1989). Table 4.3 shows assumed new capacity costs and characteristics. New units that have been announced by the utility industry are included in the unit inventory after their expected on-line date. ARGUS builds additional new units with characteristics as shown in Table 4.3.

New units are built to expand capacity as necessary as a result of repowering and capacity losses due to unit retirements. On-line dates and operating characteristics of announced nonnuclear units were obtained from 1989 NERC reports." ARGUS can expand capacity on a least-cost basis by choosing the lowest-cost option for nueded capacity or on a percent penetration basis by adding capacity as needed but basing the technology choice on a user-specified market share for each technology. The latter approach was taken for this analysis to ensure consistency with FOSSIL2 results for the NES. Specific market penetration rates can be defined for different time periods. The rates assumed here are listed in Table 4.4.

\subsubsection{Renewable Energy Technology Costs and Characteristics}

ARGUS was designed to simulate dispatchable power plants. At this time, it does not have the capability to project the market penetration of renewable energy generation technologies. Penetration rates and electricity generation from these sources must therefore be exogenously specified. Table 4.5 shows the capacity of renewable energy technologies and their electricity generation levels as projected in the FOSSIL2 analysis for the NES reference case. These figures include hydroelectric capacity.

\subsubsection{Extent to Which Retirement, Life Extension, and Repowering Occur}

Announced retirements of existing electricity generating units over the next 10 years were obtained from NERC reports.* During this period, ARGUS $r_{*}$ :ses only announced units. After

\footnotetext{
"This series of reports describes Coordinated Bulk Power Supply Programs as required by DOE Form IE-411.
} 


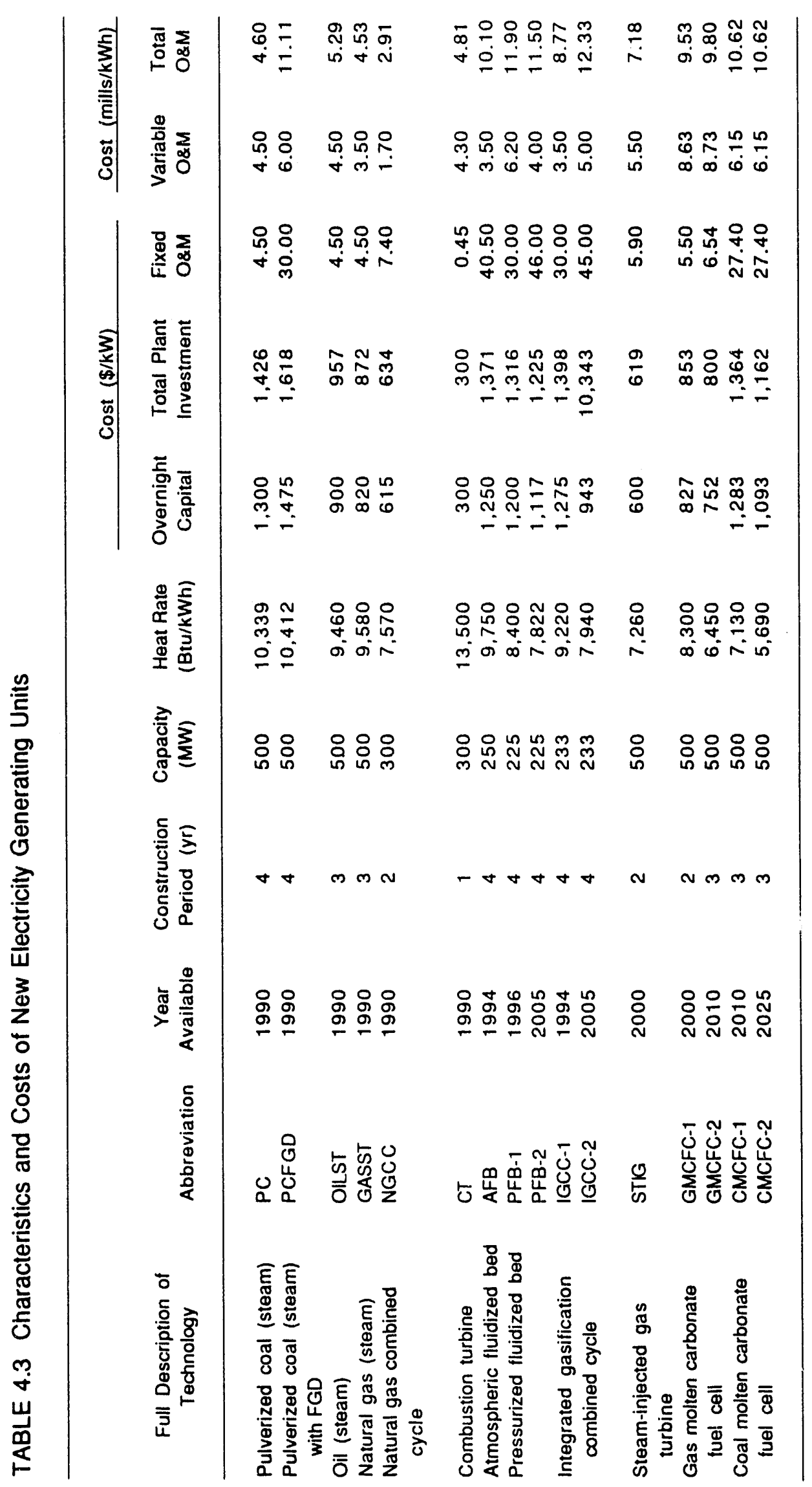




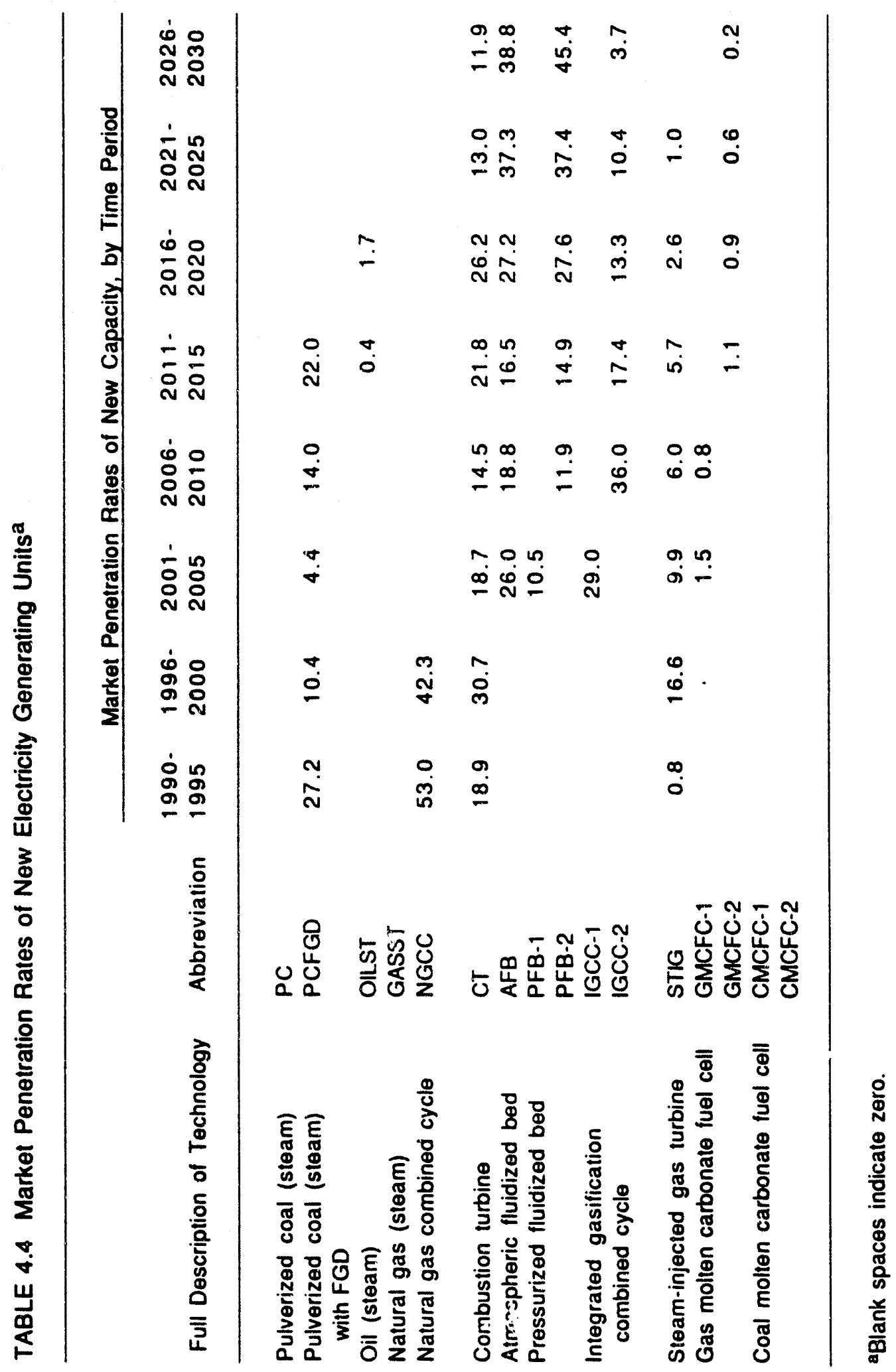


TABLE 4.5 Contribution of Renewable Energy Technologies

\begin{tabular}{clllll}
\hline & \multicolumn{5}{c}{$\begin{array}{c}\text { Capacity of and Electricity Generation by } \\
\text { Renewable Energy Technologies, by Year }\end{array}$} \\
\cline { 2 - 6 } & 1995 & 2000 & 2010 & 2020 & 2030 \\
\hline Parameter & 116.2 & 120.0 & 141.1 & 172.9 & $\begin{array}{l}220.0 \\
805\end{array}$ \\
\hline $\begin{array}{l}\text { Capacity (GW) } \\
\text { Generation (109 kWh/yr) }\end{array}$ & 377 & 399 & 497 & 643 & 805 \\
\hline
\end{tabular}

the end of the NERC projection period (1998), ARGUS takes units off line permanently when they reach their retirement ages (Table 4.6).

Units that are older than the specified retirement age at the end of the NERC projection period are retired on January 1, 1999. To remain on line for more than 40 to 45 years, a unit must be refurbished. It is assumed that units older than 45 years will incur the life-extension costs indicated in Table 4.7. Refurbishment is assumed to take place over a five-year period during scheduled maintenance outages, after the unit reaches 25 years of age.

\subsubsection{Extent to Which Nonutllity Generating Sources Are Used}

Generation contributions into the grid from nonutility sources will satisfy a portion of the loads shown in Table 4.2. ARGUS uses NERC regional projections of nonutility capacity and generation through 1998. FOSSIL2 projections, shown in Table 4.8, are used from $199^{\circ} 9$ through 2030. The data on capacities shown in Table 4.8 are included in reserve margin calculations. This capacity will not generate all the nonutility electric energy. Other nonutility sources that cannot be depended on to provide electricity during times of peak demand will supply a portion of the generation.

\subsection{Representation of Title IV}

The key features of the Title IV $\mathrm{SO}_{2}$ reduction program are the tradable allowances and the cap on the number of those allowances to be allocated in each year. Also important are two other provisions, banking and the Phase I extension program. The representation of trading in ARGUS is straightforward. It relies on the construction of a marginal cost curve for $\mathrm{SO}_{2}$ emission reductions that is based on a cost analysis of emission reduction alternatives for all plants in a trading group. The model adds emission-reducing technologies in order of increasing cost until the total desired emission reduction is achieved. The emissions cap can be maintained by a combination of two methods, emission reduction using the trading algorithm and the addition of an 
TABLE 4.6 Retirement Ages of Existing Generating Units

\begin{tabular}{|c|c|c|c|c|}
\hline \multirow[b]{3}{*}{ Type of Unit } & \multicolumn{4}{|c|}{$\begin{array}{c}\text { Retirement Ages of Units, by Power Pool and } \\
\text { Unit Capacity (yr) }\end{array}$} \\
\hline & \multicolumn{2}{|c|}{$\begin{array}{l}\text { Pools } 5,9,14,15,16 \\
20,21,26 \text {, and } 27 \\
\end{array}$} & \multicolumn{2}{|c|}{ All Other Pools } \\
\hline & $<100 \mathrm{MW}$ & $\geq 100 \mathrm{MW}$ & $<100 \mathrm{MW}$ & $\geq 100 \mathrm{MW}$ \\
\hline Coal fired & 45 & 60 & 45 & 60 \\
\hline Oil fired & 45 & 60 & 45 & 45 \\
\hline Gas fired & 45 & 60 & 45 & 45 \\
\hline Nuclear & 40 & 40 & 40 & 40 \\
\hline Other & 99 & 99 & 99 & 99 \\
\hline
\end{tabular}

emission penalty, which results in technology choices and dispatching that keeps emissions below the level of the cap. Banking and the Phase I extension program can be viewed as affecting the actual level of the cap in specific years. In other words, banking reduces the effective level in one year and increases it in a subsequent year when the banked emission allowances are used. The Phase I extension program acts in a similar way, changing the effective cap in 1995 and 1996 and leading to banking in 1997 through 1999. If the effective cap corresponding to these important provisions can be ascertained, these provisions can be represented in ARGUS.

\subsubsection{Emission Allowance Trading}

ARGUS creates the marginal cost curve for emission reductions by evaluating compliance options for all plants in a trading group. These include low-sulfur-coal retrofits and scrubber retrofits (wet and dry), with and without a consideration of coal switching options. As the number of plants in a trading group increases, the number of options to be evaluated increases - a situation that has made the direct representation of nationallevel trading impractical. As an alternative, ARGUS simulates state-level trading, and national-level trading can be represented by the user, who allocates the total national emission reduction burden among the states. Emissions trading can be optimized (although it takes a considerable amount of execution time and labor) by adjusting the reductions

TABLE 4.7 Life-Extension Costs for Generating Units More Than 45 Years Old

\begin{tabular}{lc}
\hline Type of Unit & $\begin{array}{c}\text { Capital Cost for } \\
\text { Refurbishment } \\
(1987 \$ / \mathrm{kW})\end{array}$ \\
\hline Coal fired & 300 \\
Oil fired & 125 \\
Gas fired & 125 \\
\hline
\end{tabular}


TABLE 4.8 Contribution of Nonutility Generating Sources

\begin{tabular}{|c|c|c|c|c|c|c|}
\hline \multirow[b]{2}{*}{ Parameter } & \multicolumn{6}{|c|}{$\begin{array}{c}\text { Capacity of and Electricity Generation by } \\
\text { Nonutility Sources, by Year }\end{array}$} \\
\hline & 1989 & 1995 & 2000 & 2010 & 2020 & 2030 \\
\hline Capacity (GW) & 12 & 23 & 34 & 55 & 77 & 77 \\
\hline Generation ( $10^{6} \mathrm{GWh} / \mathrm{yr}$ ) & 74 & 143 & 206 & 335 & 475 & 475 \\
\hline
\end{tabular}

achieved in each state according to the marginal cost. When the marginal cost of reduction is equal in all states, the optimal trading pattern has been established. ARGUS determines this marginal cost by performing two program executions with slightly different emission reduction requirements. The cost difference (per ton of $\mathrm{SO}_{2}$ removed) between these is taken to be the marginal cost of reduction. Emission reduction requirements can then be moved from states with a high marginal cost states to those with a low marginal cost.

One of the major uncertainties in the implementation of Title IV is the extent to which the emissions trading market will be open and thus result in an economically optimal distribution of reduction requirements. Incentives to hoard allowances include the prospect of profitable future sales and the possible need to hold allowances to accommodate future growth. Protection of local coal markets might also be seen as an incentive for hoarding, since such protection could result in more emissions than would coal switching options. On the other hand, using a scrubber to make the use of local coal feasible could actually create an opportunity to free allowances as a result of overcompliance. Completely open trading is generally regarded as unlikely. Some analysts have expressed doubt about the likelihood of any serious trading market developing. For the present analysis, a middle course is pursued. It is assumed that trading will occur primarily within utility systems; interutility trading is not permitted in most cases.

An analysis of acid rain legislation conducted for EPRI (Energy Ventures Analysis 1987) evaluates the likely responses of utilities to legislation requiring emission reductions of either 5,8 , or 10 million tons from 1980 levels. For each level, the report identifies the percentage distribution of the total reduction obligation among the 31 eastern states. This distribution is established on the basis of the assumption that trading will be done only within utility systems, some of which serve multistate regions. This assumption could be expected to lead to a conservative cost estimate, because more extensive trading should lead to lower costs. The percent reduction obligations from the EPRI 1987 study are used to distribute the reduction obligations for this analysis. These reduction shares for each state are determined on the basis of an examination of compliance options for more than 200 major power plants. The analysis for Phase I applies the EPRI results for a 5 -million-ton reduction $\left(2.5 \mathrm{lb} / 10^{6} \mathrm{Btu}\right.$ limit), and the analysis for Phase II applies the EPRI results for a 10 -million-ton reduction $\left(1.2 \mathrm{lb} / 10^{6} \mathrm{Btu}\right.$ limit). 
Table 4.9 lists four estimates of the percentage of total reduction obligations among the various states for Phase I and Phase II. The ICF analyses were performed for EPA before the CAAA90 were passed (ICF Resources, Inc. 1990). ICF analyzed a high- and a low-demandgrowth scenario for both the House and Senate versions of the bill. The results listed in Table 4.9 are for the Senate version. The distributions of reduction obligations for the two ICF cases are similar to those predicted in the EPRI analysis. The last column for each phase lists the distribution predicted by an ARGUS analysis of full trading, which was done for the NES (EIA 1990b). Again, full trading is based on equalized marginal costs among states. That full trading analysis does not include a consideration of emissions allowance banking or the Phase I extension program. For Phase II, the ARGUS full trading analysis suggests that the reduction to be achieved in Ohio and Indiana would be much larger than that indicated by the results of the other studies. Use of the EPRI distribution, which includes only the 31 eastern states, transfers by default any western state reduction obligations to the eastern states. As can be seen from Table 4.9, this is a small effect.

\subsubsection{Einission Allowance Banking and the Phase I Extension Program}

Allowance trading permits spatial shifts in emissions to occur. As long as trading does not result in a violation of other emission regulations, such as performance requirements, these shifts occur without regard to the location of participating plants. Allowance banking permits temporal shifts in emissions to occur. These temporal shifts are constrained in the sense that emissions can only be transferred to subsequent years. (Emission allowances are distributed annually and can be used only in the year in which they are allocated or in a subsequent year.) Because of this constraint, the most likely source of banked allowances is overcompliance by Phase I affected units (Table A units). By overcomplying, which is equivalent to not using all of their available allowances, units can bank allowances for future sale or use. It may be very advantageous for utilities to overcomply with the modest Phase I constraints (essentially $2.5 \mathrm{lb} / 10^{6} \mathrm{Btu}$ ) to gain allowances to ease the transition to tighter Phase II constraints (essentially $1.2 \mathrm{lb} / 10^{6} \mathrm{Btu}$ ). The appeal of this option is enhanced by the Phase I extension program that offers two incentives for scrubber retrofits. The program provides (1) a two-year extension to the compliance date for Phase I and (2) additional allowances for emission reductions achieved at an emission rate below $1.2 \mathrm{lb} / 10^{6} \mathrm{Btu}$. (See the previous discussion of Title IV, Section 404, in Section 2.2 for a description of the Phase I extension program.)

There are three ways in which ARGUS can simulate the effects of an emissions cap:

1. One way is for the user to simply tighten performance requirements on selected plants so that total emissions do not exceed the cap. This approach is not easily implemented because of the challenge of selecting appropriate plants and emission limits.

2. A more systematic approach to simulate an emissions cap is to use the trading algorithm described above, which will result in emission reductions from the units that can most economically achieve those reductions. To implement that 
TABLE 4.9 Distribution of Emission Reduction Obligations among the States as Identified in Various Studies

Distribution of Total Reduction Obligations, by Phase and Study (\%)

Phase I

$\longrightarrow$

$\begin{array}{cccc} & & & \\ & & \text { ANL } \\ & & \text { EPRI } & 1995 \\ \text { ICF 1995 ICF } 1995 & 2.5 \mathrm{lb} / & \text { Full }\end{array}$ Low High $10^{6}$ Btu Trading Limit for NES
Phase II

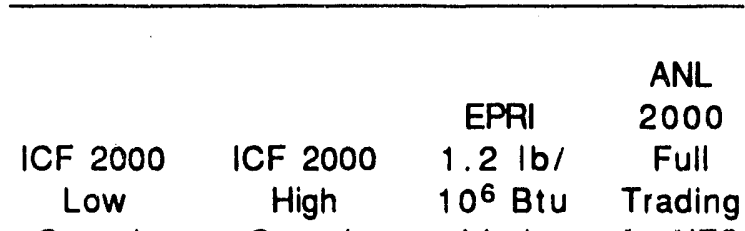

Growth Growth Limit for NES

\begin{tabular}{|c|c|c|c|c|c|c|c|c|}
\hline Ala. & 3.78 & 4.57 & 2.20 & 2.12 & 2.67 & 1.50 & 3.50 & 0.83 \\
\hline Ark. & & & & 0.10 & 0.24 & 0.43 & & \\
\hline Ariz. & & & & 0.10 & 0.03 & 0.43 & & \\
\hline Calif. & & & & 0.10 & & & & \\
\hline Colo. & & & & 0.10 & 0.12 & 0.20 & & \\
\hline Conn. & & -0.10 & & 0.10 & & & & \\
\hline D.C. & & & & 0.10 & & & & \\
\hline Del. & & & & 0.10 & 0.15 & 0.26 & 0.20 & \\
\hline Fla. & 5.70 & 4.21 & 3.50 & 1.06 & 4.01 & 4.48 & 3.10 & 0.02 \\
\hline Ga. & 14.57 & 12.27 & 6.30 & 2.96 & 9.59 & 9.37 & 7.70 & 1.94 \\
\hline $\begin{array}{l}\text { lowa } \\
\text { Idaho }\end{array}$ & 1.83 & 2.49 & 1.10 & 0.33 & 2.60 & 2.33 & 1.00 & \\
\hline III. & 6.31 & 8.57 & 11.40 & 10.72 & 8.19 & 8.41 & 9.00 & 12.08 \\
\hline Ind. & 15.02 & 14.33 & 15.60 & 19.38 & 11.70 & 10.55 & 13.10 & 23.41 \\
\hline Kans. & 0.13 & 0.12 & & 0.11 & 0.68 & 0.30 & & 0.01 \\
\hline Ky. & 5.48 & 2.20 & 4.40 & 6.84 & 5.73 & 4.44 & 4.60 & 7.00 \\
\hline La. & & & & 0.10 & 0.20 & 0.29 & & \\
\hline Mass. & -0.19 & -0.63 & & 0.10 & & & 0.30 & \\
\hline Md. & 0.38 & 0.41 & 0.40 & 0.41 & 1.44 & 1.60 & 1.40 & 0.05 \\
\hline Maine & & & & 0.10 & & 0.03 & & \\
\hline Mich. & & & & 0.98 & 0.38 & 0.80 & 0.50 & \\
\hline Minn. & & & 0.00 & 0.10 & 0.42 & 0.34 & 0.20 & \\
\hline Mo. & 4.48 & .4 .24 & 11.10 & 11.45 & 11.91 & 10.14 & 8.90 & 13.04 \\
\hline Miss. & 0.35 & 0.44 & 0.90 & 1.10 & 0.36 & 0.91 & 0.80 & \\
\hline Mont. & & & & 0.10 & 0.08 & 0.65 & & \\
\hline N.C. & 1.09 & 1.02 & & 0.10 & 1.98 & 2.07 & 0.60 & \\
\hline N.D. & & & & 0.10 & 0.26 & 0.21 & & \\
\hline Neb. & & & & 0.10 & 0.11 & 0.11 & & \\
\hline N.H. & 0.03 & 0.02 & 0.50 & 0.16 & 0.05 & 0.01 & 0.50 & 0.01 \\
\hline N.J. & 0.54 & 0.41 & 0.30 & 0.52 & 0.06 & 0.40 & 0.40 & \\
\hline N.M. & & & & 0.10 & & 0.01 & & \\
\hline Nev. & & & & 0.10 & 0.02 & 0.08 & & \\
\hline N.Y. & & & 0.80 & 0.14 & 0.18 & 0.14 & 1.70 & \\
\hline Ohio & 24.50 & 31.78 & 23.70 & 24.38 & 17.92 & 21.52 & 20.10 & 29.95 \\
\hline Okla. & 0.03 & 0.02 & & 0.10 & 0.09 & 1.03 & & \\
\hline
\end{tabular}


Distribution of Total Reduction Obligations, by Phase and Study (\%)

\begin{tabular}{|c|c|c|c|c|c|c|c|c|}
\hline \multirow[b]{2}{*}{ State ${ }^{a}$} & \multicolumn{4}{|c|}{ Phase I } & \multicolumn{4}{|c|}{ Phase II } \\
\hline & $\begin{array}{l}\text { ICF } 1995 \\
\text { Low } \\
\text { Growth }\end{array}$ & $\begin{array}{l}\text { ICF } 1995 \\
\text { High } \\
\text { Growth }\end{array}$ & $\begin{array}{c}\text { EPRI } \\
2.5 \mathrm{lb} / \\
10^{6} \mathrm{Btu} \\
\text { Limit }\end{array}$ & $\begin{array}{c}\text { ANL } \\
1995 \\
\text { Full } \\
\text { Trading } \\
\text { for NES }\end{array}$ & $\begin{array}{l}\text { ICF } 2000 \\
\text { Low } \\
\text { Growth }\end{array}$ & $\begin{array}{l}\text { ICF } 2000 \\
\text { High } \\
\text { Growth }\end{array}$ & $\begin{array}{c}\text { EPRI } \\
1.2 \mathrm{lb} / \\
10^{6} \mathrm{Btu} \\
\text { Limit }\end{array}$ & $\begin{array}{c}\text { ANL } \\
2000 \\
\text { Full } \\
\text { Trading } \\
\text { for NES }\end{array}$ \\
\hline Ore. & & & & 0.10 & & & & \\
\hline $\begin{array}{l}\text { Penn. } \\
\text { R.I. }\end{array}$ & 0.77 & 0.19 & 5.10 & $\begin{array}{l}1.93 \\
0.10\end{array}$ & 4.08 & 2.21 & 8.60 & 0.59 \\
\hline $\begin{array}{l}\text { S.C. } \\
\text { S.D. }\end{array}$ & -0.29 & -0.24 & 0.00 & $\begin{array}{l}0.10 \\
0.10\end{array}$ & $\begin{array}{l}0.80 \\
0.27\end{array}$ & $\begin{array}{l}1.60 \\
0.23\end{array}$ & 0.70 & \\
\hline $\begin{array}{l}\text { Tenn. } \\
\text { Texas }\end{array}$ & $\begin{array}{r}9.77 \\
-0.03\end{array}$ & $\begin{array}{r}8.20 \\
-0.07\end{array}$ & 6.10 & $\begin{array}{l}5.25 \\
0.10\end{array}$ & $\begin{array}{r}6.92 \\
-0.12\end{array}$ & $\begin{array}{r}6.16 \\
-0.03\end{array}$ & 6.00 & 4.92 \\
\hline Utah & & .0 .02 & & 0.10 & 0.06 & 0.25 & & \\
\hline Va. & & & & 0.10 & 0.81 & 0.98 & 0.30 & \\
\hline Vt. & & & & 0.00 & & & & \\
\hline Wash. & & & & 0.10 & 0.12 & 0.10 & & \\
\hline Wis. & & & & 4.18 & 1.40 & 1.42 & & 3.53 \\
\hline W.Va. & 5.73 & 5.57 & 6.50 & 3.44 & 4.44 & 3.76 & 6.80 & 2.56 \\
\hline Wyo. & & & & 0.10 & 0.09 & 0.28 & & \\
\hline
\end{tabular}

aAlaska and Hawaii are not included; Washington, D.C., is considered separately from Maryland.

algorithm, a reduction goal must be specified. Thus, the representation of an emissions cap in ARGUS is a two-step process. First, the program is executed through the year in which the cap is to be implemented, but the cap is not imposed. The resulting emissions are compared with the emissions allowed under the cap. The program is then rerun, with an emission reduction requirement that will result in compliance with the cap that is being imposed.

3. The third means of enforcing a cap in ARGUS is to impose an emission penalty or tax to increase the relative cost of high-emitting technologies. The emission tax will affect dispatch order and will favor lower-emitting new technologies. Changes to existing technologies, such as coal switching or scrubber retrofit, will be added only when an emission reduction goal is prescribed.

Model design considerations dictate the way in which Title IV requirements can be represented in ARGUS. Basically, an emission reduction must be specified in key years (such as at the beginning of Phases I and II) to achieve the cap, and an emission penalty must be applied in other years to maintain the cap. In any year that a major adjustment in technology or coal choice is 
expected, the two-stage analysis is required to identify and implement an emission reduction. To set up a sequence of runs to represent CAAA90, the effective cap in each year must be determined by anticipating the likely pattern of allowance banking and use. However, although ARGUS can be used to find the optimal distribution of allowances under a trading scenario, it cannot directly evaluate alternative banking schemes. Such an evaluation requires that the alternative banking schemes be individually analyzed and the results compared. Key events in this scheme are (a) the onset of Phase I (1995), (b) the start-up of Phase I extension scrubbers and a period of allowance banking (1997), (c) the onset of Phase II (2000) and a period of banked allowance use, (d) the exhaustion of banked allowances (2005), and (e) the expiration of bonus allowances. Each key event is associated with an effective emission cap, which has been estimated as described below.

Utility $\mathrm{SO}_{2}$ emissions in 1990 totaled about 16.6 million tons. ARGUS predicts that 1995 emissions will be 18.1 million tons in the absence of Phase I restrictions. Emissions should decline slightly to 17.9 million tons through 1999 . These results reflect capacity expansion and energy-demand growth projections from NERC and assume the use of least-cost coal and a leastcost dispatch order. An estimate of the reduction required in 1995 by Phase I restrictions was obtained by projecting the emissions that would result if all units were constrained to the lesser of their allowable emission rates or $2.5 \mathrm{lb} / 10^{6} \mathrm{Btu}$. Since small units are exempt from the $2.5 \mathrm{lb} / 10^{6} \mathrm{Btu}$ Phase I limit, this approach results in overestimation of the required emission reduction by perhaps $10 \%$. These estimates of a 4.5 -million-ton reduction and 18.1 million tons of emissions provide the starting point for the $\mathrm{SO}_{2}$ emissions trajectory, which is summarized in Table 4.10.

\subsubsection{Phase I $\mathrm{SO}_{2}$ Emission Allowances for 1995 and 1996}

In $1995, \mathrm{SO}_{2}$ emissions are expected to equal 18.1 million tons, minus the 4.5 million ton reduction required from Table $A$ units and adjusted by amounts reflecting adherence to two special provisions of CAAA90. The first is the Phase I extension program. The CAAA90 give Phase I affected units (Table A) that agree to install 90\% efficient scrubbing by 1997 an extension for compliance. The extension allows these units to emit at what is essentially their old SIP limit during 1995 and 1996. (Scrubbing could be applied on surrogate units as well, but this option is not important because the goal is overall reductions under an emissions trading program. ${ }^{*}$ ) It seems likely that many units will use this extension provision and install a scrubber in anticipation of Phase II requirements. However, the number of units that can elect the extension will be limited by the availability of extra allowances, which will come from a reserve of 3.5 million tons to be established from reductions achieved in 1995 (see Section 2.2). This reserve will have to cover the

\footnotetext{
* During Phase I, only Table A units are granted allowances. Thus, it would appear that only these units will be involved in trading. However, Subsection 404(b) allows the reduction requirement of Table A units to be transferred to other units under the same ownership or operating responsibility. This greatly extends the range of the trading group, even though it does not extend trading to all units across the nation as in Phase II. ARGUS cannot accommodate discrete trading groups of this type. Trading must be at a power pool or state level. However, most emission reductions in Phase I are expected to come from Table A units, so the expansion of the trading set in this simulation will not result in significant misallocation of reduction requirements.
} 
TABLE 4.10 Calculation of Net Sulfur Dioxide Emissions Allowed, 1990-2010a

\begin{tabular}{|c|c|c|c|c|c|c|c|}
\hline \multirow[b]{2}{*}{ Year } & \multicolumn{7}{|c|}{ Net $\mathrm{SO}_{2}$ Emissions Allowed ( $10^{6}$ tons) } \\
\hline & $\begin{array}{l}1990 \\
\text { CAAA }\end{array}$ & $\begin{array}{l}\text { Phase I } \\
\text { Required } \\
\text { Reduction }\end{array}$ & $\begin{array}{l}\text { Phase II } \\
\text { Basic Cap }\end{array}$ & $\begin{array}{l}\text { Phase I } \\
\text { Extension }\end{array}$ & Banking & Bonus & $\begin{array}{c}\text { Net } \\
\text { Emissions }\end{array}$ \\
\hline 1990 & 16.6 & & & & & & 16.60 \\
\hline 1995 & 18.1 & -4.5 & & 2.0 & & 0.20 & 15.80 \\
\hline 1996 & 18.1 & -4.5 & & 1.5 & & 0.20 & 15.30 \\
\hline 1997 & 18.0 & -4.5 & & & -1.45 & 0.20 & 12.25 \\
\hline 1998 & 18.0 & -4.5 & & & -1.45 & 0.20 & 12.25 \\
\hline 1999 & 17.9 & -4.5 & & & -1.45 & 0.20 & 12.15 \\
\hline 2000 & & & 8.9 & & 1.75 & 0.58 & 11.23 \\
\hline 2001 & & & 8.9 & & 1.25 & 0.58 & 10.73 \\
\hline 2002 & & & 8.9 & & 0.75 & 0.58 & 10.23 \\
\hline 2003 & & & 8.9 & & 0.50 & 0.58 & 9.98 \\
\hline 2004 & & & 8.9 & & 0.10 & 0.58 & 9.58 \\
\hline 2005 & & & 8.9 & & & 0.58 & 9.48 \\
\hline 2010 & & & 8.9 & & & 0.05 & 8.95 \\
\hline
\end{tabular}

${ }^{a}$ A blank space means not applicable.

additional emissions that will come from the Phase I extension units in 1995 and 1996. The assumption is that allowances worth 2 million tons will be used in 1995 and allowances worth 1.5 million tons will be used in 1996 (reflecting the outage of some plants in 1996 for scrubber completion and start-up). The second special provision is an additional allowance worth 200,000 tons to be allocated to units in Illinois, Indiana, and Ohio for each year in Phase I. The net emissions expected in 1995 would equal $18.1-4.5+2.0+0.2$ million tons, or 15.8 million tons, a slight reduction from the 1990 emission level. Net emissions expected in 1996 would equal 15.3 million tons, reflecting the availability of only 1.5 million tons from the Phase I extension reserve $(18.1-4.5+1.5+0.2)$.

\subsubsection{Phase $1 \mathrm{SO}_{2}$ Emission Allowances for 1997, 1998, and 1999}

In the three years 1997,1998 , and 1999, the scrubber capacity that was installed under the extension program will be on line and probably be used to its full capability. This situation will reduce the use of allowances by the owners, allowing some allowances to be banked for later use. The banked allowances have been estimated as follows. The total amount of $\mathrm{SO}_{2}$ emitted from Table A plants is 5.49 million tons. At $2.5 \mathrm{lb} / 10^{6} \mathrm{Btu}$, this implies a heat input of $4.39 \times$ $10^{9} \mathrm{Btu}$. This heat input multiplied by a new average emission rate for the Table $\mathrm{A}$ plants (which reflects the additional scrubbing) provides an estimate of emissions that includes overcompliance by the scrubbed units. If the total emission reduction required of the Table A plants is 4.5 million 
tons, and if reserve allowances worth 2 million tons are needed by the extension units, then the fraction of Table A capacity in the extension program is about 2 million tons divided by 4.5 million tons $(2 / 4.5)$. The fraction that is in direct compliance with the $2.5 \mathrm{lb} / 10^{6} \mathrm{Btu}$ limit is about 2.5/4.5. Assuming that the plants retrofit with scrubbers have an average emission rate of $1 \mathrm{lb} / 10^{6} \mathrm{Btu}$, the weighted average emission factor for Table A units is:

$$
(2.0 / 4.5) \times 1.0+(2.5 / 4.5) \times 2.5=1.84 \mathrm{lb} / 10^{6} \mathrm{Btu}
$$

This emission rate multiplied by the estimated heat input yields 4.04 million tons of $\mathrm{SO}_{2}$, which is 1.45 million tons below the total Table A allowances; this amount can be banked for use in Phase II. The net emissions in these three years is the projected emissions minus the required reductions, minus this additional reduction, and plus the special allocation of allowances worth 200,000 tons of emissions per year (see Table 4.10).

\subsubsection{Phase II SO 2 Emission Allowances}

Data on the baseline emissions and emission reductions are not needed to calculate Phase II $\mathrm{SO}_{2}$ emission allowances because of the cap mandated in the law. This cap is 8.9 million tons. In addition to this basic cap, a reserve (from reductions in the year 2000) of 5.3 million tons is set aside for distribution as bonuses during the first 10 years of Phase II. In other words, allowances worth 530,000 tons of emissions per year will be distributed as bonuses. A group of midwestern states will also receive total allowances worth 50,000 additional tons of emissions per year, in spite of the cap for all years of Phase II. These are totaled in the Task 10 column labeled "Bonus."

The remaining issue is the distribution of the allowances banked in Phase I. The total of 4.35 million tons has been allocated here in the early years of Phase II, when they clearly have the greatest value. The allocation chosen results in year 2000 emissions being slightly below those in 1999. By 2010, the bonus allowances have expired, and emissions are capped at 8.95 million tons. Table 4.10 summarizes these results. 


\section{Simulation Results}

The primary influence on how utilities will respond to Title IV is the effective emissions cap, which is determined by the allocation scheme for emission allowances. Figure 5.1 presents a summary of the key features of that allocation scheme, contrasting the basic requirements with important special provisions. The dark line displays the basic $\mathrm{SO}_{2}$ emission trajectory increasing emissions from 1990 until the onset of Phase I in 1995, a drop in emissions resulting from the reduction of the emission rates of Table A units to $2.5 \mathrm{lb} / 10^{6} \mathrm{Btu}$, nearly constant emissions until Phase II in 2000, then a precipitous decline in $\mathrm{SO}_{2}$ emissions with the onset of Phase II. At the beginning of Phas II, bonus allowances will keep the emission level above the ultimate cap of 8.95 million tons. The effect of the Phase I extension program and banking is shown by the light line. In 1995 and 1996, the extra allowances granted to units that qualify for the extension program will keep the emission level above the nominal Phase II allowable level. In 1997 through 1999, these units will be able to operate well below the $2.5 \mathrm{lb} / 10^{6}$ Btu rate on which allowances are based. The result will be reduced emissions and the banking of allowances. The use of these banked allowances will then result in more emissions early in Phase II. This trajectory for the effective emissions cap is not a result of the simulation. It is an estimate based on assumptions about the use of the Phase I extension program, banking by participants in that program, and the use of banked allowances. A complete discussion of these assumptions was provided in Section 4.3.

The growth in capacity and electricity generation over the study period is summarized in Figure 5.2. This growth is based on FOSSIL2 projections for overall growth in energy demand. The crossover of the capacity and generation lines could be misleading; it does not indicate a reduction in the capacity factor. It is an artifact of the chosen scale. In fact, the average capacity factor increases from $47 \%$ in 1990 to $55 \%$ in 2030 . Details on the assumptions about energy demand that result in this expansion were provided in the previous section. In brief, specific demand growth rates are assumed for each power pool. In the early years of the simulation, these growth rates reflect historical rates, which range from $1 \%$ to $4 \%$ per year. Toward the end of the simulation period, the growth rates converge to a common value of $1.44 \%$ in all pools.

The distribution of this generating capacity and electricity generation by fuel and technology is displayed in the next two figures. The continued dominance of coal is clear from Figure 5.3, which shows that coal consistently provides $50 \%$ of total capacity. In fact, coal's dominance under the NES assumptions is even more obvious in Figure 5.4, which depicts generation. Approximately two-thirds of total electricity generation is from coal-fired units. These figures also reflect how the contribution of energy from nuclear power declines as existing plants retire and no new nuclear capacity is built. Again, this situation reflects the NES baseline assumptions.

The emission goals of Title IV are met in spite of this reliance on coal because of the use of low-sulfur coal, the application of FGD, and the application of advanced coal technologies, including atmospheric fluidized-bed combustion (AFBC), pressurized fluidized-bed combustion (PFBC), and IGCC technologies. The relative importance of advanced and conventional coal plants is shown in Figure 5.5, which depicts the contribution to total generating capacity and 


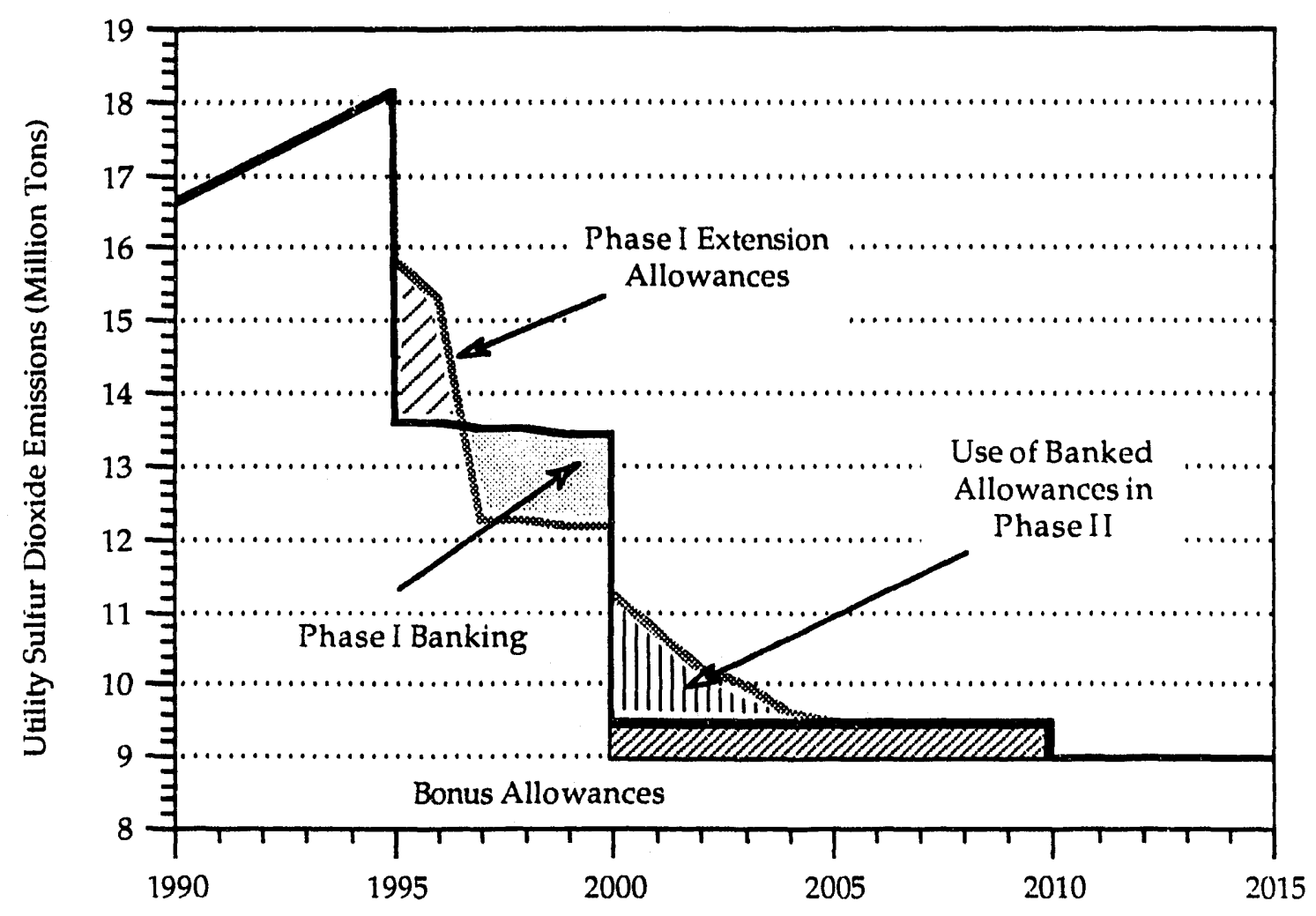

- Without Banking With Banking

FIGURE 5.1 Effect of Phase I Extension and Banking on Sulfur Dioxide Emissions

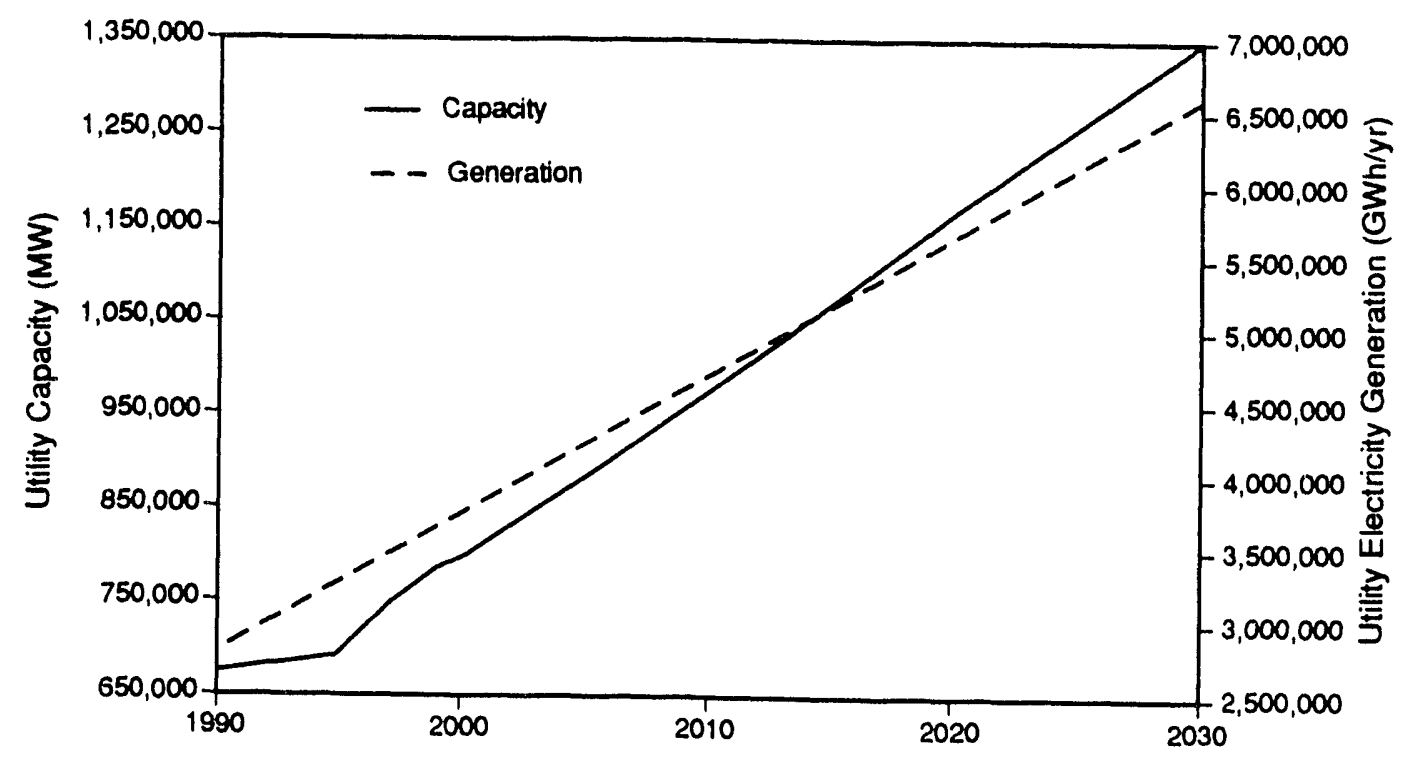

FIGURE 5.2 Growth in Total Utility Generating Capacity and Electricity Generation 


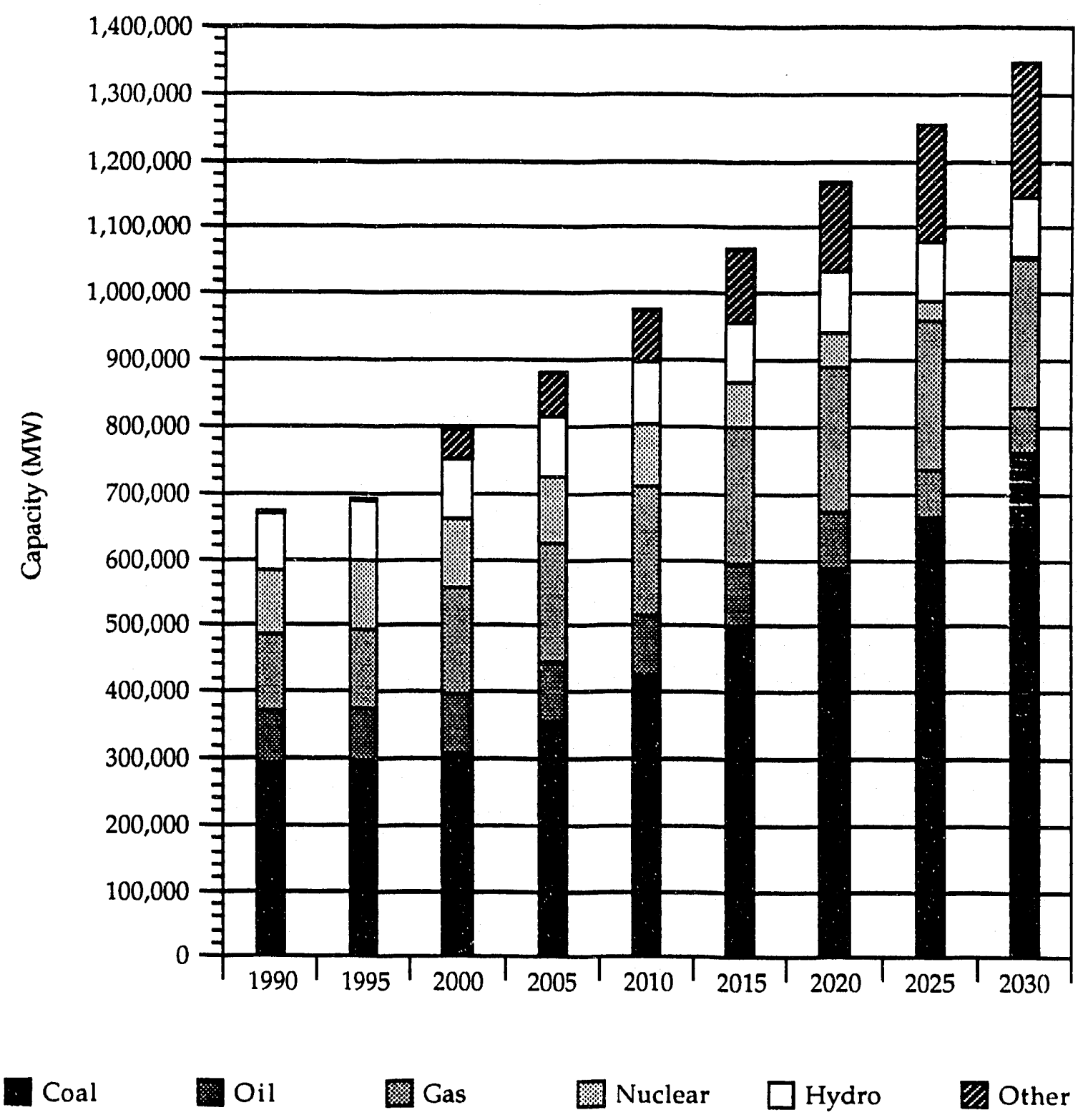

FIGURE 5.3 Distribution of Generating Capacity hy Fuel Type

electricity generation being made by these alternatives. The advanced coal technology category includes coal gasification with intercooled steam-injected gas turbine (coal-ISTIG), as well as AFBC, PFBC, and IGCC. The conventional category includes pulverized coal (PC) with and without FGD. Note that all these technologies emit a relatively small amount of pollutants when compared with the older, existing units targeted by Title IV reduction requirements.

The relative contributions of noncoal resources to capacity and generation are summarized in Figures 5.6 and 5.7. They show the decline in the contribution of nuclear power and the expanding role for natural gas. The "other" category includes renewable resources and NUG. Although this fact is not shown in Figure 5.7, NUG provides about twice as much energy as 


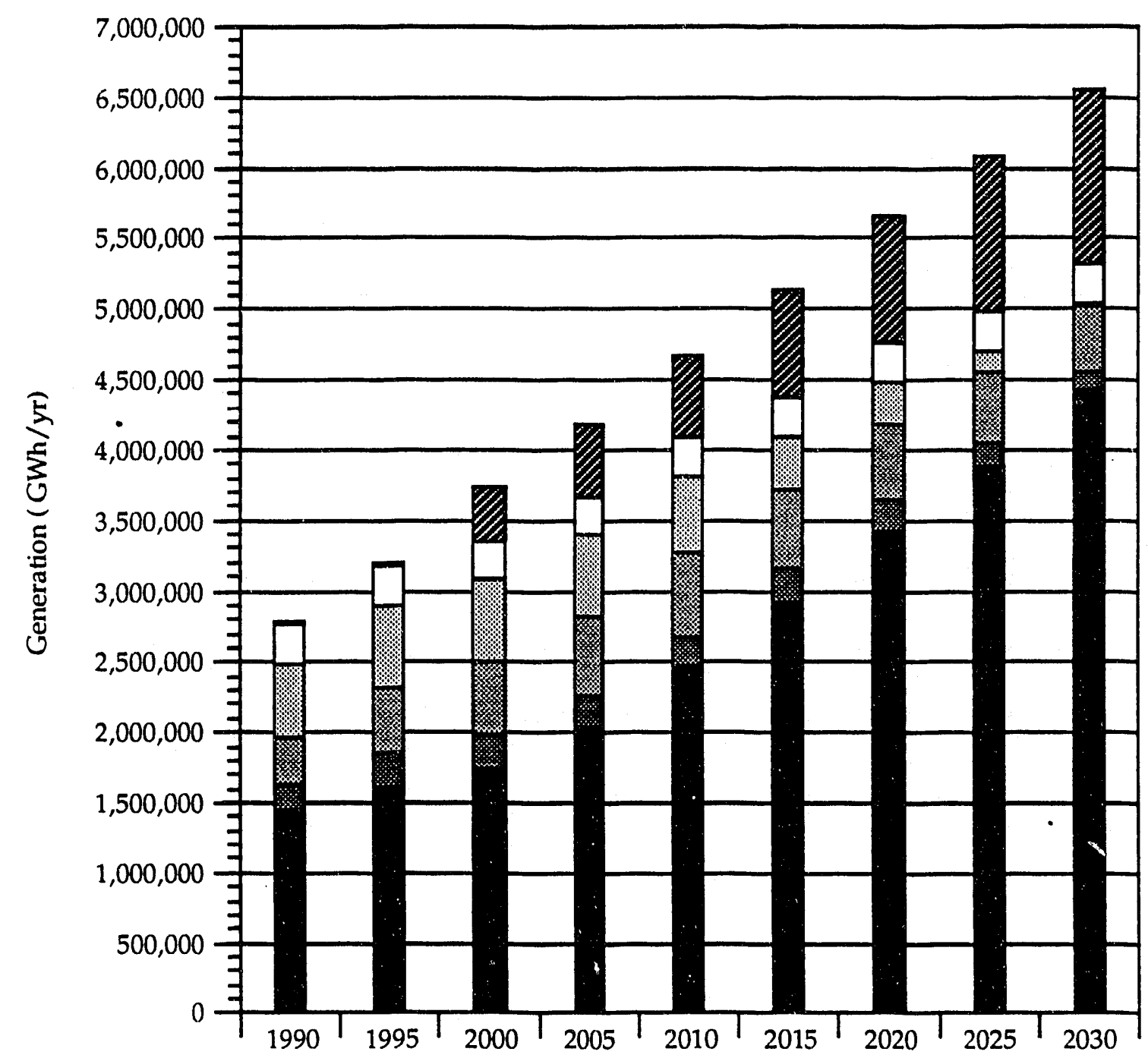

Coal Oil $\quad \square$ Nuclear $\square$ Hydro

FIGURE 5.4 Distribution of Electricity Generation by Fuel Type

renewable energy sources during much of the study period. These nonutility generators' high energy contribution (Figure 5.7) relative to their capacity (Figure 5.6) indicates their use as baseload capacity.

Like coal, natural gas relies on advanced technologies to strengthen its market share. The advanced technologies for gas include NGCC, steam-injected gas turbines (STIGs), and molten carbonate fuel cells (MCFCs). However, the relative importance of advanced technologies to total gas-fired capacity and generation is small when compared to their importance to total coal-fired capacity and generation, although advanced technologies do provide $50 \%$ of gas-fired generation by 2030 (Figure 5.8 ). 

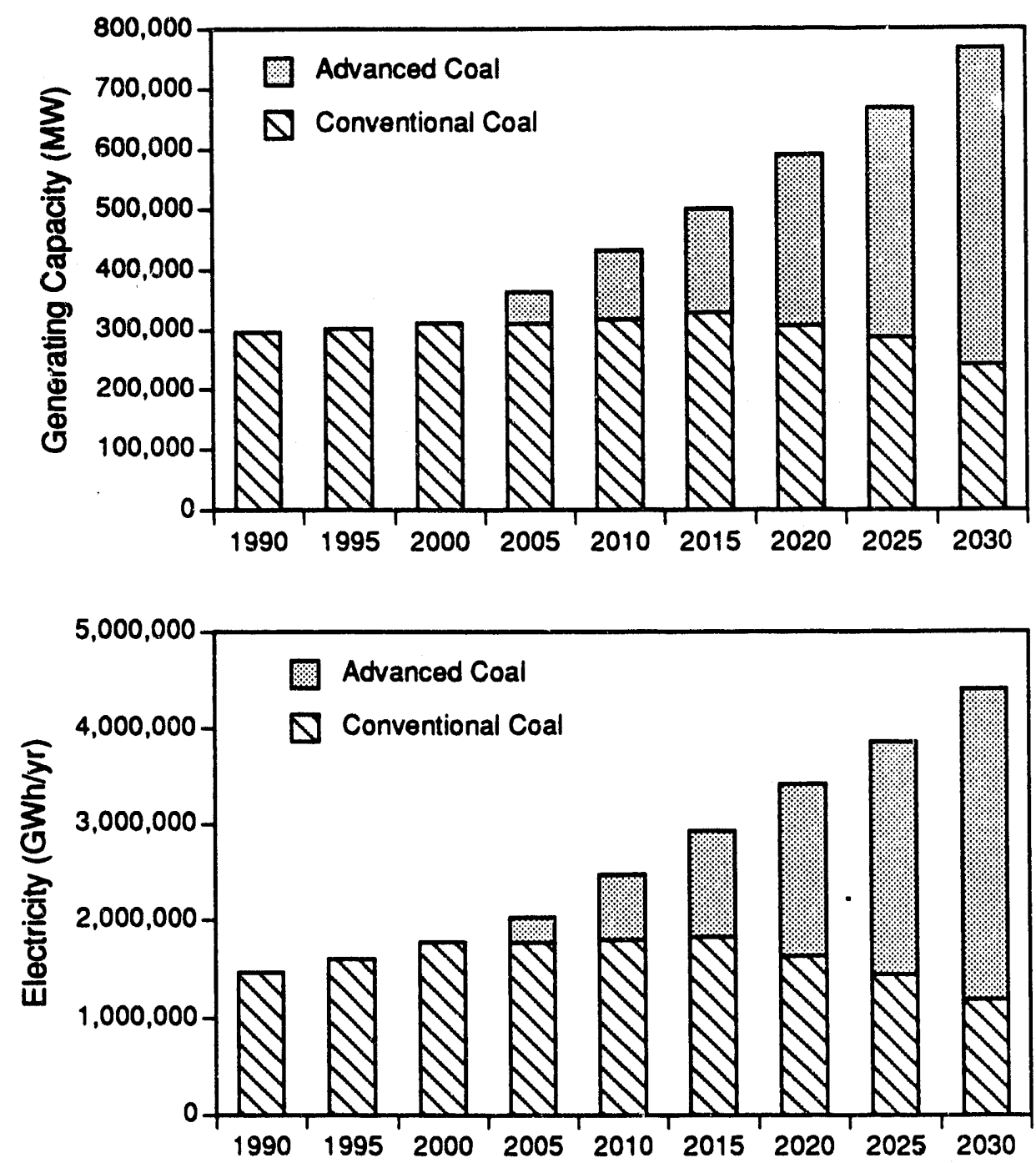

FIGURE 5.5 Distribution of Generating Capacity and Electricity Generation for Conventional and Advanced Coal-Fired Units

Part of the decline in the importance of conventional technologies is a result of their retirement and replacement during the study period. Much of the reduction in $\mathrm{SO}_{2}$ emissions achieved by Title IV would eventually have been achieved by this replacement, even without additional regulation. Figures 5.9 and 5.10 show the contributions to total generating capacity and electricity generation made by three groups of units: (1) units that currently exist; (2) units that are included in current, announced utility plans; and (3) additional new capacity added by the simulation to meet demand.

The significance of this distribution of capacity to $\mathrm{SO}_{2}$ emissions is indicated by a comparison of Figure 5.10 and 5.11. Even though existing capacity accounts for only $20 \%$ of total generation, it contributes $50 \%$ of total emissions, in spite of emission reductions imposed by Title IV. 


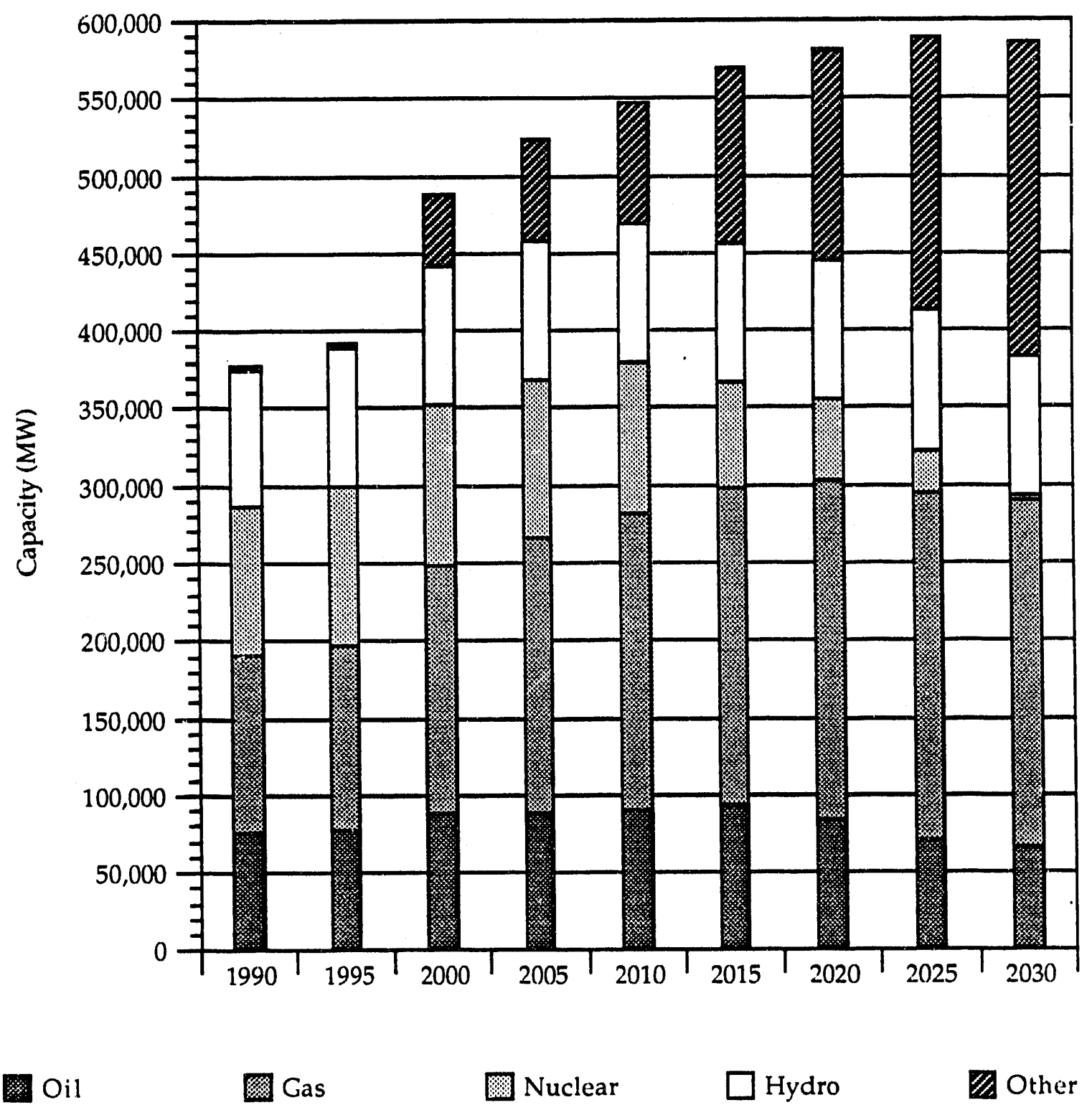

FIGURE 5.6 Distribution of Generating Capacity by Fuel Type for Noncoal Resources

A more detailed picture of the $\mathrm{SO}_{2}$ emissions time path is provided in Figure 5.12, which is basically the path suggested in Figure 5.1 (that is, the path in Figure 5.1 provides emission targets for each year of the simulation). Figure 5.12 shows the amount of $\mathrm{SO}_{2}$ emissions expected to occur as a result of the decisions regarding capacity expansion, fuel choice, scrubber retrofit, and dispatch that will be made by the simulation under the given emission target. To some extent, emissions decline as a result of the introduction of lower-emitting technologies. More significant factors in the near-term emission decline, however, are the application of scrubber retrofits and the switch to low-sulfur coal. The role of the first factor is suggested in Figure 5.12, which shows that a dramatic increase in scrubbed capacity occurs simultaneously with a reduction in emissions. The decline in scrubbed capacity in later years reflects unit retirements and the preference for advanced coal options. Note that emissions decline significantly in the reference case as well. 


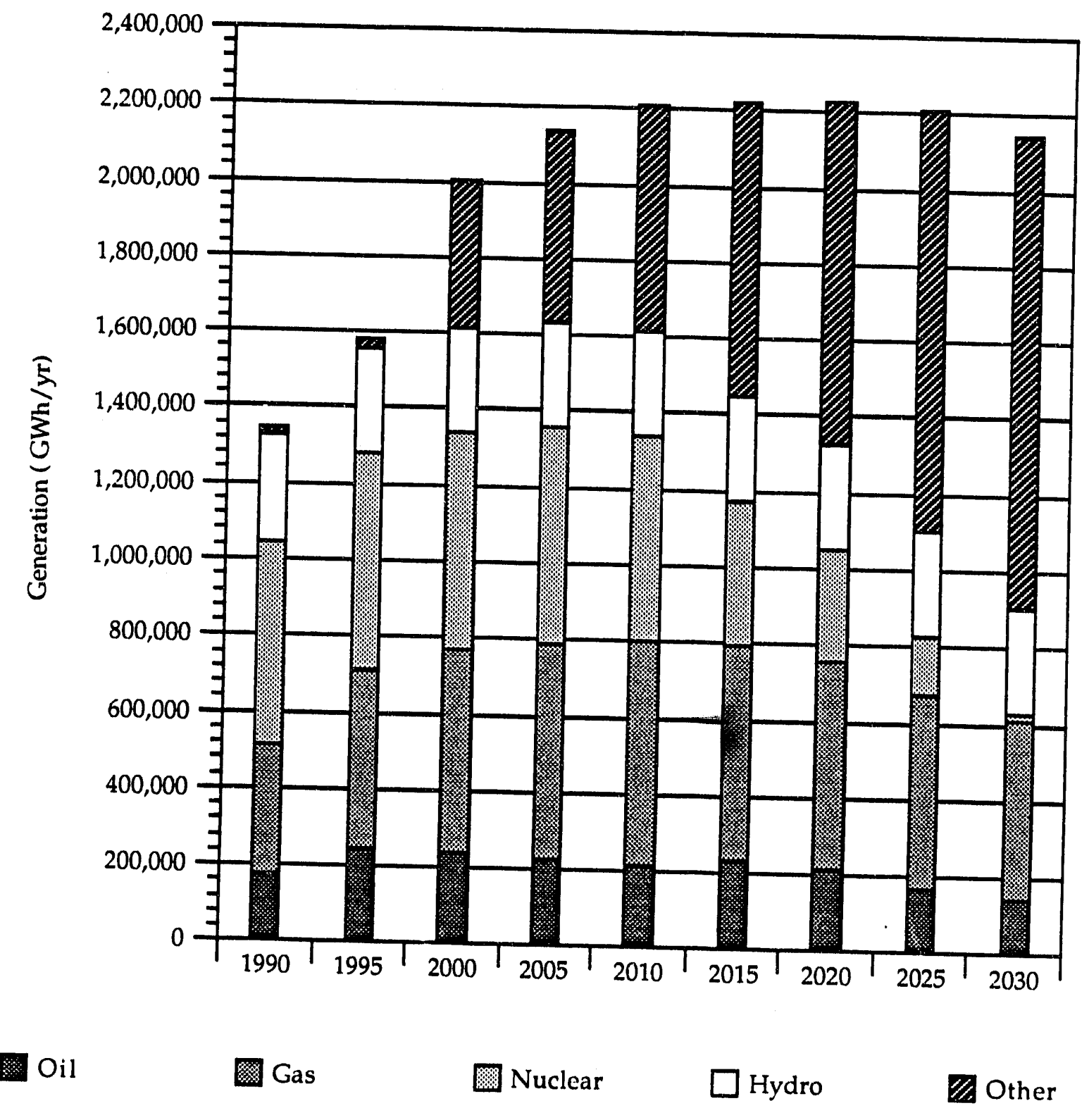

FIGURE 5.7 Distribution of Electricity Generation by Fuel Type for Noncoal Resources

The early reductions were not achieved by scrubbing alone. The use of low-sulfur coal as a way to comply with Title IV requirements is indicated by the significant decline in average coal sulfur content during Phase I and a portion of Phase II (see Figure 5.13). Note that the coal sulfur content rises again to nearly its 1990 level as inherently low-emitting technologies are introduced.

Compliance costs for Title IV are primarily associated with switching fuels and applying FGD. Figure 5.14 shows the relative importance of fuel-related and FGD-related expenses to the total cost differential between the CAAA case and the reference case, ${ }^{*}$ which does not impose

\footnotetext{
*These cost results are presented in terms of a cost differential because this type of simulation is more reliable in predicting cost differences than in predicting absolute costs.
} 

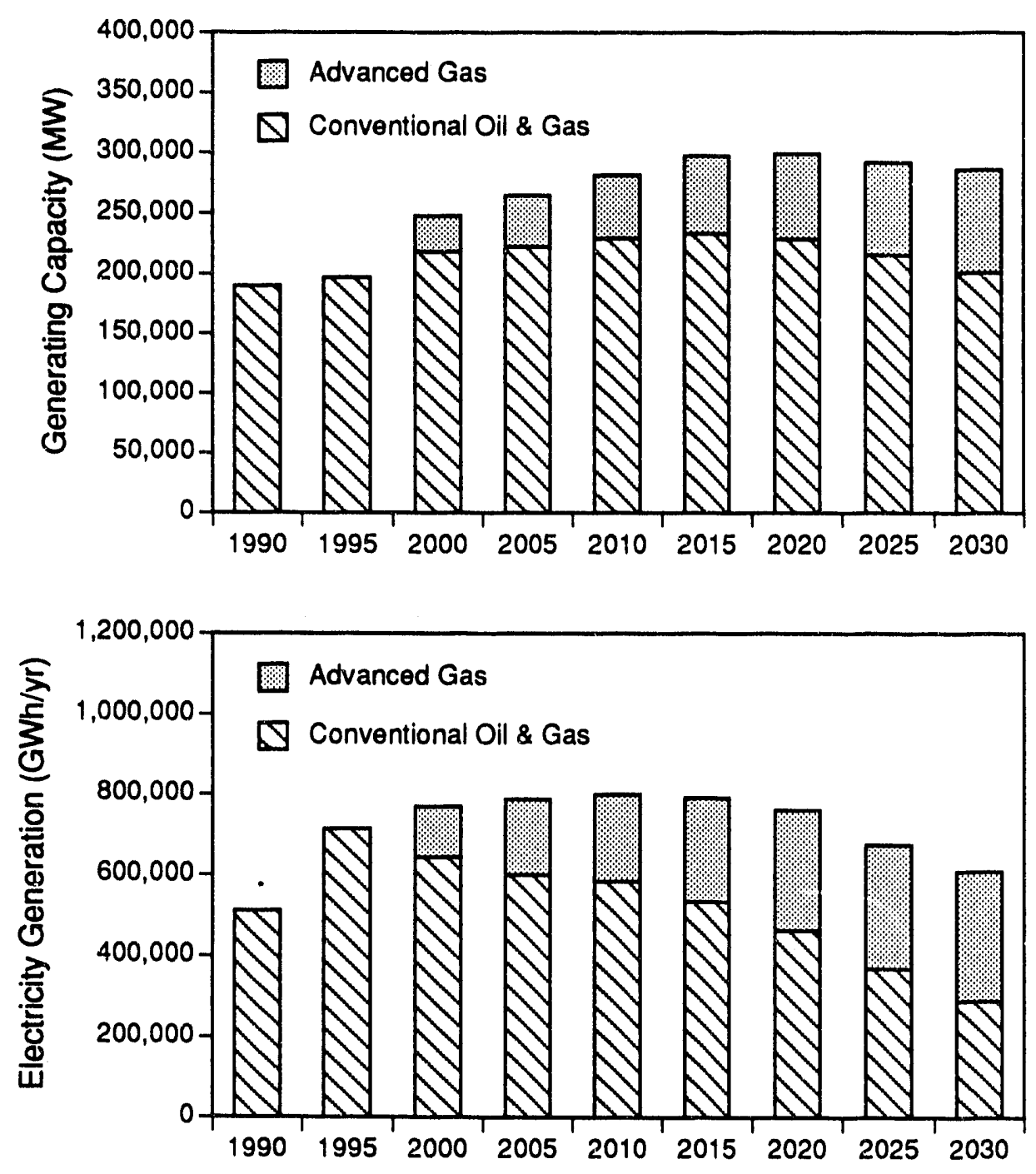

FIGURE 5.8 Distribution of Generating Capacity and Electricity Generation for Advanced Gas-Fired and Conventional Oil- and GasFired Units

Title IV restrictions. These two cost elements account for virtually all of the increased cost attributable to Title IV. The application of advanced coal technologies is not expected to carry a cost premium; that is, these are the technologies that would be likely to have been chosen on a cost basis alone. In fact, some of the FGD and fuel cost increase is offset by economies associated with the advanced technologies. These economies result in the total cost increase falling below the sum of the FGD and fuel cost increases after 2010.

Another interesting feature of the cost projection in Figure 5.14 is the lack of a sharp cost increase at the onset of Phase II. This reflects the availability of banked allowances, which can be used to ease the transition to the lower average emission rates that Phase II requires. Figure 5.14 also lists the baseline reference case costs and the percent change represented by the cost differential. 


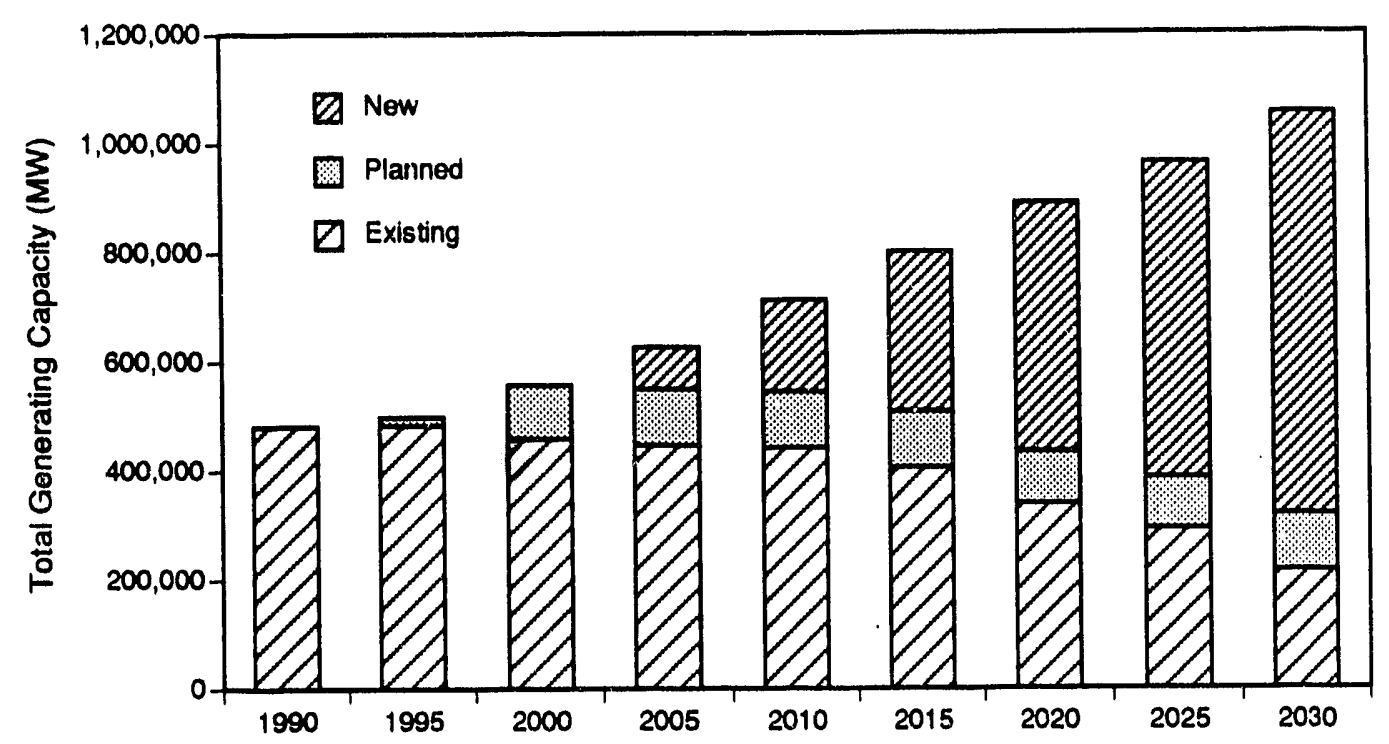

FIGURE 5.9 Distribution of Generating Capacity among New, Planned, and Existing Units

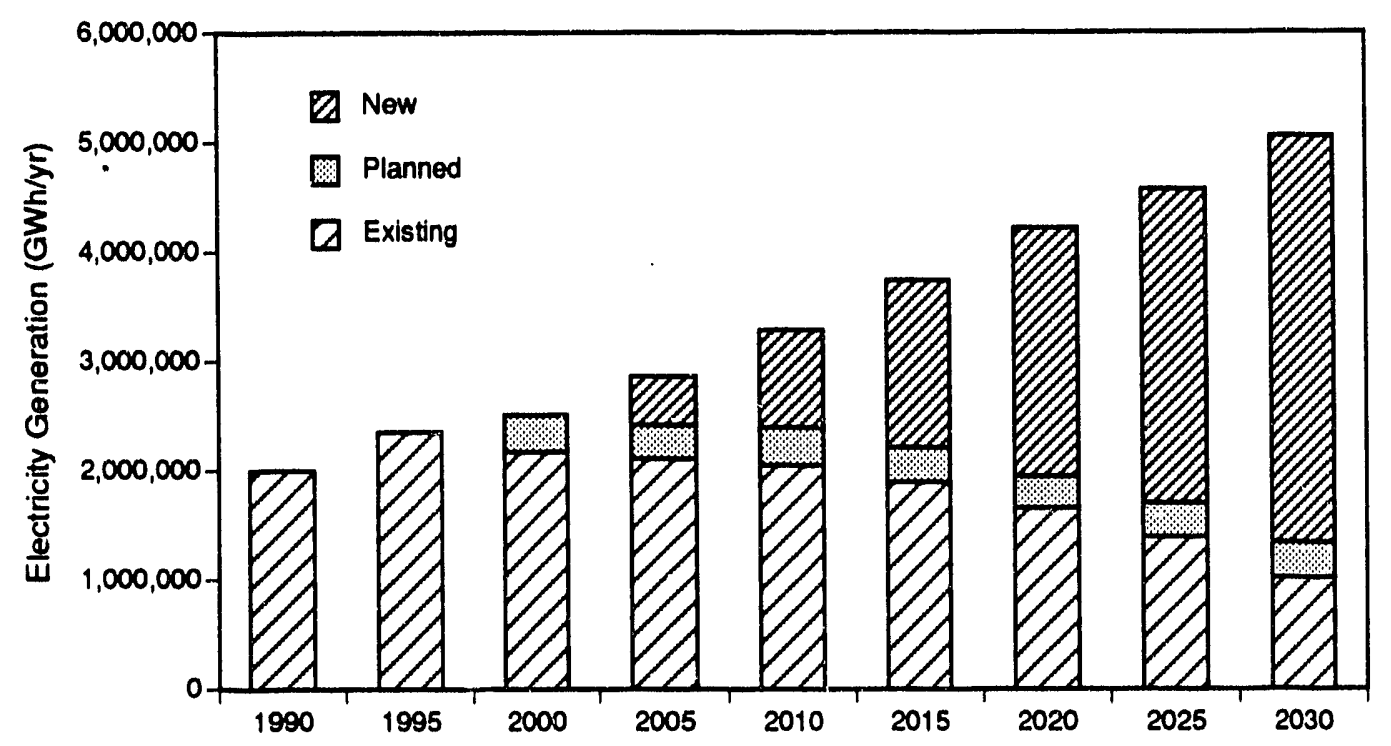

FIGURE 5.10 Distribution of Electricity Generation among New, Planned, and Existing Units 


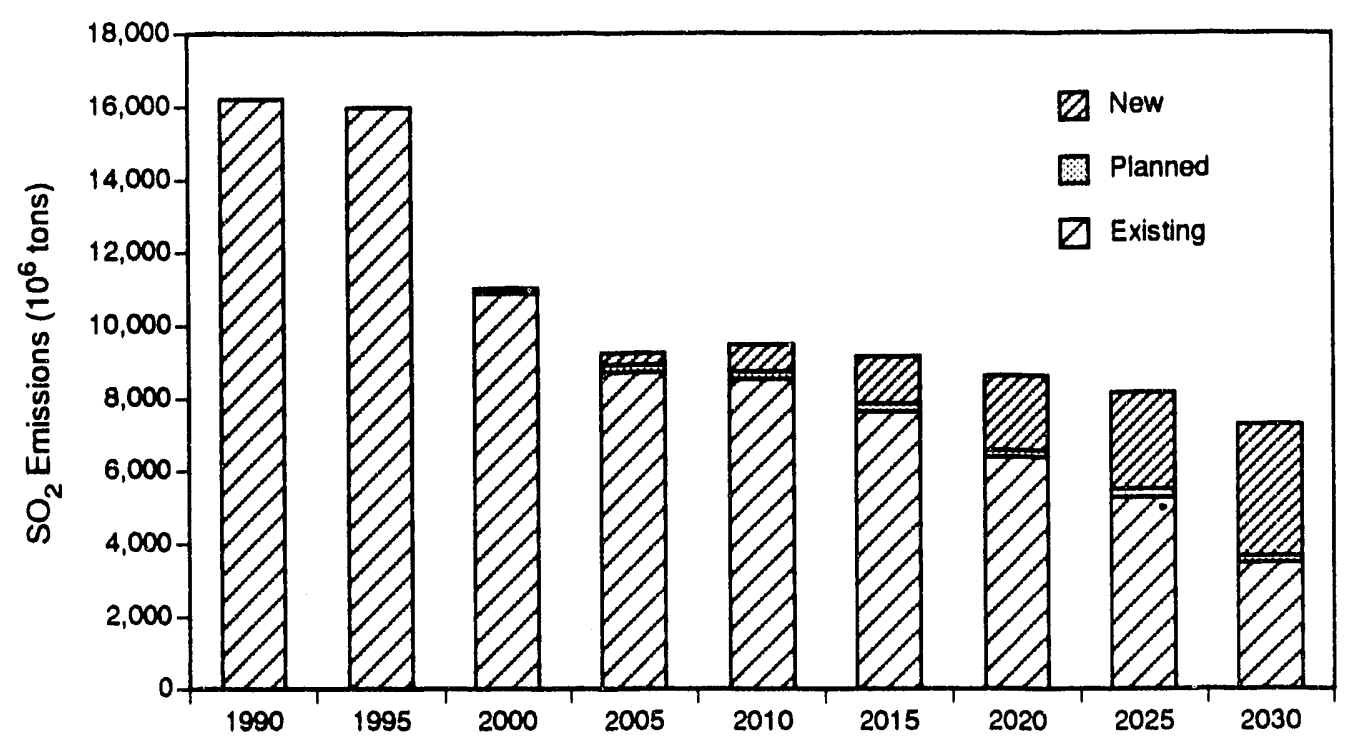

FIGURE 5.11 Distribution of $\mathrm{SO}_{2}$ Emissions among New, Planned, and Existing Units

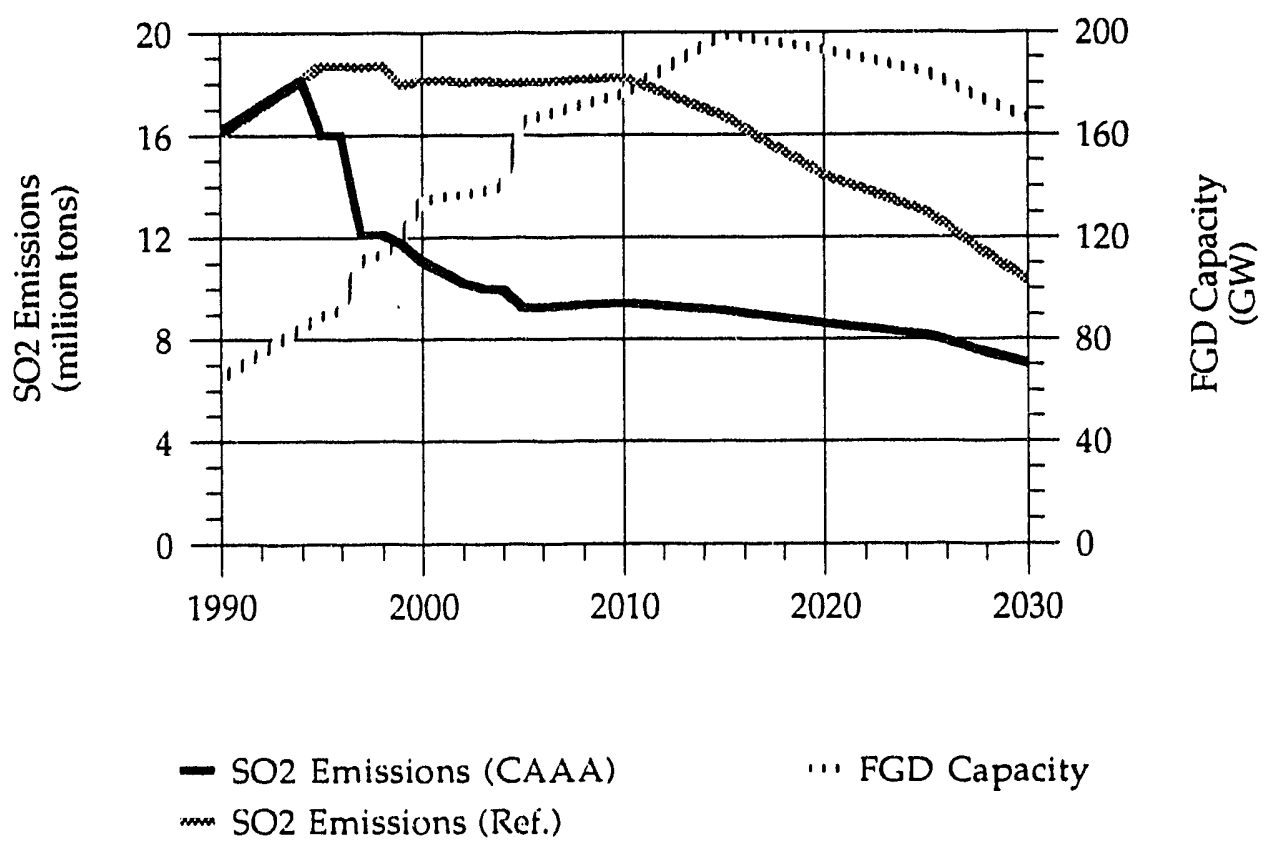

FIGURE $5.12 \mathrm{SO}_{2}$ Emissions Trajectory and Growth of Scrubbed Capacity 


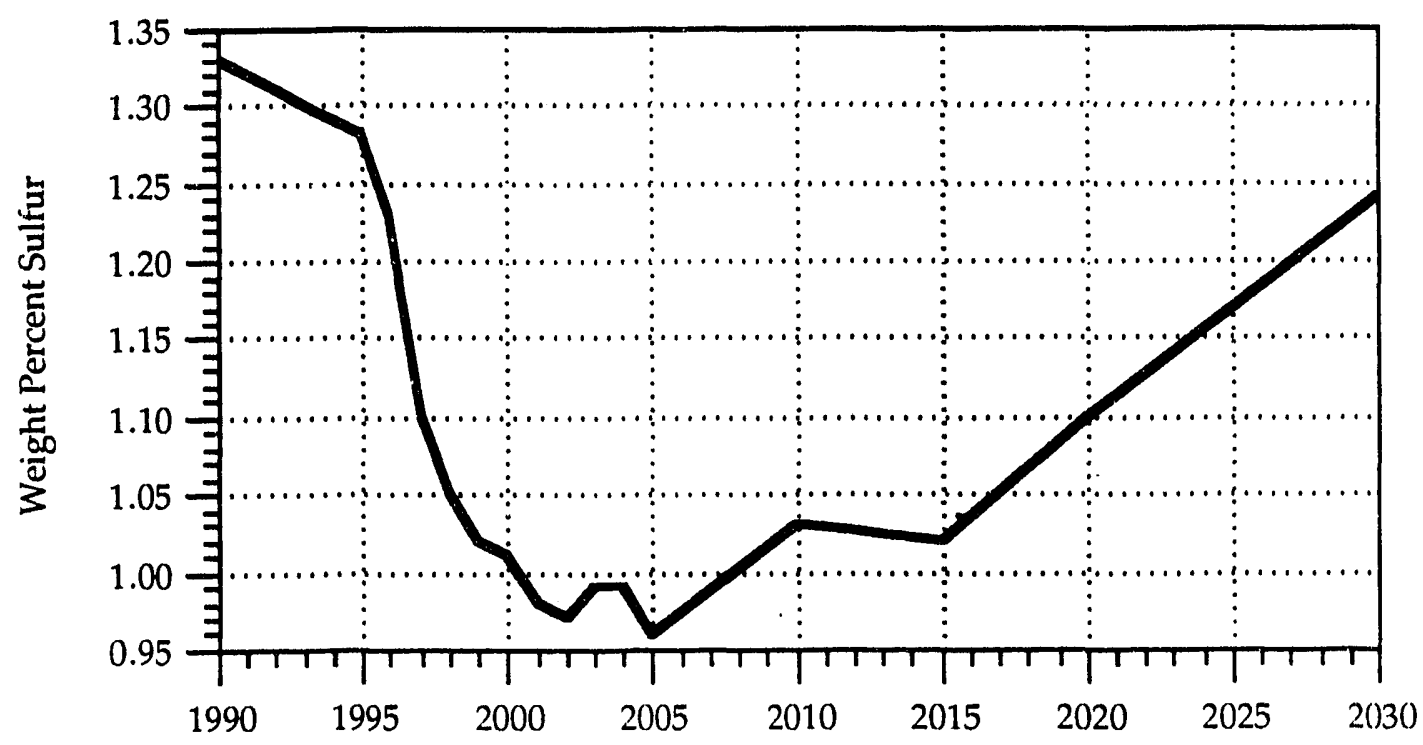

FIGURE 5.13 Projected Average Sulfur Content in Steam Coal

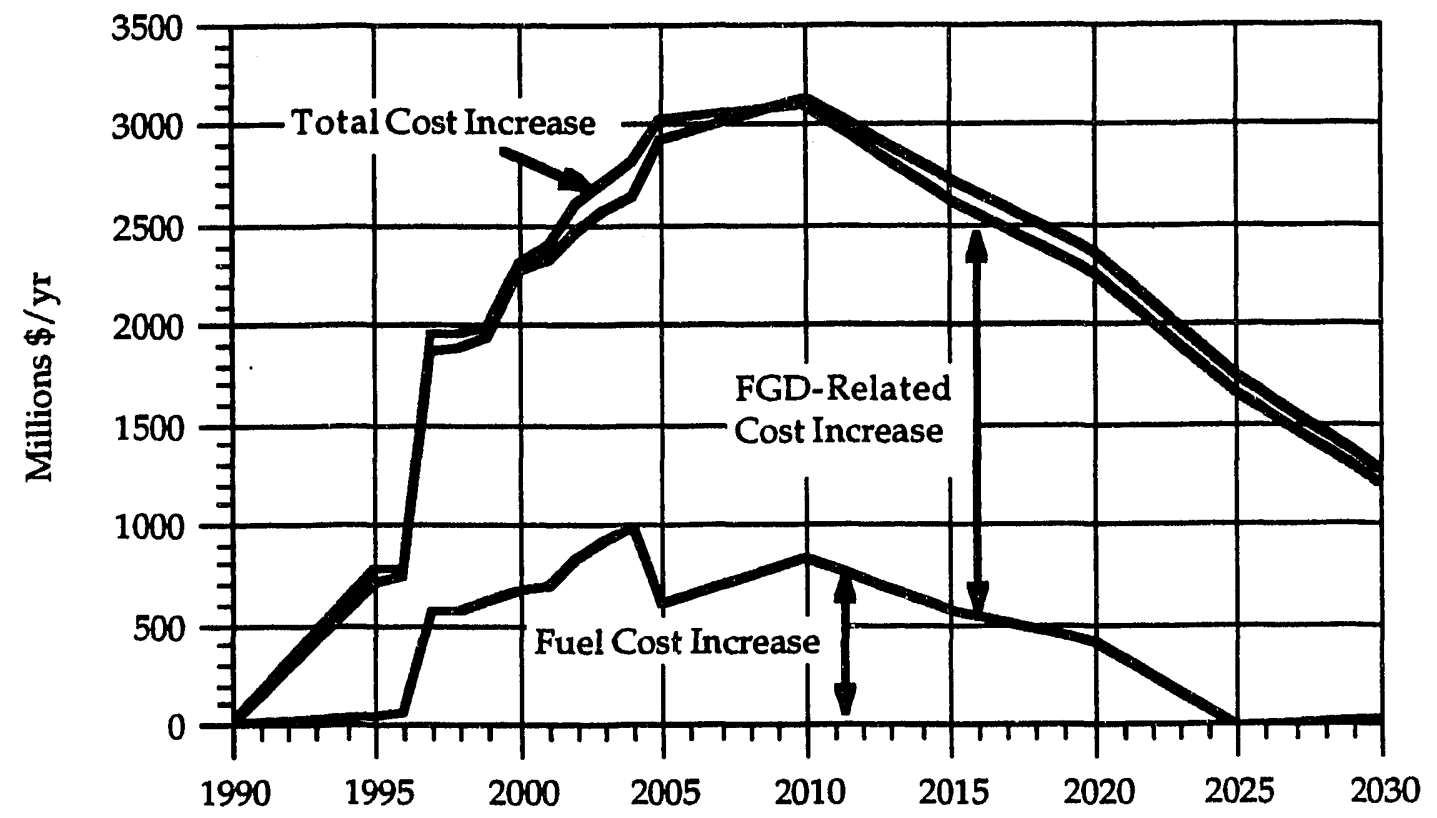

Baseline Costs

$\begin{array}{lccccccccc}\left(10^{9} \$\right) & 54.7 & 74 & 95 & 117 & 147 & 179 & 204 & 227 & 225 \\ \text { \% Change } & 0.00 & 1.01 & 2.44 & 2.57 & 2.11 & 1.46 & 1.10 & 0.72 & 0.47\end{array}$

FIGURE 5.14 Additional Costs Incurred to Comply with Title IV Requirements 
The use of low-sulfur coal as a compliance strategy has implications for the coal industry, since it results in a shift in demand for coal from high-sulfur coal regions to coal from low-sulfur coal regions. However, as can be seen in Figure 5.15, regions producing higher-sulfur coal regain their market share as new technologies penetrate the electricity-generating market. This eventual recovery does not lessen the severity of the near-term effects. At its lowest point, the market share for Illinois Basin coal is reduced by nearly $25 \%$ from what it would be were Title IV not in effect. The values for annual output in Figure 5.15 show the difference between the coal-use projections with and without Title IV.

The severity of coal market impacts might be substantially reduced by coal protection legislation (e.g., forced scrubbing) and by a continued decline in the cost of FGD. These are both seen as likely trends.

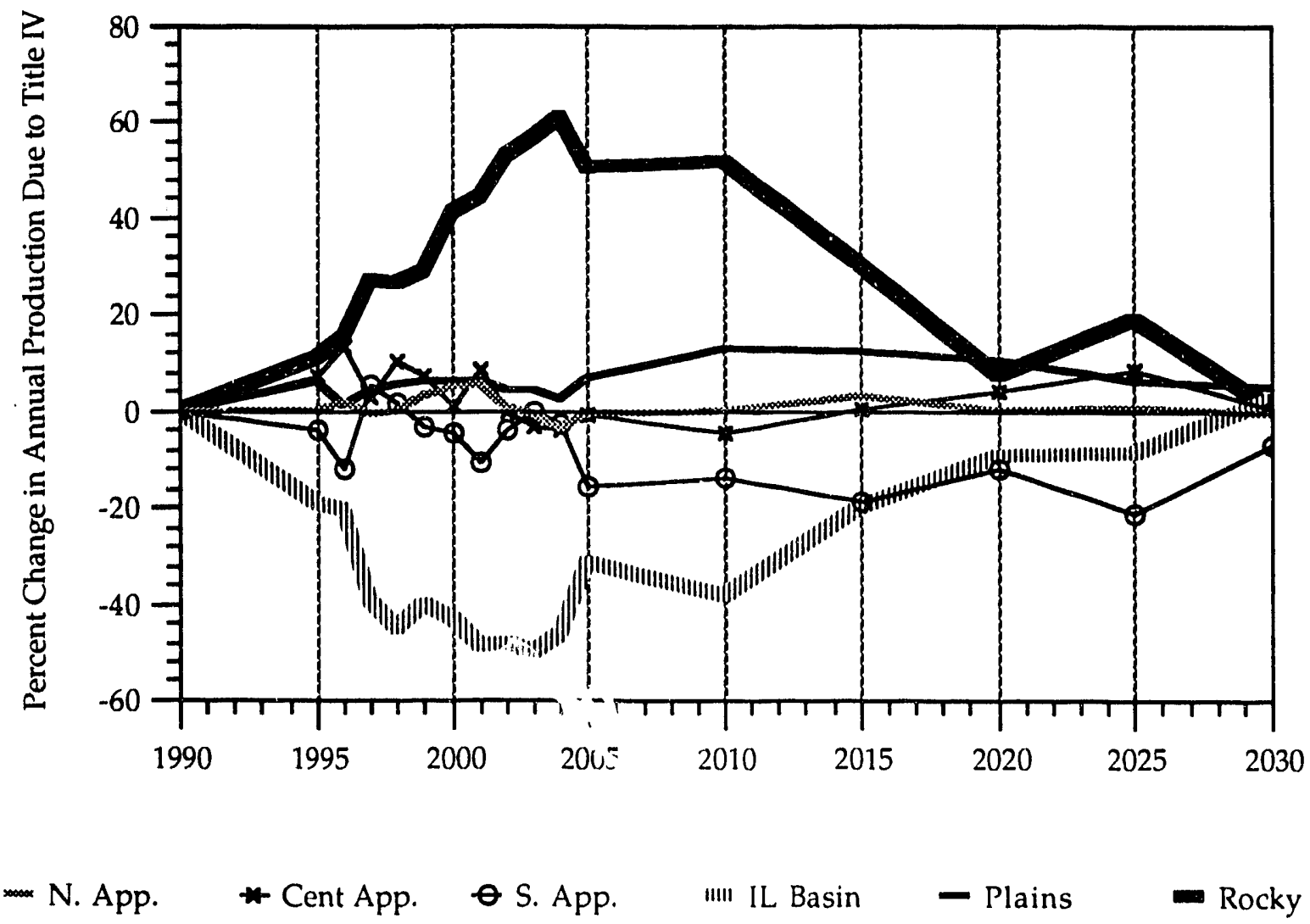

FIGURE 5.15 Changes in Regional Coal Production due to Title IV Requirements 


\section{References}

Dye, R., 1991, personal communication, U.S. Department of Energy, Office of Planning and Environment, Feb. 1.

EIA, 1987, Financial Statistics of Selected Electric Utilities, U.S. Department of Energy, Energy Information Administration.

EIA, 1990a, Annual Energy Outlook for U.S. Electric Power, report DOE/EIA-0474(90), U.S. Department of Energy, Energy Information Administration.

EIA, 1990b, Improving Technology: Modelling Energy Futures for the National Energy Strategy, report SR/NES/90-01, U.S. Department of Energy, Energy Information Administration.

EIA, 1990c, Electricity Supply: Supporting Analysis for the National Energy Strategy, report SR/NES/90-03, U.S. Department of Energy, Energy Information Administration.

EIA, 1990d, National Energy Strategy Reference Case Technical Assumptions, draft, U.S. Department of Energy, Energy Information Administration, Oct. 3.

Energy Ventures Analysis: 1987, Coal Markets and Utilities' Compliance Decisions, report EPRI P-5444, Electric Power Research Institute, Palo Alto, Calif.

EPRI, 1986, TAG ${ }^{T M}$ - Technical Assessment Guide, Volume 1, Electricity Supply - 1986, report EPRI P-4463-SR, Electric Power Research Insticute, Palo Alto, Calif., Dec.

EPRI, 1989, TAG TM -- Technical Assessment Guide, Electricity Supply - 1989, report EPRI P-6587-L, Electric Power Research Institute, Palo Alto, Calif., Sept.

EPRI, 1990, Clean Air Response: A Guidebook to Strategies, report EPRI-GS-7105, Electric Power Research Institute, Palo Alto, Calif.

ICF Resources, Inc., 1988, Documentation of the National Utility Financial Statement (NUFS) Model, Washington, D.C., Aug.

ICF Resources, Inc., 1989, Economic Analysis of Title $V$ of the Administration's Proposed Clean Air Act Amendments, Washington, D.C., Sept.

ICF Resources, Inc., 1990, Comparison of the Economic Impacts of the Acid Rain Provisions of the Senate Bill (S.1630) and the House Bill (S.1630), report prepared by ICF Resources, Inc., Washington, D.C., for the U.S. Environmental Protection Agency.

Kohout, E.J., et al., 1990, Current Emission Trends for Nitrogen Oxides, Sulfur Dioxide, and Volatile Organic Compounds by Month and State: Methodology and Results, report ANL/EAIS/TM-25, Argonne National Laboratory, Argonne, Ill., Aug. 
Moore, J.L., et al., 1989, Using Incentives for Environmental Protection: An Overview, report 89-360 ENR, Congressional Research Service, Library of Congress, June 2.

Placet, M., and D.G. Streets, 1990, "Emissions of Acidic Deposition Precursors," Chapter 1 in Volume II, Emissions and Control, of NAPAP Interim Assessment, The Causes and Effects of Acidic Deposition, National Acid Precipitation Assessment Program, Washington, D.C.

Raufer, R.K., and S.L. Feldman, 1987, Acid Rain and Emissions Trading, Rowman and Littlefield, Lanham, Md.

Smith, D.J., 1991. "Non-Utility Power Producers Will Supply Near Term Capacity," Power Engineering, July. 


\section{Appendix A:}

Affected Sources and Units in Phase I and Their Sulfur Dioxide Allowances

\begin{tabular}{|c|c|c|c|}
\hline State & Plant Name & $\begin{array}{c}\text { Generator } \\
\text { No. }\end{array}$ & $\begin{array}{c}\text { Phase I } \\
\text { Allowances } \\
\text { (tons) }\end{array}$ \\
\hline \multirow[t]{10}{*}{ Alabama } & Colbert & 1 & 13,570 \\
\hline & & 2 & 15,310 \\
\hline & & 3 & 15,400 \\
\hline & & 4 & 15,410 \\
\hline & & 5 & 37,180 \\
\hline & E.C. Gaston & 1 & 18,100 \\
\hline & & 2 & 18,540 \\
\hline & & 3 & 18,310 \\
\hline & & 4 & 19,280 \\
\hline & & 5 & 59,840 \\
\hline \multirow[t]{5}{*}{ Florida } & Big Bend & 1 & 28,410 \\
\hline & & 2 & 27,100 \\
\hline & & 3 & 26,740 \\
\hline & Crist & 6 & 19,200 \\
\hline & & 7 & 31,680 \\
\hline \multirow[t]{19}{*}{ Georgia } & Bowen & 1 & 56,320 \\
\hline & & 2 & 54,770 \\
\hline & & 3 & 71,750 \\
\hline & & 4 & 71,740 \\
\hline & Hammond & 1 & 8,780 \\
\hline & & 2 & 9,220 \\
\hline & & 3 & 8,910 \\
\hline & & 4 & 37,640 \\
\hline & J. McDonough & 1 & 19,910 \\
\hline & & 2 & 20,600 \\
\hline & Wansiey & 1 & 70,770 \\
\hline & & 2 & 65,430 \\
\hline & Yates & 1 & 7,210 \\
\hline & & 2 & 7,040 \\
\hline & & 3 & 6,950 \\
\hline & & 4 & 8,910 \\
\hline & & 5 & 9,410 \\
\hline & & 6 & 24,760 \\
\hline & & 7 & 21,480 \\
\hline
\end{tabular}




\begin{tabular}{|c|c|c|c|}
\hline State & Plant Name & $\begin{array}{c}\text { Generator } \\
\text { No. }\end{array}$ & $\begin{array}{c}\text { Phase I } \\
\text { Allowances } \\
\text { (tons) }\end{array}$ \\
\hline \multirow[t]{17}{*}{ Illinois } & Baldwin & 1 & 42,010 \\
\hline & & 2 & 44,420 \\
\hline & & 3 & 42,550 \\
\hline & Coffeen & 1 & 11,790 \\
\hline & & 2 & 35,670 \\
\hline & Grand Tower & 4 & 5,910 \\
\hline & Hennepin & 2 & 18,410 \\
\hline & Joppa Steam & 1 & 12,590 \\
\hline & & 2 & 10,770 \\
\hline & & 3 & 12,270 \\
\hline & & 4 & 11,360 \\
\hline & & 5 & 11,420 \\
\hline & & 6 & 10,620 \\
\hline & Kincaid & 1 & 31,530 \\
\hline & & 2 & 33,810 \\
\hline & Meredosia & 3 & 13,890 \\
\hline & Vermilion & 2 & 8,880 \\
\hline \multirow[t]{30}{*}{ Indiana } & Bailly & 7 & 11,180 \\
\hline & & 8 & 15,630 \\
\hline & Breed & 1. & 18,500 \\
\hline & Cayuga & 1 & 33,370 \\
\hline & & 2 & 34,130 \\
\hline & Clifty Creek & 1 & 20,150 \\
\hline & & 2 & 19,810 \\
\hline & & 3 & 20,410 \\
\hline & & 4 & 20,080 \\
\hline & & 5 & 19,360 \\
\hline & & 6 & 20,380 \\
\hline & E.W. Stout & 5 & 3,880 \\
\hline & & 6 & 4,770 \\
\hline & & 7 & 23,610 \\
\hline & F.B. Culley & 2 & 4,290 \\
\hline & & 3 & 16,970 \\
\hline & F.E. Ratts & 1 & 8,330 \\
\hline & & 2 & 8,480 \\
\hline & Gibson & 1 & 40,400 \\
\hline & & 2 & 41,010 \\
\hline & & 3 & 41,080 \\
\hline & & 4 & 40,320 \\
\hline & H.T. Pritchard & 6 & 5,770 \\
\hline & Michigan City & 12 & 23,310 \\
\hline & Petersburg & 1 & 16,430 \\
\hline & & 2 & 32,380 \\
\hline & R. Gallagher & 1 & 6,490 \\
\hline & & 2 & 7,280 \\
\hline & & 3 & 6,530 \\
\hline & & 4 & 7.650 \\
\hline
\end{tabular}




\begin{tabular}{|c|c|c|c|}
\hline State & Plant Name & $\begin{array}{c}\text { Generator } \\
\text { No. }\end{array}$ & $\begin{array}{l}\text { Phase I } \\
\text { Allowances } \\
\text { (tons) }\end{array}$ \\
\hline \multirow[t]{7}{*}{ Indiana (Cont'd) } & Tanners Creek & 4 & 24,820 \\
\hline & Wabash River & 1 & 4,000 \\
\hline & & 2 & 2,860 \\
\hline & & 3 & 3,750 \\
\hline & & 5 & 3,670 \\
\hline & & 6 & 12,280 \\
\hline & Warrick & 4 & 26,980 \\
\hline \multirow[t]{6}{*}{ lowa } & Burlington & 1 & 10,710 \\
\hline & Des Moines & 7 & 2,320 \\
\hline & George Neal & 1 & 1,290 \\
\hline & M.L. Kapp & 2 & 13,800 \\
\hline & Prairie Creek & 4 & 8,180 \\
\hline & Riverside & 5 & 3,990 \\
\hline Kansas & Quindaro & 2 & 4,220 \\
\hline \multirow[t]{17}{*}{ Kentucky } & Coleman & 1 & 11.250 \\
\hline & & 2 & 12,840 \\
\hline & & 3 & 12,340 \\
\hline & Cooper & 1 & 7,450 \\
\hline & & 2 & 15,320 \\
\hline & E.W. Brown & 1 & 7,110 \\
\hline & & 2 & 10,910 \\
\hline & & 3 & 26,100 \\
\hline & Elmer Smith & 1 & 6,520 \\
\hline & & 2 & 14,410 \\
\hline & Ghent & 1 & 28,410 \\
\hline & Green River & 4 & 7,820 \\
\hline & H.L. Spurlock & 1 & 22,780 \\
\hline & Henderson II & 1 & 13,340 \\
\hline & & 2 & 12,310 \\
\hline & Paradise & 3 & 59,170 \\
\hline & Shawnee & 10 & 10,170 \\
\hline \multirow[t]{6}{*}{ Maryland } & Chalk Point & 1 & 21,910 \\
\hline & & 2 & 24,330 \\
\hline & C.P. Crane & 1 & 10,330 \\
\hline & & 2 & 9,230 \\
\hline & Morgantown & 1 & 35,260 \\
\hline & & 2 & 38,480 \\
\hline \multirow[t]{2}{*}{ Michigan } & J.H. Campbell & 1 & 19,280 \\
\hline & & 2 & 23,060 \\
\hline Minnesota & High Bridge & 6 & 4,270 \\
\hline
\end{tabular}




\begin{tabular}{|c|c|c|c|}
\hline State & Plant Name & $\begin{array}{c}\text { Generator } \\
\text { No. }\end{array}$ & $\begin{array}{c}\text { Phase I } \\
\text { Allowances } \\
\text { (tons) }\end{array}$ \\
\hline Mississippi & Jack Watson & $\begin{array}{l}4 \\
5\end{array}$ & $\begin{array}{l}17,910 \\
36,700\end{array}$ \\
\hline Missouri & $\begin{array}{l}\text { Montrose } \\
\text { New Madrid } \\
\text { Sibley } \\
\text { Sioux } \\
\text { Thomas Hill }\end{array}$ & $\begin{array}{l}1 \\
5 \\
1 \\
2 \\
3 \\
4 \\
1 \\
2 \\
3 \\
1 \\
2 \\
3 \\
1 \\
2 \\
1 \\
2\end{array}$ & $\begin{array}{r}16,190 \\
4,850 \\
40,110 \\
37,710 \\
40,310 \\
35,940 \\
7,390 \\
8,200 \\
10,090 \\
28,240 \\
32,480 \\
15,580 \\
22,570 \\
23,690 \\
10,250 \\
19,390\end{array}$ \\
\hline New Hampshire & Merrimack & $\begin{array}{l}1 \\
2\end{array}$ & $\begin{array}{l}10,190 \\
22,000\end{array}$ \\
\hline New Jersey & B.L. England & $\begin{array}{l}1 \\
2\end{array}$ & $\begin{array}{r}9,060 \\
11,720\end{array}$ \\
\hline New York & $\begin{array}{l}\text { Dunkirk } \\
\text { Greenridge } \\
\text { Milliken } \\
\text { Northport }\end{array}$ & $\begin{array}{l}3 \\
4 \\
4 \\
1 \\
2 \\
1 \\
2 \\
3 \\
3 \\
4\end{array}$ & $\begin{array}{r}12,600 \\
14,060 \\
7,540 \\
11,170 \\
12,410 \\
19,810 \\
24,110 \\
26,480 \\
10,470 \\
12,330\end{array}$ \\
\hline Ohio & $\begin{array}{l}\text { Ashtabula } \\
\text { Avon Lake } \\
\text { Cardinal } \\
\text { Conesville }\end{array}$ & $\begin{array}{l}5 \\
8 \\
9 \\
1 \\
2 \\
1 \\
2 \\
3 \\
4\end{array}$ & $\begin{array}{r}16,740 \\
11,650 \\
30,480 \\
34,270 \\
38,320 \\
4,210 \\
4,890 \\
5,500 \\
48,770\end{array}$ \\
\hline
\end{tabular}




\begin{tabular}{|c|c|c|c|}
\hline State & Plant Name & $\begin{array}{c}\text { Generator } \\
\text { No. }\end{array}$ & $\begin{array}{l}\text { Phase I } \\
\text { Allowances } \\
\text { (tons) }\end{array}$ \\
\hline \multirow[t]{32}{*}{ Ohio (Cont'd) } & Eastlake & 1 & 7,800 \\
\hline & & 2 & 8,640 \\
\hline & & 3 & 10,020 \\
\hline & & 4 & 14,510 \\
\hline & & 5 & 34,070 \\
\hline & Edgewater & 4 & 5,050 \\
\hline & Gen. J.M. Gavin & 1 & 79,080 \\
\hline & & 2 & 80,560 \\
\hline & Kyger Creek & 1 & 19,280 \\
\hline & & 2 & 18,560 \\
\hline & & 3 & 17,910 \\
\hline & & 4 & 18,710 \\
\hline & & 5 & 18,740 \\
\hline & Miarni Fort & 5 & 760 \\
\hline & & 6 & 11,380 \\
\hline & & 7 & 38,510 \\
\hline & Muskingum & 1 & 14,880 \\
\hline & River & 2 & 14,170 \\
\hline & & 3 & 13,950 \\
\hline & & 4 & 11,780 \\
\hline & & 5 & 40,470 \\
\hline & Niles & 1 & 6,940 \\
\hline & & 2 & 9,100 \\
\hline & Picway & 5 & 4,930 \\
\hline & R.E. Burger & 3 & 6,150 \\
\hline & & 4 & 10,780 \\
\hline & & 5 & 12,430 \\
\hline & W.H. Sammis & 5 & 24,170 \\
\hline & & 6 & 39,930 \\
\hline & & 7 & 43,220 \\
\hline & W.C. Beckjord & 5 & 8,950 \\
\hline & & 6 & 23,020 \\
\hline \multirow[t]{13}{*}{ Pennsylvania } & Armstrong & 1 & 14,410 \\
\hline & & 2 & 15,430 \\
\hline & Brunner Island & 1 & 27,760 \\
\hline & & 2 & 31,100 \\
\hline & & 3 & 53,820 \\
\hline & Cheswick & 1 & 39,170 \\
\hline & Conemaugh & 1 & 59,790 \\
\hline & & 2 & 66,450 \\
\hline & Hatfield's & 1 & 37,830 \\
\hline & Ferry & 2 & 37,320 \\
\hline & & 3 & 40,270 \\
\hline & Martins Creek & 1 & 12,660 \\
\hline & & 2 & 12,820 \\
\hline
\end{tabular}




\begin{tabular}{|c|c|c|c|}
\hline State & Plant Name & $\begin{array}{c}\text { Generator } \\
\text { No. }\end{array}$ & $\begin{array}{l}\text { Phase 1 } \\
\text { Allowances } \\
\text { (tons) }\end{array}$ \\
\hline \multirow[t]{7}{*}{$\begin{array}{l}\text { Pennsylvania } \\
\text { (Cont'd) }\end{array}$} & Portland & $\begin{array}{l}1 \\
2\end{array}$ & $\begin{array}{r}5,940 \\
10,230\end{array}$ \\
\hline & Shawville & 1 & 10,320 \\
\hline & & 2 & 10,320 \\
\hline & & 3 & 14,220 \\
\hline & & 4 & 14,070 \\
\hline & Sunbury & 3 & 8,760 \\
\hline & & 4 & 11,450 \\
\hline \multirow[t]{19}{*}{ Tennessee } & Allen & 1 & 15,320 \\
\hline & & 2 & 16,770 \\
\hline & & 3 & 15,670 \\
\hline & Cumberland & 1 & 86,700 \\
\hline & & 2 & 94,840 \\
\hline & Gallatin & 1 & 17,870 \\
\hline & & 2 & 17,310 \\
\hline & & 3 & 20,020 \\
\hline & & 4 & 21,260 \\
\hline & Johnsonville & 1 & 7,790 \\
\hline & & 2 & 8,040 \\
\hline & & 3 & 8,410 \\
\hline & & 4 & 7,990 \\
\hline & & 5 & 8,240 \\
\hline & & 6 & 7,890 \\
\hline & & 7 & 8,980 \\
\hline & & 8 & 8,700 \\
\hline & & 9 & 7,080 \\
\hline & & 10 & 7,550 \\
\hline \multirow[t]{14}{*}{ West Virginia } & Albright & 3 & 12,000 \\
\hline & Fort Martin & 1 & 41,590 \\
\hline & & 2 & 41,200 \\
\hline & Harrison & 1 & 48,620 \\
\hline & & 2 & 46,150 \\
\hline & & 3 & 41,500 \\
\hline & Kammer & 1 & 18,740 \\
\hline & & 2 & 19,460 \\
\hline & & 3 & 17,390 \\
\hline & Mitchell & 1 & 43,980 \\
\hline & & 2 & 45,510 \\
\hline & Mount Storm & 1 & 43,720 \\
\hline & & 2 & 35,580 \\
\hline & & 3 & 42,430 \\
\hline
\end{tabular}




\begin{tabular}{clcr}
\hline State & Plant Name & $\begin{array}{c}\text { Generator } \\
\text { No. }\end{array}$ & $\begin{array}{c}\text { Phase I } \\
\text { Allowances } \\
\text { (tons) }\end{array}$ \\
\hline Wisconsin & Edgewater & 4 & 24,750 \\
& LaCrosse/Genoa & 3 & 22,700 \\
& Nelson Dewey & 1 & 6,010 \\
& 2 & 6,680 \\
& N. Oak Creek & 1 & 5,220 \\
& 2 & 5,140 \\
& 3 & 5,370 \\
& 4 & 6,320 \\
& Pulliam & 8 & 7,510 \\
S. Oak Creek & 5 & 9,670 \\
& 6 & 12,040 \\
& 7 & 16,180 \\
& 8 & 15,790 \\
& & & \\
\hline
\end{tabular}

Source: Clean Air Act Amendments of 1990, Title IV, Section 464, Table A. 


\section{Appendix B:}

\section{Policy Alternatives for Controlling Emissions of Precursors of Acid Precipitation}

\section{B.1 Introduction}

Many policy alternatives have been proposed for pollution abatement and control. Only those policy alternatives most appropriate for controlling the emissions of precursors of acid precipitation are discussed here. These can be grouped into two broad categories: direct controls and market incentives. First these policies are described; a discussion of their advantages and disadvantages follows.

\section{B.2 Types of Direct-Control Policies}

Direct-control policies can take the form of performance standards or technology standards. Under a performance standard, emissions are limited to a specified rate or amount. For example, sulfur dioxide $\left(\mathrm{SO}_{2}\right)$ emissions could be limited to 1.2 pounds per million $\mathrm{Btu}\left(1.2 \mathrm{lb} / 10^{6} \mathrm{Btu}\right)$ of fuel consumed. A technology standard specifies a required emission control device. For example, all coal-burning power plants could be required to install wet scrubbers. This was done in the Clean Air Act Amendments of 1977, creating the Revised New Source Performance Standards (RNSPS).

\section{B.3 Types of Market-Incentive Policies}

Market-based policies can take the form of emissions taxes, marketable emission permits, or emissions trading. Emissions taxes mean that the source would pay a specified tax for each unit of emissions. For example, a source might pay a tax of $\$ 500$ per t.un of $\mathrm{SO}_{2}$ emitted.

A system of marketable emission permits means that permits equal to the desired level of emissions in a region are issued and allowed to be freely bought and sold in the marketplace. For example, if emissions of $\mathrm{SO}_{2}$ in a region were to be limited to 100,000 tons per year, 100,000 permits, each for one ton of emissions, could be created and sold to the highest bidder.

Emissions trading can be thought of as a special case of marketable emission permits by which the permits or annual allowances are distributed free to potential polluters in proportion to their historical uncontrolled emission rate and/or other criteria. Then the individual sources are allowed to negotiate individual unit emissions to meet the area or group standard. For example, if two sources were presently emitting a total of 20 tons of $\mathrm{SO}_{2}$ per year and were required to cut emissions in half, under individual standards, each would be required to cut emissions to an individual maximum of 5 tons per year. With emissions trading, the sources could agree on any combination of individual emissions that attained total emissions of 10 tons per year or less. A graphic analysis of the cost savings from emissions trading is provided in Figure B.1. 
Plant A: Uniform reduction results in high marginal cost, $M C_{A}^{0}$

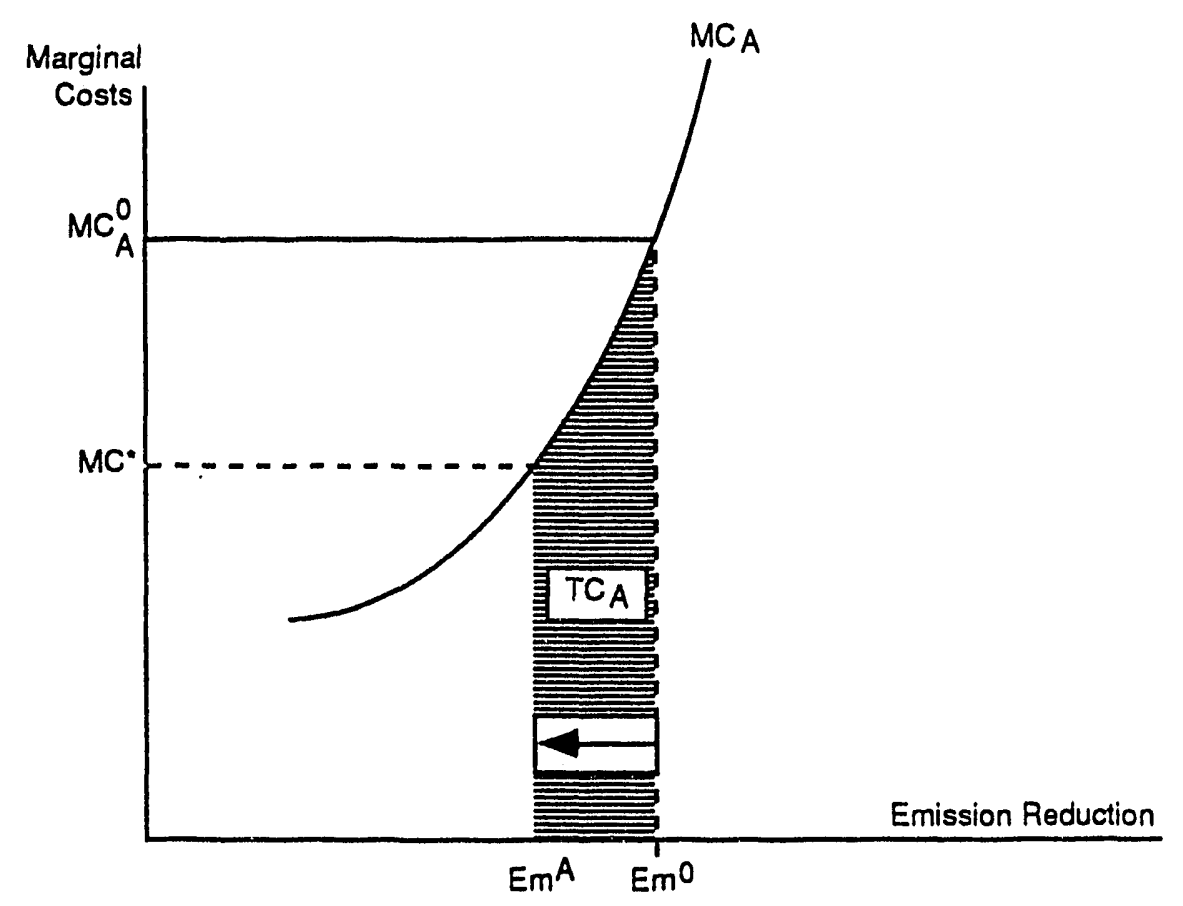

Plant B: At the same reduction as Plant $A$, Plant $B$ has a lower marginal cost.

Total costs are reduced by a trade: Plant A reduces less; Plant $B$ reduces more.

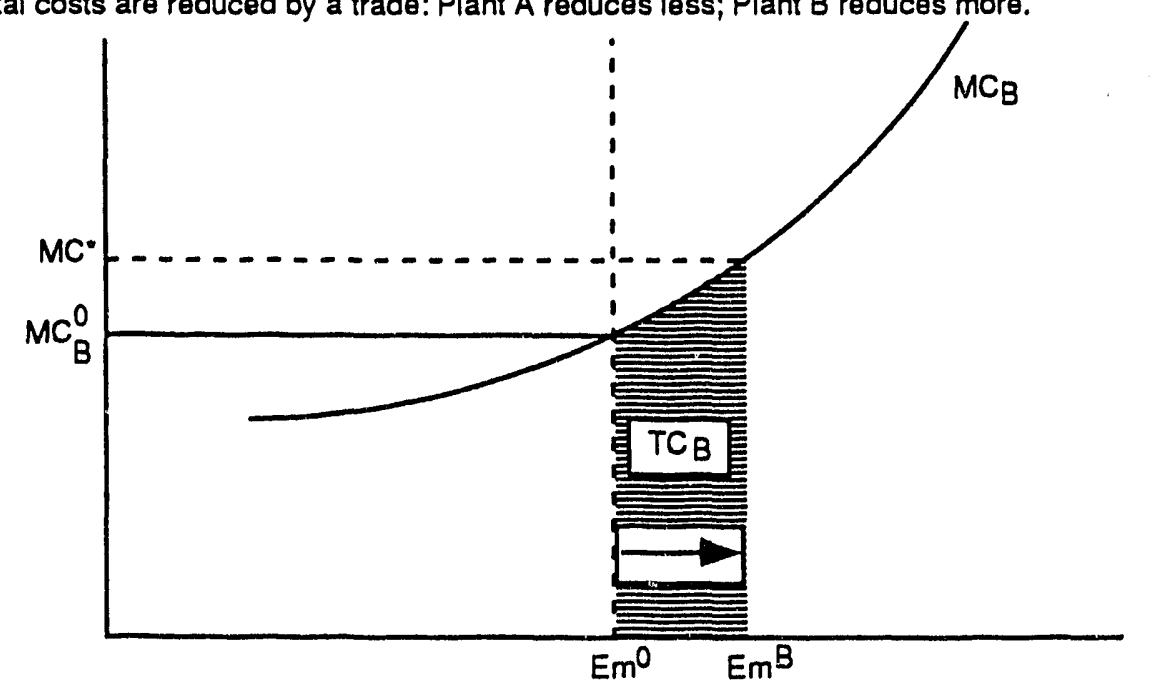

With uniform emission reduction to $E M^{0}$, marginal costs are different: $M C_{A}^{0}>M C_{B}^{0}$.

With emission trading, marginal costs are equal, $M C^{*}$, and cost savings are the difference in areas: $T C_{A}-T C_{B}$.

(The marginal cost curve is the derivative of the total cost curve.

The total cost is the area under the marginal cost curve.)

FIGURE B.1 Cost Savings with Emissions Trading 
Under the Clean Air Act Amendments of 1990 (CAAA), the U.S. Environmental Protection Agency (EPA) will allocate $\mathrm{SO}_{2}$ emission allowances in two phases. Each annual allowance allows the utility to emit one ton of $\mathrm{SO}_{2}$. In the first phase, effective January 1,1995 , 110 power plants will be required to reduce their total emissions to a level equal to an emission rate of $2.5 \mathrm{lb} \mathrm{SO}_{2} / 10^{6}$ Btu multiplied by the average of their 1985-1987 fuel use. Plants using certain control technologies may receive a two-year compliance extension or receive early-reduction bonus allowances for emission reductions achieved between 1995 and 1997. A special allocation of 200,000 annual allowances per year for each of the five years of Phase I is given to power plants in Illinois, Indiana, and Ohio.

In Phase II, which begins January 1,2000 , utilities will be required to reduce their total $\mathrm{SO}_{2}$ emissions to a level equivalent to an emission rate of $1.2 \mathrm{lb} / 10^{6} \mathrm{Btu}$ multiplied by the average of their 1985-1987 fuel use. This requirement "caps" annual utility $\mathrm{SO}_{2}$ emissions at approximately 8.9 million tons after year 2000. Plants with an $\mathrm{SO}_{2}$ emission rate below $1.2 \mathrm{lb} / 10^{6} \mathrm{Btu}$ will be able to increase emissions by $20 \%$ between a baseline year and 2000 . Bonus allowances will be distributed to allow growth by units in states in which the average $\mathrm{SO}_{2}$ emission rate is below $0.8 \mathrm{lb} / 10^{6} \mathrm{Btu}$ or will be distributed to plants being used more intensively in the last five years. Plants in 10 midwestern states that make reductions in Phase I will be allocated 50,000 bonus allowances. Plants that repower with a qualifying clean coal technology may receive a four-year extension for Phase II compliance. Up to 300,000 allowances may be allocated to energy conservation and renewable energy projects.

Thus, under the CAAA, most allowances will be allocated on the basis of 1985-1987 emissions, and a relatively small number of bonus allowances will be distributed to the Midwest or to reward lower emissions and encourage certain technologies. The utilities will be allowed to trade allowances within their systems and buy or sell allowances with other affected utilities. Each source will have to have enough allowances to cover its annual emissions. If not, the source will be subject to a $\$ 2000$-per-ton excess emissions fee and will have to offset the excess emissions in the following year. Unused allowances may be banked. EPA will also hold special sales and auctions of allowances.

\section{B.4 Advantages and Disadvantages of Direct-Control Policies}

The chief disadvantage of the direct-control policies is that they do not minimize the cost of obtaining the desired level of emissions. This disadvantage occurs because of large differences in the cost of emission reductions across sources. For example, under a performance standard, coalfired boilers could be required to limit $\mathrm{SO}_{2}$ emissions to $1.2 \mathrm{lb} / 10^{6} \mathrm{Btu}$ of coal used. This standard could be attained inexpensively by a source with access to inexpensive, low-sulfur coal, but it could be very costly to a source that would have to retrofit an expensive scrubber because it could not obtain such coal. The same total level of emissions would be obtained at lower cost if those sources with the lowest emission-reduction cost reduced emissions the most. The characteristics of the cost-minimizing solution will be discussed below. Regulators may attempt to reflect compliance costs when performance standards are set to reduce the total compliance cost. These attempts usually fall far short of obtaining the minimum-cost solution, because the wide variation in compliance costs across sources would require a set of incredibly complex standards that would 
need to be updated frequently to reflect technological developments or other changes. Furthermore, sources have no incentive to reduce emissions below the performance standard.

The control costs mentioned above may include secondary costs such as market adjustment costs. For example, a substantial switch to low-sulfur coal could disrupt coal markets and lead to a high unemployment rate for miners of high-sulfur coal. To some extent, these dislocations could be reduced by phasing in controls or other government actions such as occupational retraining programs.

The type of performance standard chosen also affects the efficiency of the emission control policy. Performance standards can be specified in terms of the rate of emissions allowed (e.g., $1.2 \mathrm{lb} / 10^{6} \mathrm{Btu}$ of fuel consumed) or the absolute level of emissions allowed (e.g., 10 tons of $\mathrm{SO}_{2}$ per year). In general, the absolute-level standards are preferred because they set a limit on total emissions and encourage improvements in energy efficiency and conservation.

In general, technology standards are less efficient than performance standards, both statically and dynamically. Static inefficiency occurs because the individual source is not able to choose the cheapest method of obtaining the required level of emission reduction. For example, if all coal-fired boilers are required to have wet scrubbers, this requirement prohibits these sources from obtaining the same level of emissions by using another method such as fuel switching. Dynamic inefficiency occurs because sources have little incentive to conduct research to develop alternative methods of reducing emissions, since these methods would not be allowed under the existing technology standards. However, technology standards would be preferred for a case in which it is desired to force a specific technological solution at a faster penetration rate than could be accomplished under performance standards or market-based plans.

The magnitude of the inefficiency caused by direct controls can be quite large. For example, Gollop and Roberts (1985) estimated that the cost of meeting the 1973-1979 $\mathrm{SO}_{2}$ emission standards was $47 \%$ higher (nearly $\$ 2$ billion in 1979) than the cost-minimizing level because of these direct controls. This inefficiency was caused by substantial differences in marginal abatement costs (in dollars per ton of $\mathrm{SO}_{2}$ removed) across individual sources. These results are confirmed by studies of proposed legislation such as those conducted by Streets, Vernet, and Veselka (1984), which show that proposed bills incorporating these direct controls do not arrive at the least-cost solution.

Technology standards generally have the lowest monitoring and administrative costs of these policy options, because the regulator can readily determine if the required device is installed and being used. Performance standards and all the market-based plans would require emissions monitoring and more administration. A report by Moore et al. (1989) cites EPA estimates of the capital cost of continuous emissions monitoring of $\mathrm{SO}_{2}$ and $\mathrm{NO}_{\mathrm{x}}$ as being between $\$ 137,000$ and $\$ 243,000$ in 1988 dollars. Since the cost of a $1000-\mathrm{MW}$ coal-steam plant usually exceeds $\$ 2$ billion, these costs are relatively small. Similarly, administrative costs for the market-based plans will be somewhat larger. However, if the savings in control costs of the market-based plans were to be as large as those reported in the studies mentioned above, these savings would more than offset any increases in administrative costs. 


\section{B.5 Advantages and Disadvantages of Market-Based Policies}

Economists believe that the market-based policies are more likely to attain a desired emissions level at the least cost. Control would occur at the least cost because each source would either pay the tax, buy the permit or allowance, trade, or control emissions - whichever option were to be cheapest. Thus, the sources for which control costs were lowest would control emissions, and other sources would pay the tax, buy the permit or allowance, or trade. These market-based approaches would attain the desired level of control at the minimum cost, because the cost-minimizing condition of equalizing the marginal cost of control across sources would be met by each of these approaches in competitive markets. In addition, the market-based approaches would give sources the maximum incentive to develop new control technologies and further reduce emissions, since these approaches would reward the source by reducing its taxes or allow it to sell permits or allowances or engage in profitable trades.

To attain the optimal level of emissions at minimum cost, the emissions tax rate for a pollutant should be set equal to the marginal damage done by that pollutant. In practice, this amount is difficult to quantify and would be subject to substantial dispute. Another method would be to determine the desired level of emissions (from a political or other standpoint) and set the tax rate equal to the marginal cost of attaining that level of emissions. As Baumol and Oates (1988) point out, this method requires substantially more information and analytical capability on the part of the regulatory authority than the other market-based plans and would be subject to substantial uncertainty and dispute. It is unlikely that experiments would be allowed to find the appropriate tax rate. Polluters would obviously prefer low tax rates, while ecologists and the government would prefer higher tax rates to reduce emissions and increase revenues. In addition, administrative and monitoring costs would be higher for this method than for technology standards.

As shown by Buchanan and Tullock (1975), polluters prefer direct controls to taxes if abatement costs are the same, because the tax payments on their remaining emissions result in higher total costs to the firm. Even if control costs are lower with the tax, it is not difficult to construct examples in which the tax payments more than offset the lower control cost, as demonstrated by Moore et al. (1989). Thus, polluters may prefer direct controls even though the society's control costs are lower if emissions taxes are used.

One advantage of marketable permit, marketable allowance, or emissions trading policies when compared with emissions taxes is that the regulatory authority does not need to know the marginal cost of control at the desired level of emissions. The emissions control agency merely issues permits or allowances equal to the desired level of emissions. In an efficient market, the equilibrium price of these allowances or rental value of the permits will be equal to marginal control costs.

Since tradable emission permits are likely to be quite valuable, the method used to initially allocate these permits can become controversial. For example, these permits could be initially distributed by having the government auction them off to the highest bidder. This policy would raise substantial revenue for the government. However, it would create the same problem of higher costs for polluters as described above in the case of emissions taxes. 
Another method would be to distribute the permits or allowances in proportion to the polluter's emissions during some base period. This method explicitly recognizes the polluter's formerly implicit right to pollute. This method is preferred by the polluter because it eliminates the cost of purchasing permits or allowances under the auction method by giving the polluter these valuable rights free. As described above, the majority of allowances under the CAAA are distributed in this way. EPA has argued that awarding existing polluters these valuable rights is a type of cost sharing that partially compensates the polluters for their control costs. In addition, these sources can reduce emissions below the required level and then sell permits. However, this method does not eliminate controversy among polluters. For example, in the case of $\mathrm{SO}_{2}$ emission regulations, the choice of base period is important in determining the distribution of emission permits. The CAAA set the baseline period on the basis of average fuel use in 1985-1987. Polluters that made substantial emission reductions before this period lose valuable allowances. However, they are compensated to some extent by the bonus allowances.

As Baumol and Oates (1988) point out, as long as permits are traded in an efficient market, the method used to distribute the marketable permits has no effect on the efficient allocation of resources in pollution control. However, the society's distribution of income and wealth will be changed, which could alter the demand for goods and services within the society.

Another difference between permits/trading and emission taxes is that the firm's tax payments or payments for annual allowances are a flow during a given period, while a purchased permit is an asset for the firm, with its value being equal to the present value of the future cost savings from not reducing emissions. Thus the value of the permit will be some multiple of the value of the pollution tax. This multiple will decline as the firm's discount rate increases or as the lifetime of the permit decreases. If this multiple is large, some firms might find it more difficult to finance the purchase of a permit rather than pay the tax or purchase an annual allowance.

For marketable permit or emissions trading policies to operate efficiently, the permit or trading market must be efficient. If the market is efficient, the rental value of the permit or the price of the annual allowance will equal the marginal abatement cost for each source, thus ensuring that the desired level of pollution is attained at minimal cost. When markets are efficient, the equilibrium rental value of the permit or annual allowance price will probably be equal to the optimal tax rate for any desired level of pollution. Two factors can cause market imperfections: barriers to competition and hoarding.

In a perfectly competitive market with a large number of well-informed buyers and sellers, the price of allowances will probably equal the marginal cost of abatement for all sources; thus, the market would allocate resources efficiently. However, if there are only one or a few sellers of allowances, the monopoly power of these sellers will allow them to sell these allowances at a price higher than the seller's marginal cost. This situation means that the sellers will reduce emissions to a level less than the optimal amount and shift some of the amount and cost of emission reduction to the purchasers of allowances. If there are only one or a few purchasers of allowances, their monopsony power will allow them to get allowances at a lower price, which means that they would reduce emissions to a level less than the optimal amount and shift some of the amount and cost of emission rediction to others. Owners of allowances may choose to hoard them for precautionary or speculative purposes. For example, precautionary hoarding may be done by 
sources concerned about their ability to meet emission limits or to hedge against a large increase in the price of low-sulfur fuel. Speculative hoarding would be done to gain from increases in the value of unused allowances. Hoarding allowances raises the price of the traded allowances, forcing sources to reduce emissions further and bear larger control costs. While hoarding would not occur in efficient markets, it could occur as a result of ignorance or other market impediments. The results of a survey by Raufer and Feldman (1987) indicates that utilities and regulatory commissions were generally unfamiliar with emissions trading. Additional market impediments could include arrangements such as state public utility commissions encouraging hoarding by allowing the firm to earn its allowed rate of return on the value of hoarded allowances or treating sales of allowances as above-the-line income that would be deducted from the revenues that the utility could collect from its electric customers. In addition, the regulatory commission could require hearings when allowances are bought or sold. This would increase the cost and difficulty of buying and selling allowances, creating an imperfect market.

There are policies that can be used to deal with inefficient markets. An antitrust policy could be used to deal with monopoly or monopsony power in the permits market. The effects of hoarding could be reduced by issuing permits with a short life rather than perpetual permits. Alternatively, the government could take a more active role in the market. For example, if hoarding becomes a problem, the government could serve as a seller of last resort by selling permits at a price approximately equal to the marginal damage done by the pollutant.

Taxes have an advantage over permits, in that these problems with imperfections in the permit market do not occur. The issue of whether emissions taxes or permits are best has been discussed in the economics literature under the general topic of "prices versus quantities." Taxes set the price of polluting (ideally at the value of the pollutant's marginal damage) and allow the firm to adjust to the efficient quantity of pollution, where the marginal abatement cost equals the tax rate. Permits set the quantity of pollution and let the price of an allowed unit of emissions vary. Weitzman (1974) showed that the choice between these policy instrument approaches depends on the types of risks that are faced in terms of damage and control costs.

These market-based plans have some shortcomings, which are largely political in nature. For example, as pointed out by Bohm and Russell (1985), some people perceive these plans as "licenses to pollute," by which wealthy firms can continue polluting by simply paying a tax, buying a permit, or trading. For profit-maximizing firms, this is true only if these alternatives are cheaper on the margin than reducing emissions. Thus, wealthy firms are not necessarily more likely to continue polluting than other firms or individuals. Another problem is that these marketbased plans will be opposed by groups that do not understand their benefits or are injured by them. For example, if a utility in State A switches to an out-of-state, low-sulfur coal and sells its unused allowances to a utility in State B that would otherwise be required to install a scrubber, many groups could complain, including the miners of high-sulfur coal in State $\mathrm{A}$, scrubber manufacturers in State B, and utility customers in both states facing increased rates. The utility customers are not likely to understand that their rate increases would be even greater without the exchange of allowances. All of these parties are likely to come before the regulatory commission to protest the exchange of the allowances. Thus, market-based plans are somewhat more complicated to set up and administer than simple direct controls. 


\section{B.6 Summary and Conclusions}

In general, market-based plans have the advantage of minimizing the cost to society of attaining a desired level of emissions; direct controls tend to have lower administrative costs and allow more rapid implementation of specific control technologies. These methods could be combined to create a policy in which market-based methods would be used to provide appropriate incentives and policies and direct controls would be used to force a specific technological solution in a subset of situations where rapid response is necessary or administrative costs are large.

\section{B.7 References}

Baumol, W.J., and W.E. Oates, 1988, "The Theory of Environmental Policy, Second Edition," Cambridge University Press, New York, N.Y.

Bohm, P., and C.S. Russell, 1985, "Comparative Analysis of Alternative Policy Instruments," Chapter 10 in Vol. 1 of Handbook of Natural Resource and Energy Economics, A.V. Kneese and J.L. Sweeney (editors), Elsevier Publishing Co., Amsterdam.

Buchanan, J.M., and G. Tullock, 1975, "Polluters' Profit and Political Response: Direct Controls versus Taxes," The American Economic Review 65:139-147.

Gollop, F.M., and M.J. Roberts, 1985, "Cost-Minimizing Regulation of Sulfur Emissions: Regional Gains in Electric Power," The Review of Economics and Statistics 67(1):81-90, Feb.

Moore, J.L., et al., 1989, Using Incentives for Environmental Protection: An Overview, report 89-360 ENR, Congressional Research Service, Library of Congress, June 2.

Raufer, R.K., and S.L. Feldman, 1987, Acid Rain and Emissions Trading, Rowman and Littlefield, Lanham, Md.

Streets, D.G., J.E. Vernet, and T.D. Veselka, 1984, Proposals for Acid-Rain Control from the 98th Congress, report ANL/EES-TM-281, Argonne National Laboratory, Argonne, Ill., Oct.

Weitzman, M.L., 1974, "Prices vs. Quantities," The Review of Economic Studies 41:477-490, Oct. 

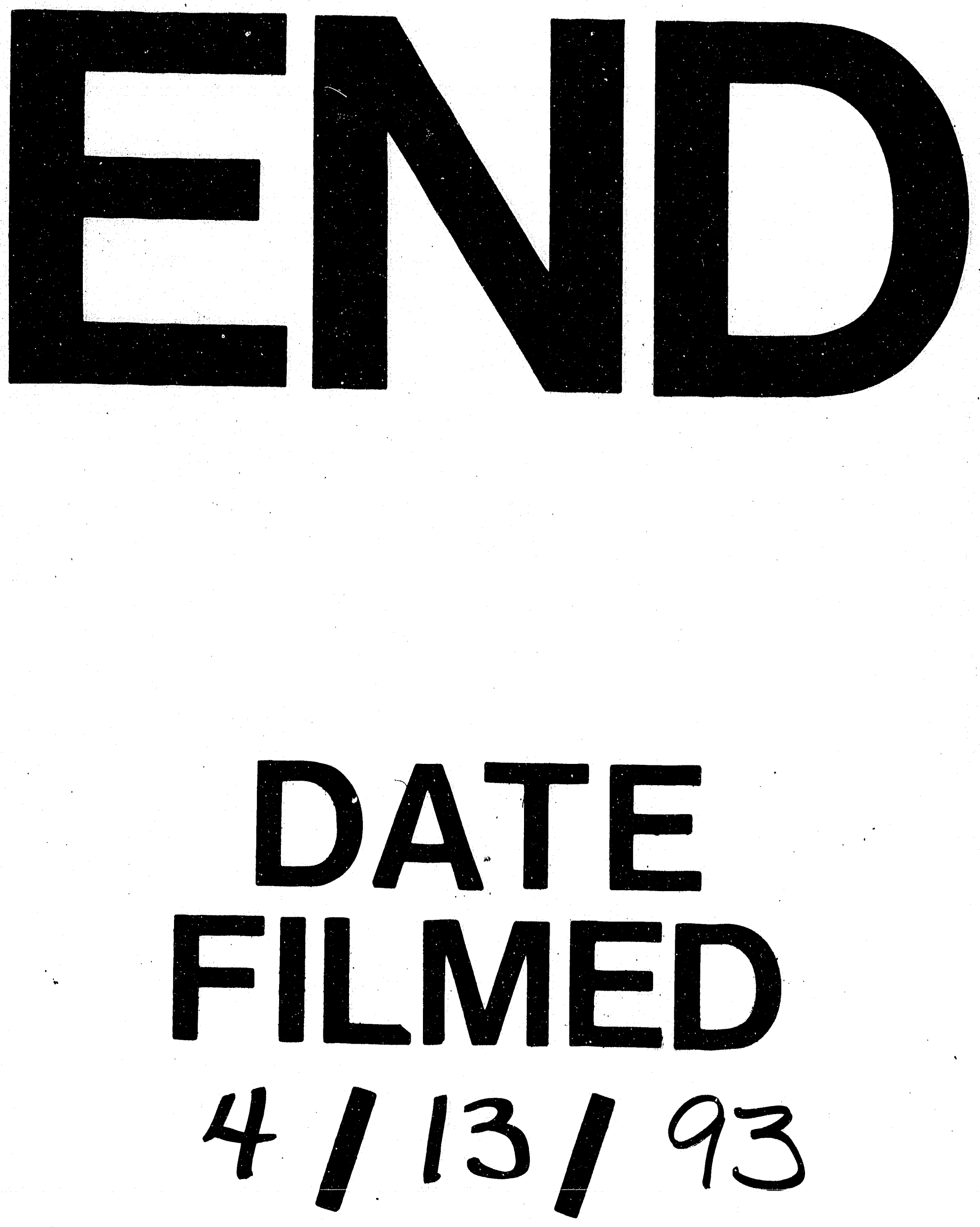